\title{
UICN
}

\section{Análisis económico de acciones para la restauración de paisajes productivos en El Salvador}

Leander Raes, Tony Nello, Melinka Nájera

Óscar Chacón, Kelly Meza Prado, Andrés Sanchún
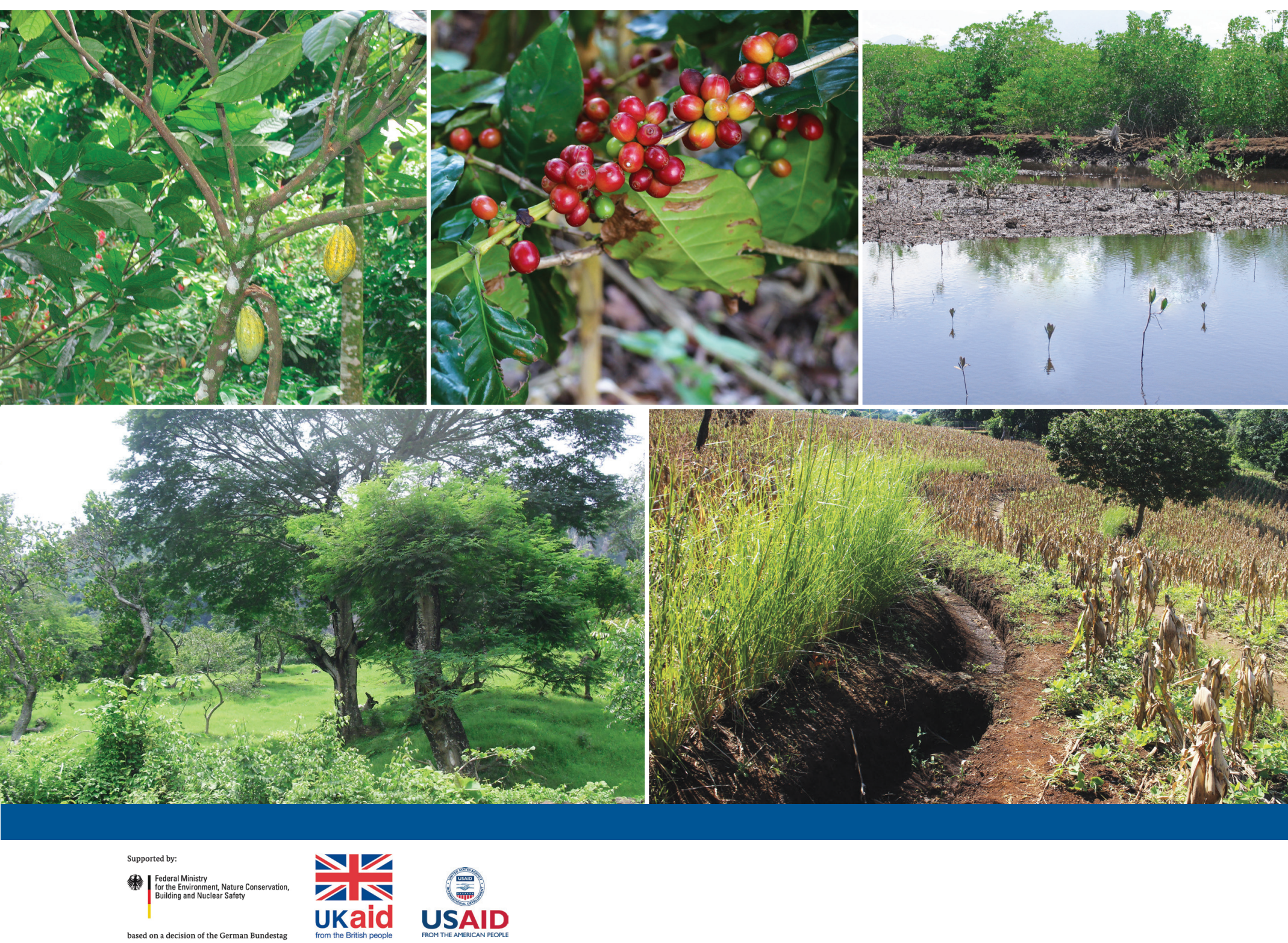



\section{Análisis económico de acciones para la restauración de paisajes productivos en El Salvador}

Leander Raes, Tony Nello, Melinka Nájera,

Óscar Chacón, Kelly Meza Prado, Andrés Sanchún † 
La presentación del material en esta publicación y las denominaciones empleadas para las entidades geográficas no implican en absoluto la expresión de una opinión por parte de la Unión Internacional para la Conservación de la Naturaleza, ni del Ministerio Federal de Medio Ambiente, ni de Conservación de la Naturaleza y Seguridad Nuclear (BMU) de Alemania, ni de la Agencia de los Estados Unidos para el Desarrollo Internacional (USAID), ni de UK AID financiado por el Departamento de Desarrollo Internacional (DFID) del Reino Unido sobre la situación jurídica de un país, territorio o zona; o de sus autoridades, o acerca de la demarcación de sus límites o fronteras.

Los puntos de vista que se expresan en esa publicación no reflejan necesariamente los de la UICN, ni del Ministerio Federal de Medio Ambiente ni de BMU de Alemania, ni de la USAID, ni de UK AID financiado por el Departamento de Desarrollo Internacional del Reino Unido.

Esta publicación ha sido posible gracias a la generosidad de BMU, USAID y UKAID; a través de los proyectos:

"Utilizando la restauración de los ecosistemas forestales a nivel de paisaje como una conexión costo efectiva para integrar las estrategias nacionales de mitigación y adaptación terrestres (BMU7)" del Ministerio Federal de Medio Ambiente, BMU de Alemania.

"Programa Regional de Cambio Climático (PRCC)", financiado por la Agencia de los Estado Unidos para el Desarrollo Internacional (USAID).

"Mejorar la manera en que el conocimiento sobre los bosques es entendido y utilizado a nivel internacional" (KNOWFOR2), financiado por UK AID, Departamento de Desarrollo Internacional (DFID).

Publicado por: UICN, Gland, Suiza en colaboración con la Oficina Regional para México, América Central y el Caribe, San José, Costa Rica.

Derechos reservados: @ 2017 Unión Internacional para la Conservación de la Naturaleza y de los Recursos Naturales (UICN).

Se autoriza la reproducción de esta publicación con fines educativos y otros fines no comerciales sin permiso escrito previo de parte de quien detenta los derechos de autor con tal de que se mencione la fuente.

Se prohíbe reproducir esta publicación para la venta o para otros fines comerciales sin permiso escrito previo de quien detenta los derechos de autor.

Citación: Leander Raes, Tony Nello, Melinka Nájera, Oscar Chacón, Kelly Meza Prado y Andrés Sanchún. 2017. Análisis económico de acciones para la restauración de paisajes productivos en El Salvador. Gland, Suiza: UICN. 2017, 72 p.

ISBN: $\quad 978-2-8317-1875-0$ (PDF)

978-2-8317-1876-7 (print version)

Doi: $\quad$ https://doi.org/10.2305/IUCN.CH.2017.19.es

Revisión técnica: Ronald McCarthy (UICN-ORMACC), Tania Ammour (UICN-ORMACC)

Edición, diseño y diagramación: Marta Lucía Gómez Zuluaga

Fotografías de la portada: Ministerio de Ambiente y Recursos Naturales (MARN) de El Salvador, 2017

Impresión: Masterlitho de San José, Costa Rica

Disponible en: UICN/Oficina Regional para México, América Central y el Caribe

San José, Costa Rica

Tel: ++506 22838449

www.iucn.org/resources/publications 


\section{Contenido}

Índices de cuadros y figuras.............................................................................. ix

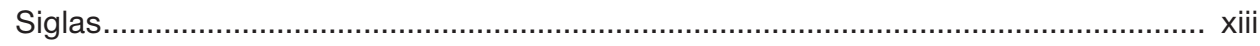

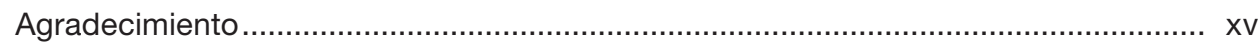

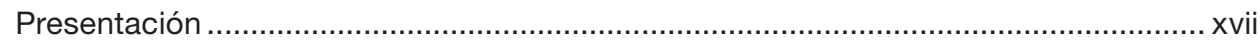

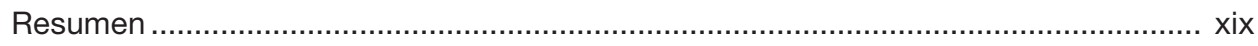

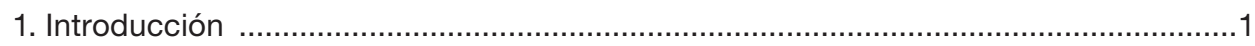

2. Acciones de restauración y uso actual del suelo ..........................................................

2.1 Descripción de las acciones de restauración...............................................................

2.1.1 Restauración de manglar ..............................................................................

2.1.2 Restauración bosque de galería ....................................................................

2.1.3 Sistema agroforestal de granos básicos .......................................................

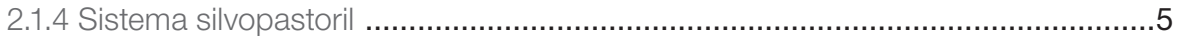

2.1.5 Sistema agrosilvopastoril ........................................................................

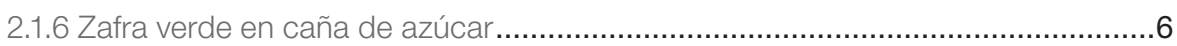

2.1.7 Sistemas agroforestales de cacao ...............................................................

2.1.8 Renovación de cafetales .............................................................................

3. Metodología del análisis costo-beneficio.............................................................

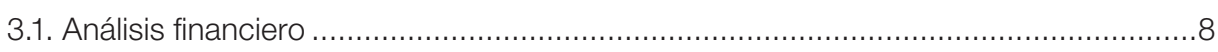

3.1.1 Beneficios (financieros) de la restauración ......................................................

3.1.2 Costos de la restauración ...........................................................................

3.1.3 Periodo de análisis ......................................................................................... 11

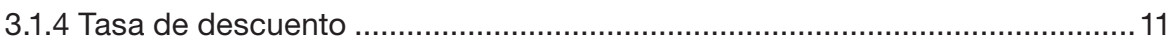

3.1.5 Indicadores del análisis costo-beneficio financiero............................................11 
3.2 Analisis cobeneficios ambientales (modelos no espaciales) 14

3.2.1 Balance de gases de efecto invernadero .................................................. 14

3.2.2 Índice de conectividad .................................................................. 15

3.2.3 Producción de leña .............................................................................. 16

3.3 Servicios ecosistémicos, erosión y exportación de sedimentos y de ............. nutrientes (modelos espaciales) .......................................................... 16

3.3.1 Cambio en la erosión y exportación de sedimentos (SDR) .............................. 16

3.3.2 Cambio en la exportación de nutrientes (NDR) ….................................... 16

3.4 Análisis del impacto social de las acciones de restauración................................ 18

3.4.1 Creación de empleo............................................................................. 18

3.4.2 Seguridad alimentaria ............................................................................ 18

3.4.3 Medios de vida .................................................................................... 18

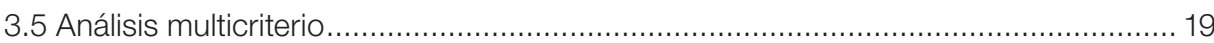

4. Resultados análisis costo-beneficios de las acciones de restauración ......................21

4.1 Costos y beneficios brutos, incrementales y netos ...................................... 21

4.2 Indicadores de desempeño de las acciones de restauración .................................. 24

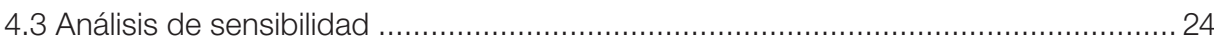

4.3.1 Sensibilidad a la tasa de descuento .......................................................... 24

4.3.2 Sensibilidad a nivel de precio y rendimiento .......................................... 26

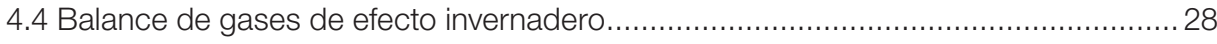

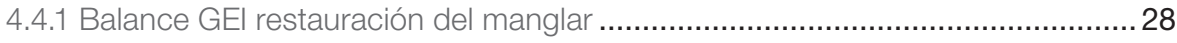

4.4.2 Balance GEl restauración de bosque de galería ...........................................2 29

4.4.3 Balance GEl sistema agroforestal de granos básicos ...................................29

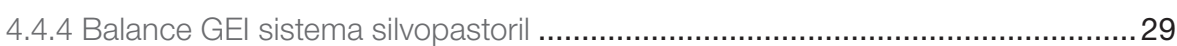

24.4.5 Balance GEl zafra verde en caña de azúcar .............................................29

4.4.6 Balance GEl sistema agroforestal de cacao............................................. 29

4.4.7 Balance GEl renovación de los cafetales .................................................. 30

4.4.8 Curva marginal de reducción de carbono.................................................. 30

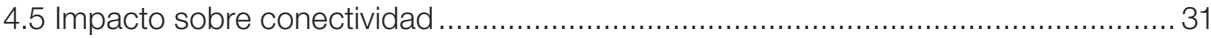

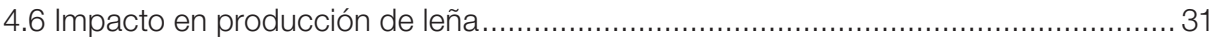

4.7 Cambio en erosión y exportación de sedimentos y de nutrientes ........................... 31

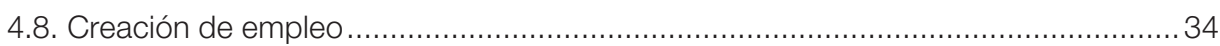

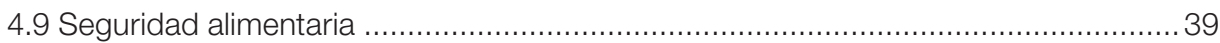

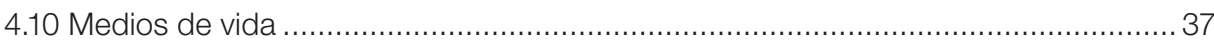

5. Resumen resultado por indicador .................................................................... 39

6. Resultados análisis multicriterio .................................................................. 41 


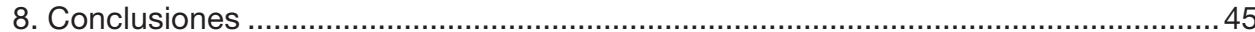

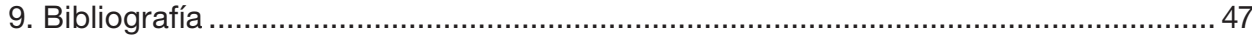

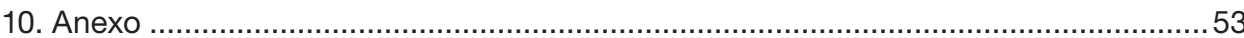

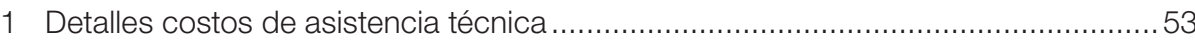

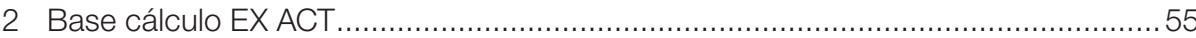

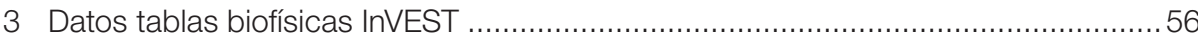

4 Costos de restauración desagregados y VAN de la restauración y uso

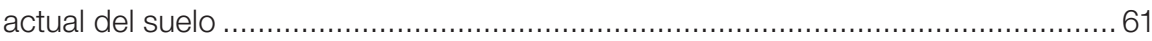

5 Costo, beneficios del uso actual y de la restauración con $r=15 \% \ldots \ldots \ldots \ldots \ldots \ldots \ldots \ldots . . . \ldots 2$

6 Costo, beneficios del uso actual y de la restauración con $r=5 \% \ldots \ldots \ldots \ldots \ldots \ldots \ldots \ldots . \ldots 4$

7 Costo, beneficios del uso actual y de la restauración con límite inferior de precio y rendimiento 66

8 Costo, beneficios del uso actual y de la restauración con límite superior

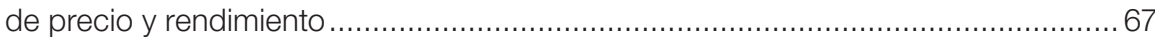

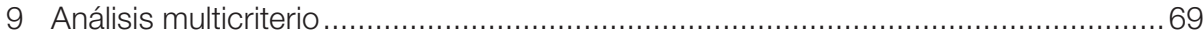





\section{Índices de cuadros y figuras}

\section{Cuadros}

1 Áreas potenciales para las acciones de restauración

2 Fuente y sumideros analizados dentro del perímetro de estudio del balance de GEI........

3 Costos de la restauración, del uso actual y costos incrementales de la restauración $(r=10 \%)$

4 Beneficios brutos de la restauración, del uso actual e incrementales de la restauración $(\mathrm{r}=10 \%)$

5 Beneficios marginales de la restauración, razón beneficio-costo $(\mathrm{RBC})$ y retorno de la inversión (ROI) (r=10\%)

8. Incremento en la producción por la implementación de las acciones de

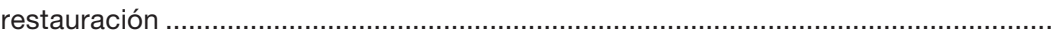

9. Ingresos que consideran la mano de obra familiar y el porcentaje de diversificación.

10 Resumen de los resultados por cada indicador del análisis.....

$11 \quad$ Matriz de rendimiento de las acciones de restauración con (Indicador 1) y $\sin$ los indicadores ambientales espaciales (Indicador 2)

\section{Índice de cuadros en anexo}

A1 Área promedio por tipo de productor

A2.1 Supuestos utilizados para parametrizar Ex Act (1) 
A2.2 Supuestos utilizados para parametrizar Ex Act (2)

A3 Tabla de valores biofísicos del uso actual del suelo utilizados para InVEST

A4 Tabla de valores biofísicos usados para la implementación de las acciones de restauración para InVEST

A5 Tabla biofísica de los usos del suelo restaurados bajo la modalidad de agroforestería y su respectiva ponderación para un área de plantación de bosque tropical

A6 Supuestos para la ponderación del área bajo condiciones forestales en sistemas agroforestales según el área de copa

A8 Beneficios netos de la restauración y del uso actual ( $\mathrm{r}=10 \%)$

A9 Costos de la restauración, del uso actual y costos incrementales de la restauración $(r=15 \%)$.

A10 Beneficios brutos de la restauración, del uso actual e incrementales de la restauración $(r=15 \%)$

A11 Beneficios netos de la restauración, del uso actual, beneficios marginales de la restauración, razón beneficio-costo $(\mathrm{RBC})$ y retorno de la inversión $(\mathrm{ROI})(\mathrm{r}=15 \%)$......

A12 Costos de la restauración, del uso actual y costos incrementales de la restauración $(\mathrm{r}=5 \%)$

A13 Beneficios brutos de la restauración, del uso actual e incrementales de la restauración $(r=5 \%)$.

A14 Beneficios netos de la restauración, del uso actual, beneficios marginales de la restauración, razón beneficio-costo $(\mathrm{RBC})$ y retorno de la inversión $(\mathrm{ROI})(\mathrm{r}=5 \%)$........

A15 Beneficios brutos de la restauración, del uso actual e incrementales de la restauración (límite inferior)

A16 Beneficios netos de la restauración, del uso actual, beneficios marginales de la restauración, razón beneficio-costo $(\mathrm{RBC})$ y retorno de la inversión (ROI) (límite Inferior)

A17 Beneficios brutos de la restauración, del uso actual e incrementales de la restauración (límite superior)

A18 Beneficios netos de la restauración, del uso actual, beneficios marginales de la restauración, razón beneficio-costo $(\mathrm{RBC})$ y retorno de la inversión $(\mathrm{ROI})$ (límite superior)

A19 Matriz de rendimiento de los Indicadores indicadores financieros

A20 Matriz de rendimiento de los Indicadores ambientales no espaciales

A21 Matriz de rendimiento de los indicadores servicios ambientales espaciales (servicios ecosistémicos). 


\section{Figuras}

3 Diferentes partes del análisis económico en este estudio......

$4 \quad$ Proceso de creación del mapa de impacto potencial en provisión de servicios ecosistémicos silvopastoril en US\$/ha en valor presente (6a), y con la aplicación de la tasa de descuento (6b)

$9 \quad$ VAN marginal de las acciones de restauración con incertidumbre por tasa de descuento $(r=5,10,15 \%)$

10 VAN uso actual y acciones de restauración con precios y rendimientos altos y bajos ( $r=10 \%)$

11 VAN marginal de las acciones de restauración con precios y rendimientos altos y bajos $(r=10 \%)$

15.1 Creación de empleo en el primer año (establecimiento) por acción de la restauración

15.2 Creación de empleo del año 2 al 20 por acción de la restauración por año

17 Beneficio bruto marginal de las acciones de restauración.

\section{Mapas}

1 Uso actual del suelo donde se analiza la implementación de las acciones de restauración 
2.1 Uso del suelo ...

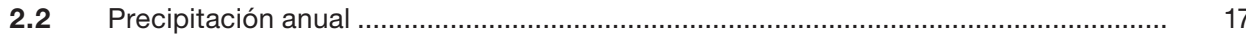

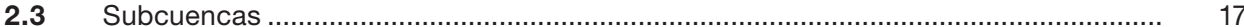

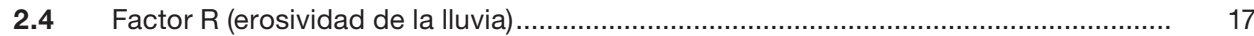

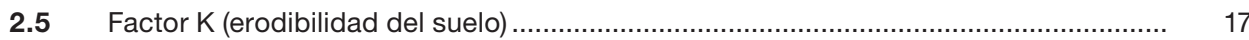

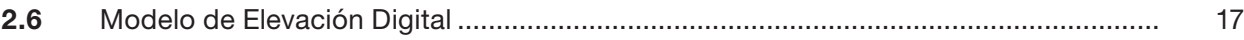

$3 \quad$ Cambio en la erosión por la implementación del SAF granos básicos........................ 32

$4 \quad$ Cambio en la exportación de sedimentos por la implementación del SAF granos

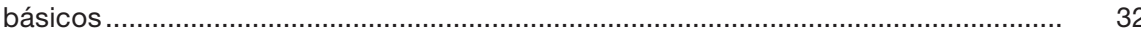

$5 \quad$ Cambio en la exportación de $\mathrm{N}$ por la renovación del café de mediana altura ............. 33

6 Cambio en la exportación de P por la adopción de la zafra verde en caña de azúcar 


\section{Siglas}

\begin{tabular}{|c|c|}
\hline BANDESAL & Banco de Desarrollo de El Salvador \\
\hline CENTA & Centro Nacional de Tecnología Agropecuaria y Forestal \\
\hline CIAT & Centro Internacional de Agricultura Tropical \\
\hline CONSAA & Consejo Salvadoreño de la Agroindustria Azucarera \\
\hline CORDES & Asociación Fundación para la Cooperación y el Desarrollo Comunal \\
\hline FAO & Organización de las Naciones Unidas para la Alimentación y la Agricultura \\
\hline FUNDESYRAM & Fundación para el Desarrollo Socioeconómico y Restauración Ambiental \\
\hline GOES & Gobierno de El Salvador \\
\hline GEl & Gases de Efecto Invernadero \\
\hline$\| C A$ & Instituto Interamericano de Cooperación para la Agricultura \\
\hline MARN & Ministerio de Medio Ambiente y Recursos Naturales \\
\hline ONG & Organización No Gubernamental \\
\hline PREP & Plan de Restauración de Ecosistema y Paisajes de El Salvador \\
\hline PRISMA & Programa Regional de Investigación sobre Desarrollo y Medio Ambiente \\
\hline $\mathrm{RBC}$ & Razón Beneficio Costo \\
\hline ROAM & $\begin{array}{l}\text { Metodología de Evaluación de Oportunidades de Restauración (por sus siglas en } \\
\text { inglés) }\end{array}$ \\
\hline $\mathrm{ROI}$ & Return on Investment (retorno de la inversión) \\
\hline SAF & Sistema agroforestal \\
\hline SASP & Sistema agrosilvopastoril \\
\hline SSP & Sistema silvopastoril \\
\hline UICN & Unión Internacional para la Conservación de la Naturaleza \\
\hline VAN & Valor Actual Neto \\
\hline
\end{tabular}





\section{Agradecimientos}

La UICN expresa su reconocimiento al Ministerio de Medio Ambiente y Recursos Naturales de El Salvador (MARN), y en especial a la Ministra Lina Pohl, por priorizar e impulsar la restauración a nivel nacional y, por su apoyo e interés en el proceso de aplicación de la Metodología de Evaluación de Oportunidades de Restauración (ROAM por sus siglas en inglés) en El Salvador.

Los autores agradecen a José Francisco Fonseca y la Corporación Educativa para el Desarrollo Costarricense (CEDECO) por su apoyo en la recopilación de información y facilitación de su experiencia y conocimiento. Asimismo este documento no hubiera sido posible sin el tiempo, voluntad y aporte de conocimiento de Alberto, A. (director de la mancomunidad La Montañona); Amaya, G. (Alianza Cacao); Arroyo, J. (Asociación Azucarera de El Salvador); Baiza, V. (MARN, El Salvador); Barry, D. (Catholic Relief Service); Córdobas, J. (FUNDESYRAM); Cortez, S. (Consejo Salvadoreño de Café); Escobar, A. (PROLECHE); García, E. (CIAT); Gomez, I. (PRISMA); Hernández, A. (Alcalde de Verapaz); Hawthorne, P. (Natural Capital Project, Universidad de Minnesota); Magaña, J. (MARN); Mauricio Orellana, J. (CORDES); Merlos, E. (FUNDE); Montoya, B. (Consultor); Oviedo, G. (FIAES); Quezada, J. (MARN, El Salvador); Regalado, T. (FUNDAZÚCAR); Rivera, C. (MARN, El Salvador); Rivera, D. (BANDESAL); Sanz, N. (MARN, El Salvador); Sharp, R. (Natural Capital Project, Universidad de Stanford); Torres, F. (CENTA); Trigueros Hecht, R. (ES-Cacao); y Vogl, A. (Natural Capital Project, Universidad de Stanford).

Los autores reconocen a los revisores Nikolay Aguirre (Universidad Nacional de Loja, Ecuador), Miguel Arato Garza (Universidad de Bonn, Alemania) y Jean-François Le Coq (CIRAD-CIAT, Francia y Colombia) por su tiempo y sus valiosas observaciones y correcciones. 



\section{Presentación}

La restauración de paisajes es reconocida como una estrategia no solo para recuperar la integridad ecológica, sino también para generar beneficios económicos y sociales a nivel local, nacional y global, al mejorar los medios de vida, las dinámicas económicas, la seguridad alimentaria y energética y la protección del recurso agua, con un enfoque de adaptación y mitigación al cambio climático.

La UICN impulsa iniciativas como el Desafío de Bonn, establecido en 2011 con el fin de lograr la restauración de 150 millones de hectáreas de tierras deforestadas y degradadas a nivel mundial para el año 2020, y 350 millones para el año 2030. Para alcanzar esta meta la UICN está apoyando a más de 25 países en el mundo en la identificación de oportunidades de restauración y la elaboración e implementación de estrategias, planes y programas, buscando una amplia participación de diversos sectores sociales para llevar los beneficios de la restauración de ecosistemas y paisajes a las comunidades. Desde hace unos cinco años la UICN está directamente involucrada en estos esfuerzos en Costa Rica, Guatemala, Honduras, México, Nicaragua y El Salvador.

El Salvador lidera el compromiso de restaurar un millón de hectáreas de tierras degradadas y deforestadas. Esta meta implica esfuerzos e inversiones significativas para revertir la degradación ambiental y desarrollar acciones de adaptación basada en mitigación, de manera a llevar beneficios a sus habitantes y contribuir a las metas globales de bienestar.

El documento que dejamos en sus manos es el resultado del análisis de los beneficios financieros, económicos, ambientales y sociales de nueve opciones de restauración que forman parte del Plan de Acción de Restauración de Ecosistemas y Paisajes de El Salvador. Las acciones definidas abarcan tanto áreas de conservación, como zonas productivas que implican cambios en el uso del suelo o mejora de prácticas agrícolas y ganaderas, en cumplimiento con el compromiso del país en el marco del Desafío de Bonn.

Confiamos que este análisis fortalecerá los importantes esfuerzos y toma de decisiones para la restauración que El Salvador está implementando en forma decidida para mejorar la calidad de vida de sus habitantes y la salud de los ecosistemas y paisajes para revertir, al mismo tiempo, la vulnerabilidad de El Salvador frente a los impactos del cambio climático.

Dra. Grethel Aguilar Rojas

Directora Regional

UICN, Oficina Regional para México, América Central y el Caribe 



\section{Resumen}

La deforestación y la degradación de ecosistemas es un problema global e impacta su capacidad de proveer una gran diversidad de bienes y servicios. La restauración del paisaje forestal tiene la intención de asegurar que la funcionalidad ecológica y la productividad de tierras deforestadas y degradadas sean mejoradas para incrementar el bienestar humano y la conservación de la biodiversidad. Para poder definir acciones de restauración y entender las ventajas y desventajas de una o una serie de acciones de restauración para un país o un territorio definido, la UICN, Unión Internacional para la Conservación de la Naturaleza, implementó en El Salvador la Metodología de Evaluación de Oportunidades de Restauración (ROAM por sus siglas en inglés). Entre los diferentes pasos para la aplicación del ROAM, se incluye el análisis económico de las acciones de restauración.

El presente análisis consiste en un estudio a nivel nacional de los beneficios financieros, ambientales y sociales de nueve acciones de restauración que forman parte del Plan de Acción de Restauración de Ecosistemas y Paisajes de El Salvador, en cumplimiento con el compromiso del país en el marco del Desafío de Bonn de restaurar un millón de hectáreas. Es uno de los primeros análisis económicos de las acciones de restauración completadas bajo el marco del ROAM. El informe provee una explicación de las metodologías aplicadas y una discusión de los resultados por cada acción de restauración y una comparación del conjunto de acciones. Es información clave no solo para identificar las ventajas y desventajas potenciales de las diferentes acciones de restauración, sino que también provee una serie de datos necesarios para diseñar un plan, programa o estrategia de restauración; incluyendo la priorización de acciones y áreas para la restauración y el diseño de mecanismos potenciales para el financiamiento de la restauración.

Las acciones de restauración propuestas para la aplicación del ROAM y el desarrollo del nuevo plan de acción son: (1) restauración de manglar, y (2) de bosque de galería; (3) la implementación de un sistema agroforestal de granos básicos, (4) un sistema silvopastoril, (5) un sistema agrosilvopastoril, y $(6,7)$ dos sistemas agroforestales de cacao; (8) la utilización de la zafra verde en caña de azúcar; y (9) la renovación de los cafetales. Las áreas donde potencialmente se pueden implementar estas acciones de restauración cubren alrededor de 1,2 millones de hectáreas.

En este documento se presenta el análisis de los costos y beneficios de estas acciones de restauración como parte de la implementación de la ROAM. Se analizaron indicadores financieros (ingresos netos, razón beneficio-costo, retorno de la inversión, análisis 
de sensibilidad), ambientales (carbono, producción de leña, conectividad, control de la erosión y retención de sedimentos y nutrientes), y sociales (creación de empleo, mejoramiento de la seguridad alimentaria e impacto sobre los medios de vida de los hogares productores).

La implementación de los sistemas agroforestales de cacao y la restauración de manglar degradado son las acciones que tienen mejor desempeño al considerar los criterios financieros. No obstante, el análisis de sensibilidad evidencia que, por encima de los 1300 metros, el sistema silvopastoril tiene mejor desempeño con precios y rendimientos bajos, pero, la renovación de café con precios y rendimientos altos. El resultado más bajo en los indicadores financieros viene de la restauración de bosques de galería, que tiene un enfoque de conservación y no de producción agrícola o forestal.

Por otro lado, la restauración de bosque de galería, al igual que la restauración de manglar, tiene el mejor desempeño para los indicadores de balance de carbono y conectividad. La restauración de manglar tiene además el mejor desempeño para el indicador de la producción de leña. Por el contrario, la implementación del sistema silvopastoril, considerado en este análisis, tiene el rendimiento más bajo en el balance de carbono, mientras que zafra verde, por no incluir la siembra de árboles, no tiene impacto alguno sobre la conectividad y la producción de leña. Para este último indicador no tiene ningún impacto la restauración de bosque de galería.

La implementación de los sistemas agroforestales de cacao crearán, en promedio, la mayor reducción de erosión y exportación de sedimentos; mientras que la restauración de bosque de galería provocaría, en promedio, la mayor disminución en la exportación de nutrientes provenientes de la aplicación de fertilizantes y del estiércol del ganado. La utilización de la zafra verde en caña de azúcar tendrá, en promedio, el impacto más bajo sobre la erosión y la retención de sedimentos, mientras que la implementación del sistema agrosilvopastoril causaría en promedio el mayor incremento en la exportación de nutrientes.

La acción de restauración que creará el mayor número de empleos por unidad de tierra es la implementación de la zafra verde, mientras que el mejor impacto sobre la seguridad alimentaria vendría del sistema agroforestal de granos básicos. Los sistemas agroforestales de cacao mejoran los impactos sobre los medios de vida de los productores.

El bosque de galería, por su enfoque hacia la conservación, es la única acción de restauración analizada que tendría un impacto negativo sobre los indicadores sociales como el empleo, la seguridad alimentaria y sobre los medios de vida.

En su conjunto, el análisis de los indicadores evidencia que los sistemas agroforestales son las acciones que generan mayores beneficios. No obstante, depende de las prioridades que se determinen a nivel nacional o en áreas específicas con sus indicadores, lo que permitirá seleccionar cuál o cuáles acciones de restauración serán la mejor opción. 


\section{Introducción}

El Salvador es un país que ha llegado al límite de la degradación en sus ecosistemas (PRISMA 2015), tanto, que ha magnificado su vulnerabilidad frente a los eventos extremos asociados con el cambio climático (Berrizbeitia et al. 2014). Falta cobertura arbórea en un $42 \%$ del total de las áreas propensas a deslizamientos y en el $64 \%$ de las principales zonas de recarga hídrica. De igual forma, se ha perdido un $67 \%$ de los bosques de galería de los principales ríos (MARN 2014).

Gran parte de la degradación de estos ecosistemas se debe a la expansión agrícola, mientras que, aproximadamente el $46 \%$ de las tierras son aptas para agricultura y el 48\% para bosque (MARN 2002), se estima que el 72\% está ocupado por agricultura y solo el 22\% por bosque (UICN y MARN 2015).

Como respuesta a los eventos extremos y a la variabilidad climática, en 2012, el gobierno de El Salvador formuló la Política Nacional de Medio Ambiente (GOES 2012a), que tiene como uno de sus principales componentes la restauración y la conservación de los ecosistemas para reducir riesgos, sostener actividades productivas y asegurar el bienestar de la población (MARN 2013). En ese marco se estructuró el Programa Nacional de Restauración de Ecosistemas y Paisajes ${ }^{1}$ (PREP), concebido en sinergia con las otras estrategias de la Política Nacional del Medio Ambiente: Biodiversidad, Saneamiento Ambiental y Recursos Hídricos y; el Plan Nacional de Cambio Climático (PRISMA 2015).

El PREP tiene un "abordaje integral de restauración de paisajes para restituir y conservar las zonas boscosas, al promover el establecimiento de corredores biológicos y la transformación de las zonas agrícolas, mediante la adopción de prácticas sostenibles, con un enfoque holístico que incluye, además de la rehabilitación ecológica de los ecosistemas y recuperación de servicios ecosistémicos, la mejora de los medios de vida, el estímulo a las economías locales, el fortalecimiento de las capacidades y la protección de la biodiversidad, todo esto en forma altamente participativa e incluyente" (MARN 2012).

El PREP propone una intervención integral de los paisajes y los territorios con el propósito de abordar tres componentes estratégicos: (1) el desarrollo de una agricultura

1 http://www.marn.gob.sv/programa-nacional-de-restauracion-de-ecosistemas-y-paisajes-prep/ 
resiliente al clima y amigable con la biodiversidad, (2) la restauración y conservación inclusiva de ecosistemas críticos, y (3) el desarrollo sinérgico de la infraestructura física y la infraestructura natural (Barry 2012, Banco Mundial 2015).

En el marco del Desafío de Bonn, ${ }^{2}$ el Gobierno de El Salvador asumió el compromiso de restaurar un millón de hectáreas, cerca de la mitad del territorio salvadoreño (Pancel 2016), que procura cumplir con el nuevo Plan de Acción de Restauración de Ecosistemas y Paisajes. ${ }^{3}$ El Desafío de Bonn no incluye nuevos compromisos, es solo una manera de lograr las metas y parte de los acuerdos internacionales como el objetivo 15 de Aichi, la Decisión XI/16 de la Convención sobre Diversidad Biológica, o el Objetivo 3 (b) (i) de la IPBES (CDB 2010, CDB 2012, IPBES 2013).

La Unión Internacional para la Conservación de la Naturaleza (UICN) apoya el desarrollo del Plan de Acción mediante la aplicación de la Metodología de Evaluación de Oportunidades de Restauración (ROAM por sus siglas en inglés). ${ }^{4}$ Como parte de este proceso se analiza, en este documento, una serie de acciones de restauración del paisaje que podrían formar la base del Plan de Acción de Restauración de Ecosistemas y Paisajes.

La metodología ROAM consiste en:

1. Analizar las necesidades de restauración con base en las prioridades nacionales.

2. Definir las acciones de restauración con base en dichas prioridades.

3. Identificar el alcance y la disponibilidad de las tierras por cada técnica de restauración.

4. Analizar los costos y cobeneficios de cada técnica de restauración.

5. Identificar y establecer las prioridades entre las oportunidades de restauración del paisaje con base en las limitaciones y oportunidades. (UICN y WRI 2014).

Este documento presenta los hallazgos del cuarto paso de la ROAM, que corresponde al análisis de los costos y beneficios de las acciones de restauración, así como el impacto sobre la generación de una serie de servicios ecosistémicos considerados de importancia para el país. Este estudio identifica, analiza y prioriza las diferentes opciones de restauración del paisaje forestal y funcional.

2 El Desafío de Bonn es una iniciativa global que tiene como objetivo restaurar 150 millones de hectáreas de tierras degradas y deforestadas, en todo el mundo, al año 2020 y 350 millones para 2030. Más información: http://www.bonnchallenge.org/

3 El Plan de Acción se construye sobre la base del PREP.

4 La guía que explica la metodología se puede descargar en: https://portals.iucn.org/library/node/45770 


\section{Acciones de restauración y uso actual del suelo}

El Salvador tiene un área terrestre aproximada de $21000 \mathrm{~km}^{2}$, la mayor parte de ese territorio son áreas de uso agrícola (Figura 1).

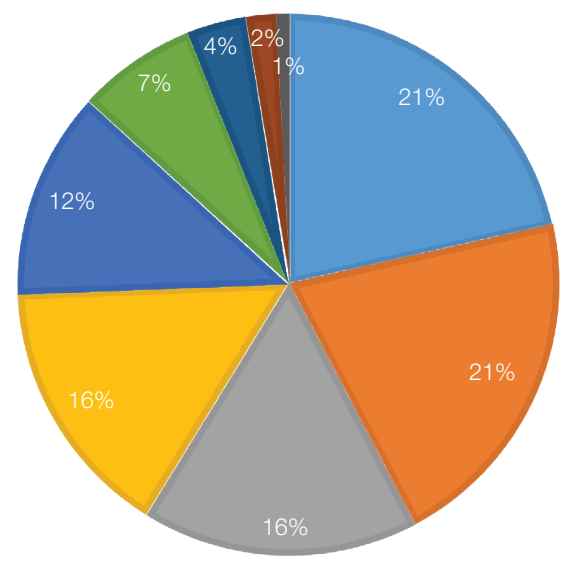

Figura 1. Clasificación del uso actual del suelo en El Salvador.

* Mosaico de cultivos y pastos, mosaicos de cultivos, pastos y vegetación.

** Incluye áreas de bosques secundarios.

${ }^{\star \star \star}$ Zonas quemadas, salinas, roqueada, lavas, playas, dunas y arenales.

A partir de los diferentes usos actuales de suelo se identificaron, de manera participativa y en colaboración con el Ministerio de Medio Ambiente y Recursos Naturales (MARN), siete usos de suelo priorizados (Mapa 1) para implementar una serie de

acciones de restauración, ${ }^{5}$ con el objetivo de mejorar y recuperar los bienes y servicios ecosistémicos relevantes para el país (McCarthy et al. 2017).

Las nueve acciones de restauración definidas en conjunto con el MARN, y consideradas para este análisis (Cuadro 1), se basaron en las opciones de restauración identificadas anteriormente en el PREP y se fundamentaron en criterios de agricultura climáticamente inteligente ${ }^{6}$ (Banco Mundial 2015).

Como parte de este estudio se define a continuación, con más detalle, cada acción de restauración ${ }^{7}$ y los respectivos usos actuales del suelo. ${ }^{8}$ Las características de los diferentes sectores productivos y de los productores se establecieron con base en los resultados del censo agropecuario más reciente (DIGESTYC 2008a). Adicionalmente, se utilizaron datos de las gremiales cuando proveían datos más actuales.

5 Son las técnicas y acciones de restauración consideradas para su análisis e implementación dentro del proceso ROAM.

6 La agricultura climáticamente inteligente busca aumentar la productividad agrícola de manera sostenible. Implementa técnicas para apoyar a los productores en la adaptación al cambio climático, mediante el mejoramiento de la resiliencia de medios de vida y de los ecosistemas, y siempre que sea posible, proporcionar el cobeneficio de la reducción de los gases de efecto invernadero (FAO 2013).

7 Los supuestos que se generaron para definir las especificaciones técnicas de cada opción de restauración se presentan en las fichas técnicas de cada acción de restauración (véase 2.1).

8 Los usos actuales del suelo se definieron con base en las imágenes de Rapid Eyes de El Salvador, los cuales se afinaron, cuando procedía, con el criterio de expertos locales. 

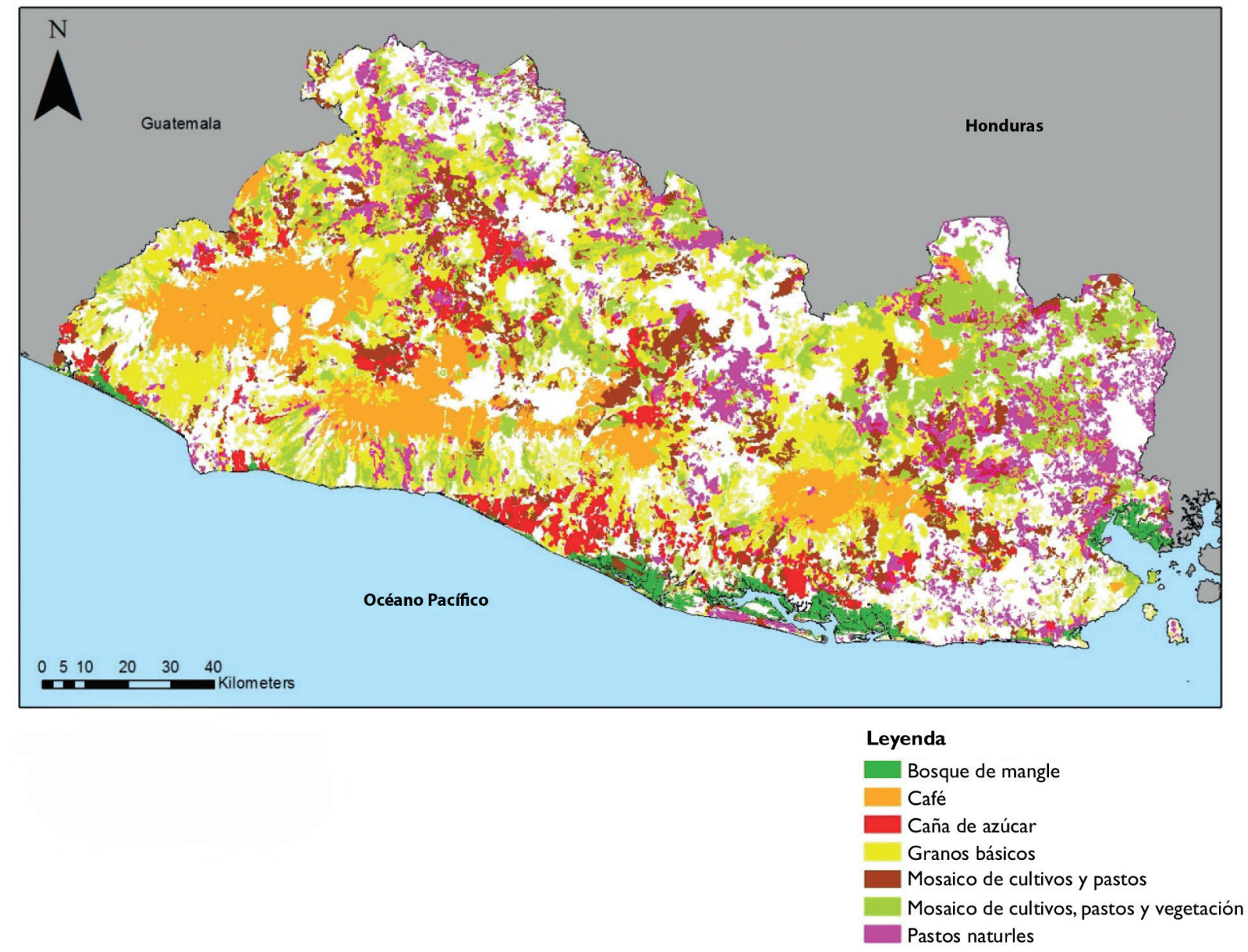

Mapa 1 Uso actual del suelo donde se analiza la implementación de las acciones de restauración.

Fuente: Elaboración propia basado en UICN y MARN 2015.

Cuadro 1 Áreas potenciales para las acciones de restauración

\begin{tabular}{|c|c|c|}
\hline Acciones de restauración & Uso actual del suelo & Área potencial de restauración (ha) \\
\hline 1. Restauración de manglar & Mangle degradado (azolvamiento) & 2000 \\
\hline \multirow{5}{*}{ 2. Restauración bosque de galería } & Granos básicos & 5653 \\
\hline & Pasto natural & 2995 \\
\hline & Caña & 3821 \\
\hline & Mosaico de cultivo y pasto & 3158 \\
\hline & Mosaico de cultivos, pastos y vegetación & 4298 \\
\hline 3. Sistema agroforestal de granos básicos & Granos básicos & 375133 \\
\hline 4. Sistema silvopastoril & Pasto natural & 197353 \\
\hline 5. Sistema agrosilvopastoril & Mosaico de cultivos y pasto & 162850 \\
\hline 6. Zafra verde en caña & Caña bajo quema & 81389 \\
\hline 7. Sistema agroforestal de cacao (1) & Café < 900 msnm & $66369^{\mathrm{a}}$ \\
\hline 8. Sistema agroforestal de cacao (2) & Mosaico de cultivos, pastos y vegetación <900 msnm & 234686 \\
\hline \multirow{3}{*}{ 9. Renovación café } & Café < 800 msnm & 47615 \\
\hline & Café $800<1200$ msnm & 41000 \\
\hline & Café >1200 msnm & 26000 \\
\hline Total & & 1187951 \\
\hline
\end{tabular}

a/ Es la misma área que en el caso del café de bajío y una parte de café de mediana altura.

Fuente: Elaboración propia, basado en UICN y MARN 2015, MARN 2016, CONSAA 2016. 


\subsection{Descripción de las acciones de restauración}

\subsubsection{Restauración de manglar}

Uso actual del suelo: esteros dentro del área de manglar donde el MARN identificó obstrucción en las corrientes por exceso de sedimentos y biomasa (troncos), representa unas 2000 hectáreas. En este estudio no se consideran los ingresos provenientes del uso actual, tomando en cuenta que la restauración se llevaría a cabo en manglar degradado con poca fauna que pueda ser extraída, sobre todo a lo largo del periodo de análisis.

Técnica de restauración: la restauración ecológica de manglar incluye el restablecimiento del balance hidrológico (FIAES 2011, Lewis 1999) a través de la limpieza y el dezasolvamiento (remoción de sedimentos) del estero, lo que permitirá su regeneración natural. ${ }^{9}$

Las dos actividades consideradas generadoras de ingreso, como resultado de la restauración, son la extracción de madera y leña; y la extracción de dos especies de cangrejos: los punches (Uciles occidentalis) y los cangrejos azules (Cardisoma crassum).

Estos recursos estarían operados por miembros de las comunidades bajo planes locales sostenibles, e incluye la conformación de grupos de puncheros con monitoreo y regulación para la extracción de crustáceos (Rivera 2013). ${ }^{10}$

\subsubsection{Restauración bosque de galería}

Uso actual del suelo: el área potencial para esta restauración incluye zonas de granos básicos (28\%); mosaico de cultivo, pasto y vegetación (22\%); caña (19\%); mosaico de cultivo y pasto (16\%); y pasto natural (15\%) ubicadas en los márgenes de los ríos principales y secundarios (25 m a ambos lados).

Técnica de restauración: en cumplimiento con la Ley del Medio Ambiente (República de El Salvador 2012), se plantea la reforestación del bosque de galería en 25 m en las márgenes de los ríos principales y secundarios. La restauración se realizará con la siembra de plantas forestales y técnicas de regeneración natural (Sanchún et al. 2016). Las actividades de manejo se limitan a las prácticas que faciliten la regeneración natural (plazueleado, raleo) durante los primeros cinco años y con raleos en los años ocho y once.11

9 Comunicación personal con el Ing. Rivera, C., especialista en la técnica restauración de manglar del MARN, julio 15 de 2016.

10 Más detalles en: Nello et al. (2018a).

11 Más detalles en: Nello et al. (2018a).

\subsubsection{Sistema agroforestal de granos básicos}

Uso actual del suelo: área de granos básicos donde se siembra maíz, frijol y maicillo con pocos árboles (4 árboles/ha) (Sermeño 2009). La práctica de la quema de rastrojos se realiza en un $40 \%$ del área nacional de cultivo. ${ }^{12}$ En este análisis, el paquete agrícola que distribuye el Ministerio de Agricultura y Ganadería (MAG) de unos US\$129/ha, no se toma en cuenta como subsidio a la producción para evitar un sesgo en el momento de hacer la comparación con la restauración (White et al. 2011).

Técnica de restauración: sistema agroforestal (SAF) de cultivos en callejones con siembra de árboles dentro del área de granos básicos para producir leña, madera y frutas (marañón y jocote de verano). Los árboles derivados de la regeneración natural, dentro de la parcela, sirven para fines dendroenergéticos (leña) y se mantiene una baja densidad de siembra de árboles frutales con el propósito de mantener el rubro de producción de granos básicos. Se abandona la práctica de la quema. ${ }^{13}$

\subsubsection{Sistema silvopastoril}

Uso actual del suelo: los pastos naturales representan superficies con hierba densa de variedades nativas sin ninguna práctica agronómica fuera del pastoreo. La densidad arbórea es baja (18 árboles/ha) (Sermeño 2009). Se estima que cada productor posee en promedio 16 cabezas de ganado, lo cual representa una carga animal de tres cabezas por hectárea (MAG 2003, DIGESTYC 2008a, DEA 2015). Los ganaderos se distribuyen en productores de leche para subsistencia, ganaderos especializados en la producción de leche para el mercado y productores con ganadería de doble propósito. (MAG 2011).

Técnica de restauración: el sistema silvopastoril (SSP) introduce cuatro variedades de pasto tropical mejorado, arreglos de barreras vivas (p. ej. caña forrajera como King Grass) y cercas vivas, así como árboles nativos y maderables dispersos dentro de las divisiones del potrero. Este arreglo espacial permite producir ensilaje y manejar el hato bajo pastoreo rotacional. ${ }^{14}$ Dentro de las acciones se incorpora el mejoramiento genético del hato bovino para cosechar mayores beneficios productivos, a partir de una alimentación enriquecida. ${ }^{15}$

12 Comunicación personal con el Ing. Torres, F. del Centro Nacional de Tecnología Agropecuaria y Forestal (CENTA), julio 21 de 2017.

13 Más detalles en: Nello et al. (2018b).

14 En el caso del presente sistema, el pastoreo rotacional consiste en alternar el pastoreo de los apartos de 5 a 7 días, dejando 30 días de descanso para una recuperación completa del pasto.

15 Más detalles en: Nello et al. (2018c) 


\subsubsection{Sistema agrosilvopastoril}

Uso actual del suelo: el mosaico de cultivos y pasto corresponde a pequeñas parcelas de cultivos anuales (principalmente granos básicos), y pastos cultivados o naturales. La densidad arbórea es baja (15 árboles/ha) (Sermeño 2009). ${ }^{16}$

Técnica de restauración: el sistema agrosilvopastoril (SASP) integra técnicas del SAF de granos básicos y el SSP es apto para productores ${ }^{17}$ que combinan la producción de granos básicos y ganadera en una determinada área de la finca. ${ }^{18}$

\subsubsection{Zafra verde en caña de azúcar}

Uso actual del suelo: corresponde a las áreas cultivadas con caña de azúcar. La práctica de quema está generalizada en toda el área nacional de cultivo, fuera de las áreas destinadas para resiembra ${ }^{19}$ y producción de panela ${ }^{20}$ (Hudges et al. 2016).

Técnica de restauración: consiste en el abandono de la quema que usualmente se da previo a la cosecha. Se aprovecha la hoja y el cogollo como abono verde. Se asume que un $40 \%$ de la caña se quedaría en el campo, luego de la recolección de los residuos agrícolas de cosecha (Casen et al. 2016). La parte recolectada se lleva a los ingenios para la generación de electricidad, se acepta que una tonelada de residuo agrícola de cosecha equivale a una tonelada de bagazo ${ }^{21}$ (Mathier et al. 2013). ${ }^{22}$

\subsubsection{Sistemas agroforestales de cacao}

Uso actual del suelo: existen existen dos sistemas de manejo agroforestal con cacao. El primero consiste en un mosaico de cultivo, pasto y vegetación debajo de 900 msnm, que corresponde a las áreas donde se combinan cultivos (caña, granos básicos), pasto natural y matorrales. El segundo es el área de cafetales ubicados por debajo de los $900 \mathrm{msnm}$.

16 Más detalles en: Nello et al. (2018c).

17 Para efectos de simplificación, a lo largo de este documento se entiende por 'productores' tanto mujeres como hombres.

18 Más detalles en: Nello et al. (2018c).

19 Comunicación personal con Arroyo, J. del Consejo Salvadoreño de la Agroindustria Azucarera (CONSAA), septiembre 20 de 2016.

20 Comunicación personal con el alcalde de Verapaz, Hernández, A., julio 15 de 2016.

21 El bagazo es otra parte del cultivo de caña de azúcar que se aprovecha, comúnmente, para cogeneración eléctrica en los ingenios de El Salvador.

22 Más detalles en: Fonseca et al. (2018a).
Técnica de restauración: consiste en policultivos que combinan el plátano (sombra temporal), cacao (cultivo principal) y árboles frutales (níspero (Manilkara zapota) y mango (Mangifera indica)). El plan de manejo de la sombra no debe sobrepasar el 40\% del área para no perjudicar la producción del cacao.

En este documento nos referimos a "sistema agroforestal de cacao (1)" a aquellos sistemas establecidos por debajo de 900 msnm y a "sistemas agroforestal de cacao 2" como mosaico de cultivos, pasto y vegetación establecido por debajo de los 900 msnm. ${ }^{23}$

\subsubsection{Renovación de cafetales}

Uso actual del suelo: las zonas productoras de café se dividen de acuerdo con su altura: bajío (<800 msnm), mediana altura (800-1200 msnm) y altura (>1200 msnm), las cuales representan respectivamente $41 \%, 36 \%$ y $23 \%$ del área nacional de este cultivo. Debido al efecto de la crisis de 2002 (Flores et al. 2002), y la roya a partir de 2011 (CEPAL 2014), se estima que un $27 \%$ de los cafetales están en semiabandono (PROCAFÉ 2014).

Técnica de restauración: la restauración del paisaje cafetalero incorpora la renovación y manejo tecnificado de cafetales, diferenciados según las distintas alturas. De acuerdo con los ecosistemas identificados, se usarán variedades resistentes a la roya recomendadas por el CENTA (Centro Nacional de Tecnología Agropecuaria y Forestal). El plan de renovación incluye la diversificación del ingreso con cultivos de aguacate, mango y árboles maderables. ${ }^{24}$

\footnotetext{
23 Más detalles en: Nello et al. (2018d)
}

24 Más detalles en: Fonseca et al. (2018b). 


\section{Metodología del análisis costo-beneficio}

El análisis costo-beneficio es una herramienta analítica para estudiar las ventajas o desventajas económicas de una decisión de inversión al examinar sus costos y beneficios (DG REGIO 2015). Se aplica, principalmente, para evaluar la eficiencia económica de las diferentes opciones que logran alcanzar algún objetivo predeterminado de política o gestión (James y Predo 2015).

Asimismo se aplica un enfoque incremental, donde el análisis costo-beneficio compara un escenario de implementación de la restauración con una base de referencia, en este caso un escenario sin restauración, es decir, la continuación con el uso actual del suelo25 (DG REGIO 2015). Con el fin de cuantificar y cualificar los impactos potenciales de la restauración, se evaluaron, primero, los resultados financieros y económicos a largo plazo ${ }^{26}$ de los usos actuales y de las acciones de restauración, de acuerdo con los diferentes sistemas de manejo ${ }^{27}$ considerados; segundo, se compararon los resultados para ambos usos de suelo (Figura 2).

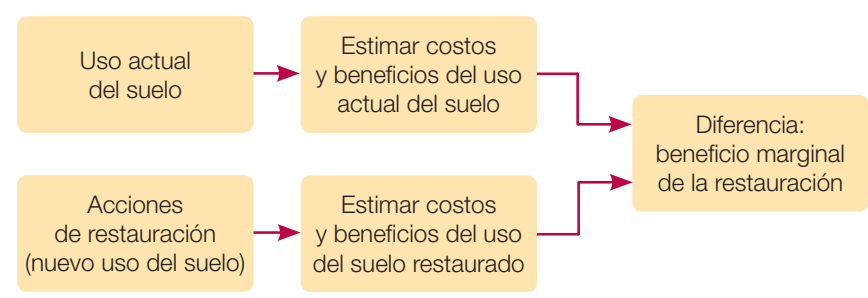

Figura 2 Beneficio marginal de la restauración.

Fuente: Elaboración propia a partir de UICN y WRI 2014.

25 El modelo del escenario de uso actual no incluye estimaciones del impacto potencial de la degradación, el impacto del cambio climatico ni el impacto de innovación tecnológica, entre otras, sobre la productividad.

26 El plazo considerado es de 20 años, tanto para los ingresos como para los costos, basado en el tiempo de crecimiento de las especies madereras (Cordero y Boshier 2003).

27 Incluyendo prácticas agronómicas/forestales, la productividad de los cultivos, y el crecimiento de especies forestales.
La base de este análisis consiste en comparar los costos y los beneficios por una hectárea bajo el uso actual, y bajo las acciones de restauración. Como tal, no se consideran los efectos de la economía de escala.

Además de estimar los ingresos directos (beneficios monetarios), el análisis consistió en evaluar los beneficios ambientales y sociales de las acciones de restauración, es decir los cobeneficios (UICN y WRI 2014).

Los cobeneficios ambientales analizadas son: (1) el balance de carbono, (2) el impacto sobre la conectividad de un paisaje, (3) la producción de leña de las acciones de restauración. Además se considera, (4) el impacto de la restauración sobre el control de la erosión, y (5) la exportación de sedimentos y nutrientes.

Los cobeneficios sociales analizadas son: (1) creación de empleo, (2) impacto sobre la seguridad alimentaria, y (3) impactos sobre los medios de vida. Para analizar estos beneficios, en conjunto, el estudio finaliza con un análisis multicriterio (Figura 3).

No se consideran las diferencias espaciales para estimar los costos, beneficios y cobeneficios, sino que se estima un efecto promedio a nivel del país. La excepción son los modelos espaciales aplicados para estimar el impacto de la restauración sobre la erosión y la exportación de sedimentos y nutrientes.

Asimismo se considera, en primera instancia, todos los flujos financieros, tanto los beneficios como los costos. La diferenciación de quién paga cuáles costos dependerá del tipo de costo (p. ej. asistencia técnica puede ser proporcionado por un servicio de extensión agrícola que no cobra a los agricultores). La diferenciación de quién podría pagar qué costos y recibir qué beneficios es la base para el diseño de instrumentos 


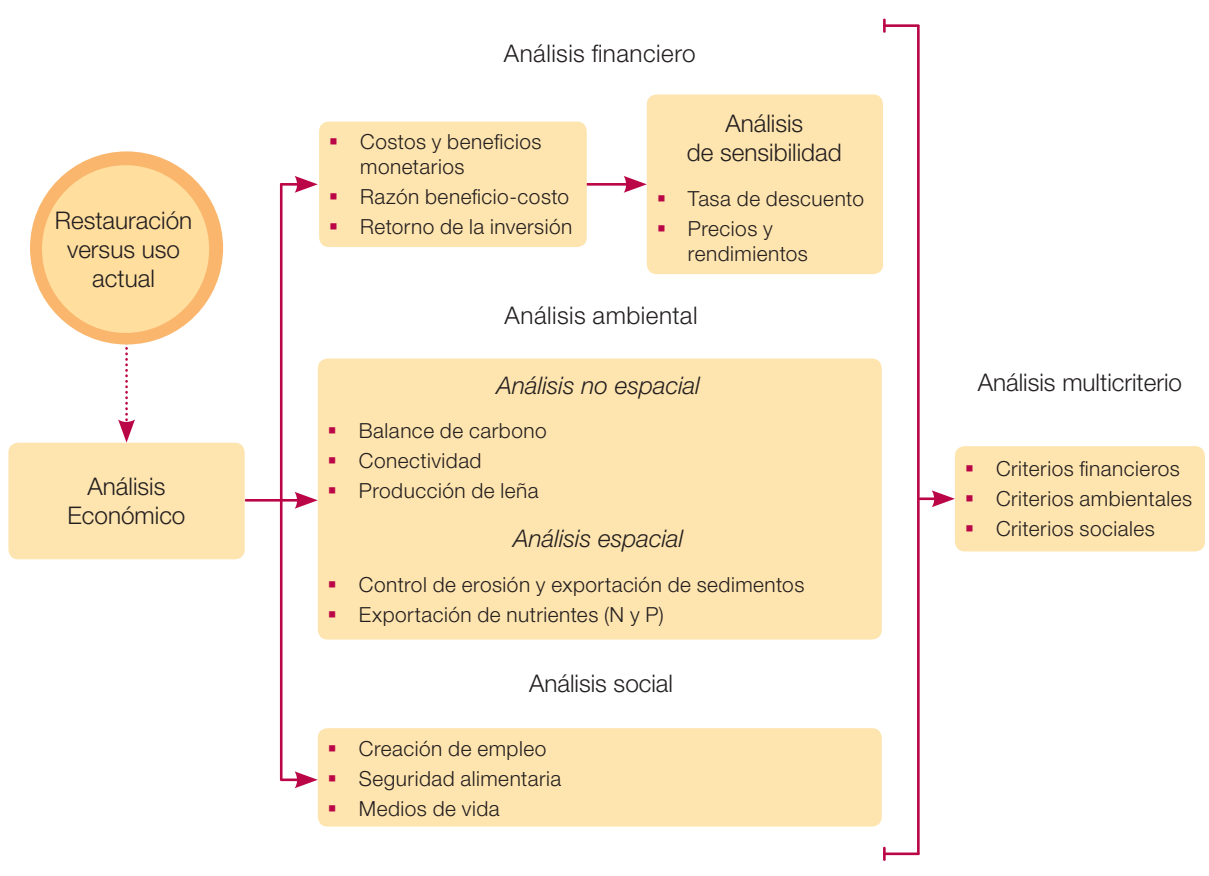

Figura 3 Aspectos e indicadores utilizados para desarrollar los analisis financiero, economico y multicriterio.

de financiamiento para apoyar la restauración. ${ }^{28}$ En el presente documento no se incluye el analisis de este aspecto. Se toman en cuenta los costos y los beneficios como un conjunto sin distinguir entre los diferentes actores involucrados o los diferentes beneficiarios potenciales de las acciones de restauración. Lo que implica, por ejemplo, que la rentabilidad financiera de una acción de restauración sea la rentabilidad en general de la acción y no, necesariamente, la rentabilidad exclusiva para un propietario (o un arrendatario) de tierras o un actor que considera implementar el proyecto de restauración.

No obstante, en líneas generales se puede entender que los beneficios financieros de las acciones de restauración son beneficios privados al igual que la mayoría de los costos (dependiendo de quién y cómo se financia la implementación de las acciones de restauración). Los beneficios ambientales y sociales son acciones que proveen tanto beneficios a los productores (p. ej. disminución de la erosión o mejoramiento de la seguridad alimentaria) como beneficios públicos (p. ej. balance de carbono o creación de empleo).

\subsection{Análisis financiero}

Un análisis financiero intenta determinar cómo individuos, hogares y empresas comerciales, entre otros, pueden maximizar

28 UICN (2017). sus propios rendimientos financieros netos o minimizar los costos de llevar a cabo sus actividades (James y Predo 2015). Mientras que en un análisis costo-beneficio económico se evalúan todos los costos y beneficios de las diferentes alternativas.

Después de haber definido las acciones de restauración, en el análisis financiero, se procede con las siguientes etapas:

- identificar todos los costos y beneficios financieros;

- valorar costos y beneficios en unidades monetarias;

- establecer el horizonte temporal de la evaluación;

- establecer la tasa de descuento;

- hacer indicadores de selección y/o rentabilidad, y;

- realizar un análisis de sensibilidad de los indicadores a las variables del valor más incierto (Martinez-Paz et al., 2013).

\subsubsection{Beneficios (financieros) de la restauración}

Los beneficios brutos se calculan a partir de los ingresos financieros de los productos forestales maderables, forestales no maderables (leña) y agrícolas (cultivos de granos básicos, frutales y carne, entre otros) (UICN y WRI 2014):

1.1 forestales maderables;

1.2 forestales no maderables como leña; y 
2. agrícolas (granos básicos, frutas, leche, carne, entre otros). El beneficio bruto para un año determinado se calcula mediante:

$$
B B_{t}(X)=\sum_{i}^{n}\left(Q_{i}^{*} P_{i}\right)(\text { ecuación 1) }
$$

Donde:

$B B(X)$ : beneficios brutos, por hectárea, de la restauración/uso actual del suelo $X$ en US\$ en el año $t$;

$Q_{i}$ : rendimiento del producto $i$ en año $t$;

$P_{i}$ : precio del producto $i$; y

$i$ : productos agrícolOas y forestales considerados en cada acción de restauración y su respectivo uso actual del suelo;

$n$ : número total de productos agrícolas y forestales considerados en cada acción de restauración o su respectivo uso actual del suelo.

\section{Rendimientos considerados}

Las estimaciones de rendimiento para los cultivos estudiados se hicieron con base en fuentes primarias y secundarias. ${ }^{29}$ Se consultaron, en una primera etapa, las guías prácticas utilizadas por las organizaciones, que son referentes en la asistencia técnica a nivel nacional, como el Instituto Interamericano de Cooperación para la Agricultura (IICA) y el CENTA, lo cual se sumó a la literatura gris consultada. Asimismo se complementó esta información con datos históricos de rendimiento sobre cada cultivo durante los últimos 10 años (FAOSTAT 2016). Finalmente, se entrevistó al personal del CENTA, MARN y las gremiales de interés durante las visitas de campo en julio y septiembre de 2016, su finalidad era llevar un control cruzado y una validación de supuestos para las premisas de cada acción de restauración.

Adicionalmente, para la recolección y el procesamiento de las frutas, se descontó del volumen total de producción un $10 \%$ por robo ${ }^{30}$ y un $15 \%$ por pérdida debido al manejo poscosecha. ${ }^{31}$

\section{Precios utilizados}

Las cantidad de producto generado por hectárea se multiplica por el precio que recibe el productor. Para ingresos maderables

29 Para mayor información, véase las fichas técnicas de cada acción de restauración.

30 Comunicación personal con Sanz, N. del MARN, septiembre 22 de 2016.

31 Comunicación personal con Torres, F. de CENTA, julio 21 de 2016. se considera el precio de las distintas especies de alto valor en $\mathrm{m}^{3}$ en pie y para productos agrícolas, el precio de finca.

Los productores a menudo toman decisiones sobre la producción basados en los precios recientes (Aimin 2010, Benítez et al. 2006). Para poder hacer una estimación de los ingresos futuros, se calcularon los precios de los cultivos agrícolas que forman parte de los planes de restauración, a partir de los precios históricos compilados por la FAO para el periodo 2002 $2013^{32}$ (FAOSTAT 2016). Para los años 2014 y 2015 los datos se completaron con la información recopilada en el anuario estadístico agropecuario (MAG 2016a). Se actualizaron todos los precios a 2015 basados en la inflación del precio al consumidor (BCR 2016).

El precio por pante ${ }^{33}$ de leña se estimó a través de la base de datos del MARN. ${ }^{34}$ En cuanto a los precios de árboles maderables en pie, se usó la información levantada por la UICN y el MARN en 2015,35 como parte de la evaluación del mercado forestal de El Salvador. Debido a la falta de datos históricos se aplicó una incertidumbre del 10\% a los precios y rendimientos de la producción de madera (Knoke et al. 2009, Knoke y Wurm 2006).

\subsubsection{Costos de la restauración}

Basado en UICN y WRI (2014); y Wunder et al. (2008) los costos considerados son: (1) costos de implementación de las acciones de restauración, (2) costos de manejo y producción; y (3) costos de oportunidad.

Los costos totales de las acciones de restauración incluyen:

1. Costos de implementación:

1.1 En la finca: inversión inicial requerida para la restauración como material de siembra, ${ }^{36}$ insumos ${ }^{37}$ y mano de obra. ${ }^{38}$

32 Se decidió tomar como periodo de referencia a partir de 2002, ya que la dolarización del país, a partir de 2001, dificulta la comparación con precios de periodo 1996-2001, debido a la hiperinflación que caracterizó este periodo.

33 Un pante de leña equivale a 1,85 $\mathrm{m}^{3}$ de leña. Es la unidad más usada para su comercialización en El Salvador.

34 Comunicación personal con Baiza,V., ingeniero del MARN, agosto 29 de 2016.

Comunicación personal con Montoya B., noviembre 22 de 2016. Por ejemplo, plantas, semillas de pasto mejorado, material para cercado. Incluye semillas, fertilizantes, agroquímicos, equipos y herramientas.

38 Medida en jornales a precio actual y real (no necesariamente igual al salario mínimo sino con lo pagado en el campo a nivel nacional). 
1.2 Fuera de la finca: asistencia técnica e infraestructura para el encadenamiento de productos agrícolas.

2. Costos de producción y mantenimiento: insumos y mano de obra para la gestión del área luego de la implementación de la restauración.

3. Costos de oportunidad: ingresos estimados de continuar con el uso actual del suelo.

Costos de implementación dentro de la finca y costos de producción y mantenimiento

(i) Mano de obra

En El salvador a nivel nacional existe una variación en el costo de la mano de obra. Por ejemplo, en el municipio Chalatenango se paga por lo menos US\$ 7 por jornal, ${ }^{39}$ mientras que en la zona oriental tiene un promedio de US\$ 5.40 Las regulaciones vigentes del salario mínimo se establece en US\$3,94 por jornal en el sector agrícola, que equivale a un sueldo de unos US\$ 118 por mes (Consejo Nacional de Salario Mínimo 2016). Para efectos del presente análisis económico, se asume un promedio nacional de US\$ 6 por jornal, tal como la mayoría de los entes financieros nacionales lo incorporan en sus proyecciones. ${ }^{41}$ Adicionalmente, se considera que un trabajo a tiempo completo equivale a 21 días trabajados por mes, lo cual corresponde a 250 jornales al año.

(ii) Insumos

La cantidad de insumos requeridos para la producción de los cultivos considerados, se extrajeron de las estructuras de costos compiladas por el centro nacional de investigación del MAG, a precios de 2015 para granos básicos (MAG 2016b): caña de azúcar (Ovando 2015), café (PROCAFÉ 2010, PROCAFÉ 2014) y ganadería (IICA 2011, Benavides Martínez et al. 2007).

(iii) Costos fijos

Para los costos fijos se tomó en cuenta el gasto de intereses que se asumió en 4\% (MAG 2016b) con base en la carga financiera relativa sobre los insumos comprados, ya que se requiere capital de trabajo que el productor no siempre puede pagar antes de la cosecha, por lo tanto, recurre al crédito. Los gastos de imprevistos y administración se calculan sobre la base de

39 Comunicación personal con Arnulfo, A., director de la mancomunidad La Montañona, agosto 5 de 2016.

40 Comunicación personal con Gómez, I. de PRISMA, julio 13 de 2016.

41 Comunicación personal con el presidente del Fondo de la Iniciativa para las Américas, Oviedo G., julio 28 de 2016. los costos variables con una tasa respectiva de 5\% y 3\% (MAG 2016b).

Costos de implementación fuera de la finca

(i) Asistencia técnica

Para garantizar la adopción y permanencia de las acciones de restauración, se incorporó el gasto de desarrollo de asistencia técnica para los productores, a través de las llamadas 'escuelas de campo'. Se trata de fincas modelo implementadas en las comunidades donde se fomentan las capacidades organizativas y productivas que usan las principales instituciones de extensión (CENTA, las ONG, mancomunidades). Este gasto se mantiene durante tres años para garantizar un acompañamiento al productor durante la fase de convencimiento y aprendizaje. ${ }^{42}$ En el Anexo 1 se describen los supuestos con más detalle.

(ii) Costo de inversión en infraestructura

Dependiendo de cada actividad de restauración se incluyeron inversiones básicas en infraestructura de acopio y procesamiento de los cultivos, como gastos indirectos, siempre y cuando:

- Los excedentes de productos agrícolas de la restauración lo justifiquen a nivel de territorio y/o comunidades.

- Haya capacidad organizativa o apertura para conformarla.

\section{Costo de oportunidad}

Markandya et al. (2001) definen los costos de oportunidad de una actividad que utiliza recursos escasos, como el valor alternativo de la opción mas rentable al que podrían haberse asignado esos recursos. Según Pirard (2008), el concepto de costo de oportunidad involucra dos nociones básicas: (a) la noción de oportunidad perdida, que significa que una inversión, actividad o uso de un recurso impide toda inversión, actividad o uso alternativo del recurso; y (b) la noción de costo, lo que significa que la oportunidad perdida habría proporcionado beneficios.

En este estudio, continuar con el uso actual del suelo en lugar de implementar las actividades de restauración, es el escenario con el que se comparan las acciones de restauración.

42 Comunicación personal con Orellana, J.M., gerente de la Asociación Fundación para la Cooperación y el Desarrollo Comunal de El Salvador (CORDES), julio 13 de 2016. 
Se usaron las tasas de aplicación de insumos y necesidades de mano de obra para la evaluación del escenario donde se asume la continuación de las prácticas agrícolas del uso actual del suelo, sin la adopción significativa de las nuevas tecnologías que componen las acciones de restauración. Asimismo, se esquiva el escollo de hacer supuestos sobre usos hipotéticos de la tierra, ahorros en costos de producción y aumentos productivos (White et al. 2011).

No se incluye el posible cambio de uso del suelo que podría ocurrir dentro del uso actual del suelo, ${ }^{43}$ al ser la restauración de paisajes productivos el elemento que se analiza como parte de este estudio. Se prefiere trabajar con los sistemas actuales de producción identificados para cada uso del suelo, según se recomienda para el análisis económico de REDD+ (UNIQUE 2016). Se asume una producción continua que se repite anualmente.

\subsubsection{Periodo de análisis}

En todas las acciones de restauración el periodo de análisis se estableció en 20 años, plazo que permite tomar en cuenta los ciclos de cultivo y el aprovechamiento de los árboles maderables. Es importante anotar que ciertos cultivos como el cacao y el café mantienen su productividad más allá de este plazo. No obstante, el plazo de 20 años permite tomar en cuenta la variabilidad de dichos cultivos, sin extender el periodo de análisis, lo cual permite limitar el sesgo ${ }^{44}$ que puede ocurrir al aplicar la tasa de descuento en un horizonte de tiempo demasiado extenso (White et al. 2011). Además, este plazo está en línea con el modelo de predicción de incrementos de carbono de suelo, ${ }^{45}$ utilizado para la valoración del balance de GEl (Bernoux et al. 2010).

\subsubsection{Tasa de descuento}

Las tasas de descuento se usan para comparar los valores actuales y futuros de los beneficios y de los costos, por dos razones.

La primera es porque dada la opción de consumir un conjunto de bienes o servicios, ahora o en el futuro, la gente tiende a

43 Por ejemplo, que se cultive mayor cantidad de sorgo y frijol que maíz por unidad de área de producción de grano básico o que el café sea reemplazado por otro cultivo.

44 Por ejemplo, si se considera una tasa de descuento del 10\%, el VAN de la rentabilidad en el año 20 'pierde' el $85 \%$ de su valor.

45 El plazo de 20 años es el tiempo mínimo para asumir que se alcance el equilibrio en el contenido de materia orgánica como resultado de la adopción de prácticas agrícolas y/o forestales (Lefèvre et al., 2017). dar más importancia a consumir ahora. Además, puede haber incertidumbre sobre la disponibilidad futura del mismo paquete de bienes y servicios y, como el consumo en el presente es más cierto, se valora más que el consumo en el futuro (James y Predo 2015).

La segunda justificación es que la tasa de descuento apropiada refleja el costo de oportunidad del capital. Significa que al invertir en una determinada acción de restauración, se renuncia a invertir en otro proyecto. Por ende, esta tasa representa el rendimiento que se podría recibir, de la inversión, en otros sectores de la economía (Cubbage et al. 2011). Cuanto más altas sean las tasas de descuento, mayor será la preferencia por el consumo actual (Gollier 2002, Martínez-Paz et al. 2013).

Se aplicó una tasa de descuento del 10\% para calcular el valor actual neto (VAN) de los flujos de caja futuros, por tratarse de la tasa de referencia usada por el gobierno de El Salvador, en el marco del análisis económico de proyectos de protección ambiental de la misma índole (GOES 2012b). Esta tasa es conservadora ya que la remuneración promedio sobre la deuda del sector público no financiero es del 6\% (Pérez Trejo 2013). En general, la tasa de preferencia temporal adoptada por los formuladores de políticas, al priorizar las actividades e inversiones del sector público, es menor que la tasa privada de preferencia temporal (James y Predo 2015).

\subsubsection{Indicadores del análisis costo-beneficio financiero}

Para interpretar los resultados de este análisis financiero sobre las acciones de restauración se determinaron una serie de indicadores que se describen a continuación.

\section{Beneficios netos (valor actual neto)}

EI VAN es el primer resultado de cualquier análisis costo-beneficio. Se trata de los beneficios menos los costos calculados a su valor actual, es decir, se aplica la tasa de descuento al flujo de beneficios y costos para el periodo considerado. Si el cálculo conduce a un VAN positivo, entonces una acción de restauración tiene sentido desde un punto de vista financiero. Cuanto mayor es el VAN, mejor será el valor de una acción de restauración (Noleppa 2013).

Se obtiene el VAN de acuerdo con la siguiente fórmula (James y Predo 2015):

$$
\operatorname{VAN}(X)=\sum_{\mathrm{t}=0}^{T}\left(\left(B B_{t}(X)-C T_{t}(X)\right) *\left(\frac{1}{1-r}\right)^{t}\right) \text { (ecuación 2) }
$$


Donde:

$\operatorname{VAN}(X)$ : valor actual de los beneficios netos, por hectárea, de la restauración/uso actual $X$ en US\$;

$B B(X)$ : beneficios brutos, por hectárea, de la restauración/uso actual de $X$ en US\$ en el año $t$;

$C T(X)$ : costos, por hectárea, de la restauración/uso actual de $X$ en US\$ en el año $t$;

$T$ : horizonte temporal;

$t$ : año; y

$r$ : factor de descuento.

\section{Beneficios marginales (adicionales)}

Además de calcular el VAN de la acción para el periodo considerado, tambien se calculó el VAN marginal, o sea, la rentabilidad adicional de la restauración. Lo anterior corresponde al beneficio neto marginal, que expresa los ingresos adicionales generados por la restauración del paisaje en comparación con el uso actual.

Para que el proyecto sea aceptable por razones financieras, el VAN marginal debe ser positivo. Significa que la opción produce mayores beneficios netos, evaluados en términos de valores actuales, en comparación con el escenario de continuar con el uso actual del suelo (James y Predo 2015). Se calcula de la siguiente forma:

$$
\operatorname{VAN}_{M}(X)=\left[\sum_{\mathrm{t}=0}^{T} B r_{t}(X)-C r_{t}(X)\right]-\left[\sum_{\mathrm{t}=0}^{T} B a_{t}(X)-C a_{t}(X)\right]
$$

(ecuación 3)

Donde:

$V A N_{M}(X)$ : valor actual de los beneficios netos por hectárea marginales de una determinada acción de restauración;

$B r_{t}(X)$ : valor actual de los beneficios brutos, por hectárea, restaurado en el año $t$;

$C r_{t}(X)$ : valor actual de los costos, por hectárea, restaurado en el año $t$;

$B a_{t}(X)$ : valor actual de los beneficios, por hectárea, bajo el uso actual en el año $t$;

$C a_{t}(X)$ : valor actual de los costos, por hectárea, bajo el uso actual en el año $t$;

$T$ : horizonte temporal; y

t: año.
Razón beneficio-costo

El indicador razón beneficio-costo (RBC) expresa la relación entre los beneficios y los costos, o sea, el beneficio generado por cada unidad de costo. Indica el vínculo entre el valor actual de los beneficios brutos totales de cada acción de restauración como la suma de costos: (1) implementación, (2) mantenimiento y producción; y (3) costos de oportunidad ${ }^{46}$ (James y Predo 2015). Expresa el nivel de rentabilidad de la restauración en relación con los ingresos que se dejan de percibir (uso actual) y los costos de la restauración.

Cuando este indicador supera 1, la restauración llevaría beneficios mayores a la suma de los costos de la restauración y el ingreso que se deja de percibir por no seguir con el uso actual del suelo. En otros términos, la restauración del paisaje sería más rentable que la continuación del escenario 'hacer lo mismo'. Si es menor a 1, indica que la continuación de las prácticas que caracterizan el uso actual del suelo, brindaría mayores beneficios monetarios que la implementación de una determinada acción de restauración.

Se calcula con la siguiente ecuación (James y Predo 2015):

$$
R B C(X)=B \operatorname{Tr}(X) / C \operatorname{Tr}(X)+B N a(X)) \text { (ecuación 4) }
$$

Donde:

$R B C(X)$ : razón beneficio-costo de una determinada restauración;

$B \operatorname{Br}(X)$ : valor actual de los beneficios esperados de la restauración;

$C \operatorname{Tr}(X)$ : valor actual de los costos de la restauración; y

$B N a(X)$ : valor actual de los beneficios netos generados por el uso actual donde se implementaría la restauración (costo de oportunidad).

\section{Retorno de la inversión}

El retorno de la inversión (ROI por sus siglas en inglés) mide el beneficio del inversor como resultado de una inversión. En este análisis se mide la eficiencia de la inversión en una determinada técnica de restauración al comparar los beneficios netos adicionales de la restauración con la inversión. Por esta razón, en este análisis, se utilizan los costos de implementación porque permite comparar las acciones de restauración, entre ellas, por

46 En este estudio se considera el ingreso neto de suelo actual como el costo de oportunidad. 
su rentabilidad adicional en relación con sus respectivos costos de implementación.

Se calcula con la siguiente ecuación:

$$
R O I(X)=\frac{\left(B N_{r}(X)-B N_{a}(X)\right)}{C I(X)}(\text { ecuación 5) }
$$

Donde:

$R O I(X)$ : retorno adicional de la inversión en la restauración;

$B N_{r}(X)$ : valor actual de los beneficios netos de la restauración;

$B N_{a}(X)$ : valor actual de los beneficios netos del uso actual donde se implementaría la restauración (costo de oportunidad); y

$C I(X)$ : costos de implementación de la restauración.

\section{Análisis de sensibilidad}

(i) Sensibilidad a la tasa de descuento

Los resultados de un análisis económico siempre deben someterse a un análisis de sensibilidad para evaluar su robustez y los factores que podrían cambiar cualquier clasificación inicial de las diferentes opciones (James y Predo 2015). Los resultados presentados a continuación se expresan por su VAN a 20 años con la tasa de descuento de referencia de 10\% sino se menciona lo contrario.

En primera instancia se define un escenario donde se considera una tasa de descuento de 5\%, de esta forma se ajusta a las condiciones de financiamiento otorgado por fuentes multilaterales y del Fondo Verde del Clima (GCF 2014). Este escenario aumenta el valor de los beneficios y costos futuros frente a los actuales (Campos et al. 2016).

En segunda instancia, se define otro escenario donde se toma como referencia la tasa de descuento de acuerdo con lo definido por el sector financiero privado al considerar el riesgo de la acción. Se estima la tasa del 15\% como nivel de rentabilidad que exigen los fondos privados de inversiones de impacto (Campanale 2014, Yin y Meyer 2016). Para proyectos con mayor nivel de riesgo pueden exigir tasas anuales de interés de hasta $20 \%$, lo cual se considera extremo pues corresponde a la rentabilidad máxima de proyectos sobre las plantaciones tropicales de árboles maderables (Clenaghan et al. 2014). Se prefiere la tasa del $15 \%$ porque sigue más elevada (y por ende conservadora) que las tasas de préstamos comerciales de largo plazo (11,7\%) ofrecido por bancos nacionales en 2015 (BCR 2016). (ii) Sensibilidad variaciones de precio y productividad

El análisis de sensibilidad debe completarse con un estudio de escenarios que examine el impacto de las combinaciones de valores de las variables críticas. En particular, las combinaciones de valores 'optimistas' y 'pesimistas' de las variables críticas, pueden ser útiles para construir diferentes escenarios realistas, que pueden mantenerse bajo ciertas hipótesis. Para definir los escenarios optimistas y pesimistas es necesario elegir para cada variable los valores extremos (inferior y superior) dentro de un rango definido como realista. Las variables "criticas" seleccionadas son los precios y los rendimientos de las actividades productivas (DG REGIO 2015).

Para medir la influencia de un incremento o descenso de precios y rendimientos, se crearon dos escenarios adicionales basados en los cambios históricos y regionales de los precios y los rendimientos. Se determinaron valores inferiores y superiores de cada parámetro, basado en un intervalo de confianza del 95\% ${ }^{47}$ o cuando no había datos históticos se aplicó una incertidumbre del $10 \%$.

Se determinan precios y niveles de productividad bajos y altos, según la ecuación descrita a continuación.

$$
\begin{aligned}
& \text { Limite inferior }(Y)=\bar{Y}-1,96 * \frac{\sigma}{\sqrt{n}} \text { (ecuación 6.1) } \\
& \text { Limite superior }(Y)=\bar{Y}-1,96 * \frac{\sigma}{\sqrt{n}} \text { (ecuación 6.2) }
\end{aligned}
$$

Donde:

$\bar{Y}$ : el valor promedio histórico de rendimiento (tonelada/ha o $\mathrm{m}^{3}$ / árbol) o precio (US\$/tonelada o $\mathrm{m}^{3}$ );

1,96: numero z obtenido a partir de la tabla de valor tipificado para la distribución normal ${ }^{48}$ que consiste en el múltiplo de la desviación estándar que corresponde al ancho del intervalo deseado, en nuestro caso 95\%; y

$\sigma$ : Desviación estándar9 de la variable.

Luego de haber calculado los límites inferiores y superiores de los rendimientos y precios, se determinó el efecto de la variabilidad de precios y rendimientos sobre el VAN de los beneficios

47 Significa que el 95\% de la observaciones se ubican dentro el rango definido por los límites inferior y superior (Payton et al. 2003).

48 Para ver un caso concreto de aplicación en la ingeniería ambiental, véase: http://ocw.upm.es/ingenieria-agroforestal/climatologia-aplicada-a-la-ingenieria-y medioambiente/contenidos/percentiles/DISTRIBUCIONNormal.pdf

49 La desviación estándar indica la variación promedio de los valores de una distribución estadística en relación con su media aritmética. Se obtiene al calcular la raíz cuadrada de la varianza de la variable. 
netos de la restauración y del uso actual. A modo de ejemplo, se detalla a continuación la ecuación usada para estimar el límite inferior -o VAN "pesimista"- de los beneficios netos.

$$
\left.V A N_{i n f}(P, Q)=\sum_{\mathrm{t}}^{T}\left(\sum_{\mathrm{n}}^{N}\left(P_{i n f, t, n} \mathrm{X} Q_{i n f, t, n}\right)-C T_{t}\right) \mathrm{X}\left(\frac{1}{1-r}\right)^{t}\right)
$$

(ecuación 7)

Donde:

$\operatorname{VAN}_{\text {inf }}(P, Q)$ : límite inferior del valor actual de los beneficios netos del escenario uso del suelo

(US\$/ha);

$P_{i n f, t, n}:$ límite inferior del precio del producto n (US\$/tonelada o $\mathrm{m}^{3}$ en pie);

$Q_{i n f, t, n}$ : límite inferior del volumen unitario de la producción $\mathrm{n}$ (tonelada o $\mathrm{m}^{3}$ en pie/ha);

n: producto maderable o agrícola, según el uso del suelo;

$C T_{t}$ : costos en el año t asociado al uso del suelo (US\$/ha);

$r$ : tasa de descuento;

$T$ : horizonte temporal; y

t: año.

Todos los cálculos se llevaron a cabo con hojas de cálculo de Microsoft Office Excel. Según James y Predo (2015) estos modelos de hoja de cálculo ofrecen un marco efectivo para compilar y analizar toda la información involucrada en un análisis costo-beneficio.

Los cobeneficios responden a las prioridades para la restauración establecidas a nivel nacional e internacional. Estos son los valorados en el marco de este análisis:

1. balance de gases de efecto de invernaderos (GEI) (en CO2eq):50

2. mejoramiento de la conectividad del paisaje forestal;

3. producción de leña para satisfacer la necesidades energéticas domésticas;

4. reducción de erosión y exportación de sedimentos;

5. reducción de la exportación de nutrientes (nitrógeno y fósforo);

50 Las $\mathrm{TCO}_{2}$ e o toneladas $\mathrm{CO}_{2}$ equivalente abarcan los principales GEl antrópicos al considerar el 'poder de calentamiento global' de cada tipo de gas (nitrógeno, dióxido de carbón, metano, entre otros) para convertirlos en $\mathrm{CO}_{2}$ unidad de referencia para medir los gases de efecto invernadero.
6. creación de empleo;

7. seguridad alimentaria; $y$

8. medios de vida (mejoramiento de los ingresos de las familias productoras).

\subsection{Analisis cobeneficios ambientales (modelos no espaciales)}

Como ya se mencionó, no se hace una diferenciación especial para el análisis de la mayoría de los beneficios, con la excepción de algunos de los cobeneficios ambientales. Para los cobeneficios no se utilizaron modelos espaciales sino valores promedios a nivel nacional: (1) balance de carbono, (2) conectividad, y (3) producción de leña.

\subsubsection{Balance de gases de efecto invernadero}

Para determinar el balance de los GEl asociado a las acciones de restauración, se utilizó la herramienta Ex Ante Carbon Balance Tool V7 (la herramienta de balance de carbono ex ante) desarrollada por la FAO y IRD. ${ }^{51}$ Esta herramienta ha sido desarrollada para facilitar la medición ex ante del desempeño de políticas y proyectos de inversión en agricultura y silvicultura en cuanto a la mitigación del cambio climático (FAO 2014). Para la recolección de información sobre los parámetros seleccionados se privilegiaron los datos de las comunicaciones nacionales sobre cambio climático, ${ }^{52}$ y, cuando se requirió, se utilizó la base de datos de la FAO53 (Tubiello et al. 2015, FAOSTAT 2016).

Una fortaleza de la herramienta Ex Act, a la hora de medir los beneficios de la restauración de pasto natural y del SSP, es que ofrece un marco integral de análisis que abarca no solo el carbono biológico y las emisiones generadas por la aplicación de fertilizantes sintéticos sino que también incluye las emisiones por fermentación entérica, ${ }^{54}$ lo cual es relevante debido a

51 Se puede descargar la herramienta en: http://www.fao.org/tc/exact/paginaprincipal-de-ex-act/es/

52 Las comunicaciones nacionales sobre cambio climático son documentos elaborados por gobiernos nacionales en el marco de la Convención Marco de las Naciones Unidas sobre el Cambio Climático, donde se procede a un inventario de gases de efecto invernadero a nivel nacional, usando directrices y métodos estandarizados a nivel internacional. Para mayor información véase: http://unfccc.int/files/national_reports/non-annex_i_parties/ica/application/pdf/fin_and_techn_support_gef.pdf

53 Para el uso actual, se utilizaron los valores promedio de las emisiones resutado de la aplicación los principales fertilizantes, según la lista preestablecida en la herramienta Ex Act.

54 La fermentación entérica es el proceso digestivo de nutrientes donde los microorganismos descomponen los carbohidratos en moléculas simples 
que constituyen alrededor del 50\% de las emisiones del sector agrícola del país (MARN 2013).

Se definieron dos escenarios para comparar los respectivos balances de GEI, luego de 20 años de implementación, y así, calcular el aporte neto de mitigación del cambio climático de las acciones de restauración.

Escenario A (sin restauración): se caracteriza por la continuación de las actividades y usos de suelo actual, sin la implementación de las acciones de restauración.

Escenario B (con restauración): se desarrollan las actividades de cada acción de restauración en las áreas potenciales.

En el Anexo 2 se presentan los principales supuestos que se usaron para determinar los balances de GEl en ambos escenarios. En el Cuadro 2, se detalla para cada fuente/sumidero, el tipo de GEl considerado, las actividades según el uso actual del suelo y las acciones propuestas para la restauración.

Una curva de costo (o beneficio) marginal de reducción representa la relación entre el costo (o rentabilidad) de diferentes opciones de reducción y la cantidad total de GEI disminuido. El histograma creado, evalúa el costo o beneficio y el potencial de reducción de cada medida. Cada barra representa una sola opción de mitigación.El ancho de la barra representa la cantidad de potencial de reducción disponible de la acción. La altura de la barra representa el costo unitario medio o el beneficio de la acción, por hectárea (costo/beneficio por tonelada de $\mathrm{CO}_{2}$ ahorrado). El área (altura * ancho) de la barra representa el coste/beneficio adicional de la acción de restauración por hectárea (Bockel et al. 2012).

\subsection{2 Índice de conectividad}

Se clasifican las acciones de restauración según su importancia para la conectividad de las áreas forestales en El Salvador. Para este fin, se generó un indicador que considera cada acción: (a) el incremento del número de árboles por hectárea, (b) el estrato arbóreo (2 o 3), y (c) las características del componente arbóreo (si es nativo o exótico; si es monocultivo o mixto; si las especies son de crecimiento rápido o lento; si son o no resistentes a la poda; si tienen capacidad o no de rebrote; el tamaño del árbol; si los árboles sustentan o no la fauna; y si son de copa amplia o estrecha). Basado en esta clasificación y según el criterio de un experto foresta ${ }^{55}$ se creó un indicador que tiene una puntuación de 1 (mayor impacto positivo para la conectividad), hasta 0 (menor (o nulo) impacto positivo en la conectividad). ${ }^{56}$

\subsubsection{Producción de leña}

Para este indicador se toma en cuenta el incremento en la cantidad de leña, en $\mathrm{m}^{3}$ /año, que será producida por las acciones de restauración. En El Salvador entre el 20 y el 30\% de los

Cuadro 2. Fuentes y sumideros analizados dentro del perímetro de estudio del balance de GEl

\begin{tabular}{|c|c|c|c|}
\hline Fuente/sumidero & Tipo de GEI & Uso actual del suelo & Acción de restauración \\
\hline Aforestación y reforestación & $\mathrm{CO}_{2}, \mathrm{CH}_{4}, \mathrm{~N}_{2} \mathrm{O}$ & $\begin{array}{l}\text { Caña de azúcar, granos básicos, pasto natural, } \\
\text { mosaico de pastos y cultivos, mosaico de } \\
\text { cultivos, pastos y vegetación }\end{array}$ & Restauración bosque de galería \\
\hline Quema de residuos agrícolas de cosecha & $\mathrm{CO}_{2}, \mathrm{CH}_{4}, \mathrm{~N}_{2} \mathrm{O}$ & Caña de azúcar, granos básicos, pasto natural & $\begin{array}{l}\text { Zafra verde en caña de azúcar, granos básicos, } \\
\text { pasto natural }\end{array}$ \\
\hline Insumos (aplicación y producción) & $\mathrm{CO}_{2}$ y $\mathrm{N}_{2} \mathrm{O}$ & Todos & $\begin{array}{l}\text { Todos (con la excepción de restauración de } \\
\text { bosque de galería) }\end{array}$ \\
\hline $\begin{array}{l}\text { Ganadería (fermentación entérica, aplicación } \\
\text { de estiércol) }\end{array}$ & $\mathrm{CH}_{4}$ y $\mathrm{N}_{2} \mathrm{O}$ & Pasto natural y mosaico de pastos y cultivos & Sistema silvopastoril, sistema agrosilvopastoril \\
\hline Cultivos anuales & $\mathrm{CO}_{2}, \mathrm{CH}_{4}, \mathrm{~N}_{2} \mathrm{O}$ & Caña de azúcar, granos básicos & Caña de azúcar, granos básicos \\
\hline Sistemas agroforestales (cacao 2) & $\mathrm{CO}_{2}, \mathrm{CH}_{4}, \mathrm{~N}_{2} \mathrm{O}$ & $\begin{array}{l}\text { Café, mosaico de cultivos, pastos y vegetación } \\
<900 \text { msnm }\end{array}$ & $\begin{array}{l}\text { Renovación de café, sistema agroforestal de } \\
\text { cacao, sistema agroforestal de granos básicos, } \\
\text { sistema silvopastoril, sistema agrosilvopastoril }\end{array}$ \\
\hline Rehumidificación de manglar & $\mathrm{CO}_{2}, \mathrm{CH}_{4}, \mathrm{~N}_{2} \mathrm{O}$ & Manglar degradado & Manglar \\
\hline
\end{tabular}

para su absorción en el flujo sanguíneo. Este proceso da como resultado emisiones de gas metano (Dong et al. 2006).
55 Sanchún, A., experto forestal de la UICN, marzo 13 de 2017.

56 Debido a su enfoque de restauración de paisajes productivos y forestales no se considera ninguna acción que disminuya la cantidad actual de árboles. 
hogares utilizan leña para cocinar (OLADE 2010, PAHO 2012, DIGESTYC 2003). Al considerar la presión que la demanda de leña ejerce sobre los recursos forestales, se busca identificar las acciones que generen un impacto ambiental positivo. Para cada técnica de restauración la producción de leña se determinó con base en la densidad de siembra de árboles, su manejo (frecuencia de poda, raleo, aprovechamiento) y las características de las especies sembradas (incremento volumétrico, capacidad de rebrote). Cuando el uso actual ya ofrecía cierta capacidad de producción de leña (el caso de los cafetales), se restó dicho aporte a la cantidad de leña producida con la restauración, solo para tomar en cuenta la contribución incremental de leña disponible por hectárea.

El propósito de este análisis económico no es solo analizar las diferentes acciones de restauración, sino proveer insumos para la creación de un modelo de priorización espacial. Para la restauración de manglar, el MARN ya identificó 2000 ha para la restauración, por lo tanto, se excluye de este análisis espacial. Además, los modelos utilizados en este estudio, no son los más adecuados para analizar el impacto de la restauración de manglares sobre la provisión de servicios ecosistémicos, por ejemplo el control sobre la erosión costera.

\subsection{Servicios ecosistémicos, erosión y exportación de sedimentos y de nutrientes (modelos espaciales)}

Al igual que para el balance de carbono, se determinó el cambio que provoca cada acción de restauración en la provisión de otros servicios ecosistémicos. Los dos servicios ecosistémicos analizados fueron: la exportación de sedimentos y el impacto de la restauración sobre la exportación de nutrientes.

Se midieron los cambios en la exportación de sedimentos producto de la erosión del suelo, así como los cambios en la exportación de nutrientes provenientes de la aplicación de fertilizantes, antes y después de la implementación de las acciones de restauración (Figura 4). Para medir estos cambios se utilizó la herramienta InVEST, ${ }^{57}$ diseñada para cuantificar diversos servicios ecosistémicos, y así, informar las decisiones sobre el manejo de los recursos naturales. Esencialmente, proporciona información sobre como los cambios en los

57 La herramienta InVEST es un software con una serie de modelos que permiten medir la provisión de una serie de servicios ecosistémicos. Determina los servicios acorde con los datos geoespaciales y biofísicos y genera mapas donde se visualiza la provisión de un determinado servicio ecosistémico. Fue desarrollada por el Natural Capital Project (http://www.naturalcapitalproject.org/). ecosistemas conducen a cambios en los flujos de beneficios para las personas (Sharp et al. 2016). Para medir los impactos sobre los servicios ecosistémicos considerados se utilizaron los modelos InVEST Sediment Delivery Ratio (SDR) y Nutrient Delivery Ratio.

\subsubsection{Cambio en la erosión y exportación de sedimentos (SDR)}

El objetivo del modelo de entrega de sedimentos InVEST es mapear la generación y entrega de sedimentos terrestres a las corrientes de agua (Sharp et al. 2016). El modelo está basado en la ecuación universal de suelo revisado (USLE por sus siglas en inglés), el cual fue adaptado para representar los sedimentos aportados por el paso de capas de sedimento (sheet flow erosion) (Vogl et al. 2016). Es decir, este modelo analiza las descargas de sedimento del área terrestre pero obvia la formación de los desniveles de terreno que impiden el paso del sedimento o de otras fuentes de sedimento (p. ej. barrancos, deslizamientos, entre otros). El servicio de retención (menor exportación) de sedimentos incide en mayor fertilidad de suelo y menor dragado de los sedimientos de ríos y reservorios (Vigiak et al. 2012, Solís et al. 2007). El mapa de erosión basado en la USLE es un resultado intermedio del modelo SDR, mientras que el mapa de exportación de sedimentos es un resultado final.

\subsubsection{Cambio en la exportación de nutrientes (NDR)}

Se refiere a la cantidad de nutrientes de fuentes naturales y/o antrópicas que se exportan por efectos de la erosión hídrica a partir de un determinado manejo de uso del suelo. En el presente estudio, se consideraron las siguientes fuentes de nutrientes asociadas a la actividad agrícola y ganadera: aplicación de fertilizantes, el estiércol del ganado y la vegetación (hojarascas, residuos de cosecha, entre otros). El objetivo del modelo de exportación de nutrientes es mapear las fuentes de nutrientes desde las cuencas hidrográficas y su transporte a las corrientes.

Esta información espacial es utilizada para evaluar el servicio de retención de nutrientes que hace la vegetación natural. Una manera de reducir la contaminación de fuentes no puntuales, es reducir la cantidad de insumos antropogénicos (es decir, la gestión de fertilizantes). Cuando esta opción falla, los ecosistemas pueden proporcionar un servicio de purificación al retener o filtrar los contaminantes que se descargan en ríos y arroyos. El modelo fue diseñado para los nutrientes nitrógeno y fósforo (Sharp et al. 2016). 
La estructura de este modelo hace que los resultados sean sensibles al patrón espacial de uso del suelo en cada cuenca. En particular, los amortiguadores de la vegetación perenne pueden filtrar eficazmente los nutrientes antes de que alcancen una corriente de agua. Una vez que los nutrientes llegan a un cuerpo de agua el modelo no asume ninguna retención o remoción adicional (Kovacset al. 2013).

Los cambios en estos servicios ecosistémicos repercuten en el mejoramiento de la calidad del agua para la producción hidroeléctrica o para el consumo humano, en el caso de una disminución de la exportación de sedimentos, o se puede detectar donde puede haber potencialmente un mayor impacto negativo,

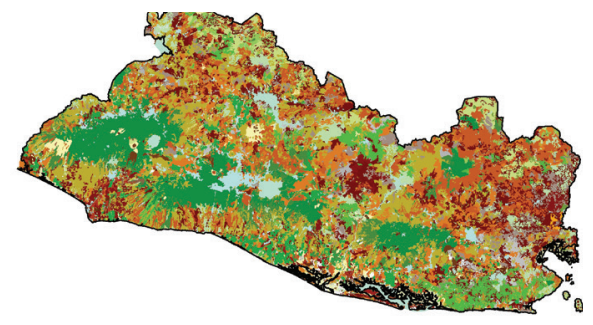

Mapa 2.1 Uso del suelo.

Fuente: UICN y MARN, 2015

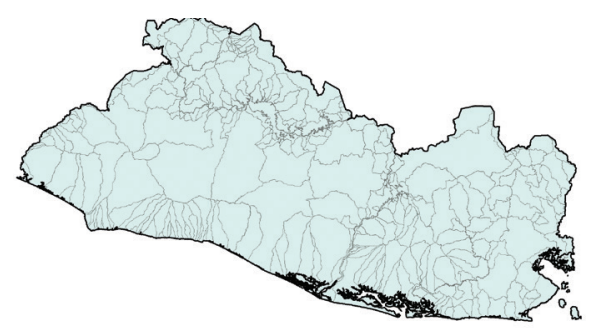

Mapa 2.3 Subcuencas.

Fuente: MARN-CNR, 2002

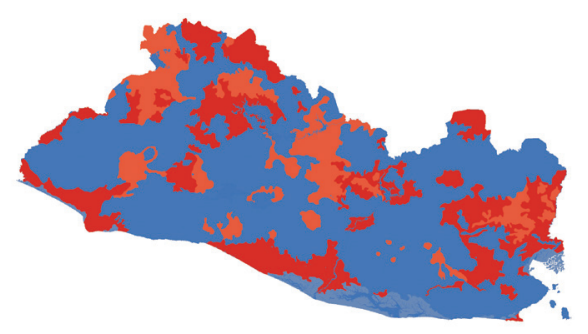

Mapa 2.5 Factor K (erodibilidad del suelo).

Elaborado por Johnson, J. de Natural Capital Project. Proveniente de mapas globales de R y K, aun sin publicar. por ejemplo, si hay un incremento en la exportación de fósforo por un aumento en la aplicación de un determinado fertilizante.

Para configurar y aplicar la herramienta InVEST, acorde con las características del país, se procedió a la recolección de información geográfica (Mapas 2.1 a 2.6) y datos biofísicos extraídos de la literatura científica (Anexo 3, Cuadros A3 y A4).

Luego de determinar el valor de la exportación de los sedimentos y los nutrientes como resultado, tanto en el escenario de uso actual del suelo como en el escenario de adopción de las acciones de restauración, se crea el mapa de impacto potencial (Figura 4).

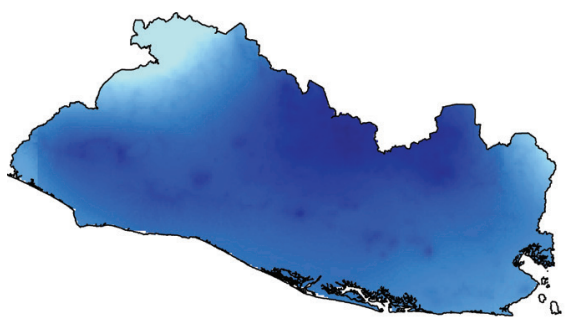

Mapa 2.2 Precipitación anual.

Fuente: Worldclim, 2016.

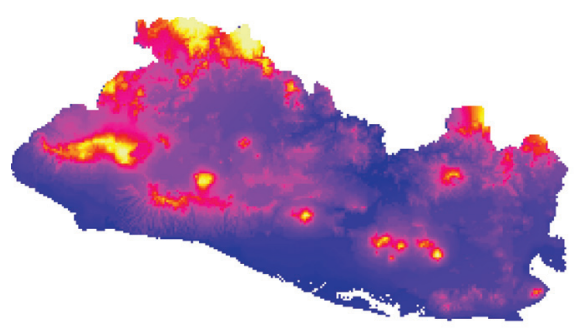

Mapa 2.4 Factor R (erosividad de la lluvia).

Elaborado por Johnson, J. de Natural Capital Project. Proveniente de mapas globales de R y K, aun sin publicar.

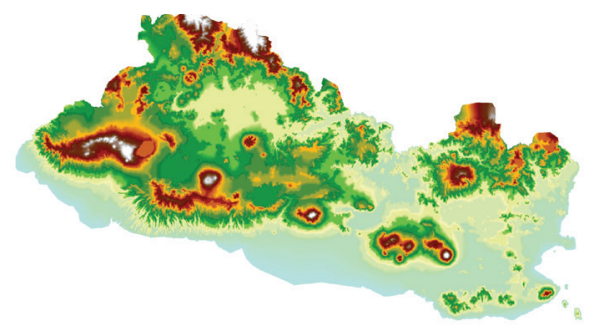

Mapa 2.6 Modelo de elevación digital.

Fuente: WorldClim, 2017. 

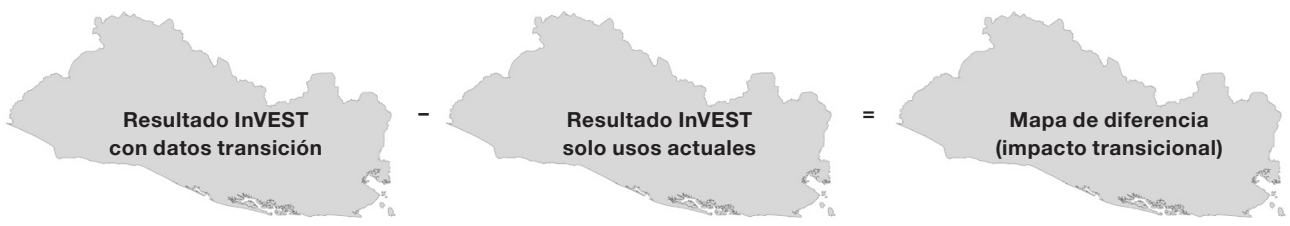

Figura 4 Proceso de creación del mapa de impacto potencial en provisión de servicios ecosistémicos

Se crearon mapas de impactos sobre la erosión, la exportación de sedimentos y la exportación de nutrientes para cada una de las acciones de restauración. ${ }^{58}$ Estos mapas muestran, por hectárea, el cambio en estos servicios ecosistémicos como resultado de la restauración, con diferenciación espacial en los cambios.

\subsection{Análisis del impacto social de las acciones de restauración}

\subsubsection{Creación de empleo}

A nivel nacional, se estima que la tasa de desempleo, en 2014, es de un 7\% de la población económicamente activa. El sector de agricultura y ganadería es el segundo sector que más empleo concentra en El Salvador, mantiene alrededor del 18\% del empleo a nivel nacional (MEC 2016). Por esta razón, el mantenimiento o la creación de empleo mediante la implementación de la restauración de los paisajes productivos, es considerado un cobeneficio relevante desde una perspectiva social. Para medir dicho impacto, se comparó el empleo promedio (jornales por ha/año), mantenido a lo largo de 20 años, bajo el uso actual con el nivel de empleo generado bajo las fases de implementación y mantenimiento de la restauración.

Para expresar el resultado neto de la restauración de una forma más tangible, se convirtieron los valores marginales, así obtenidos, en empleo a tiempo completo por año, asumiendo cinco días trabajados. Por semana, durante 50 semanas por año (CSC 2016). Se consideran dos periodos para el análisis de la generación de empleo, (1) durante el primer año, la implementación de la restauración, y (2) del año 2 al 20, mantenimiento de la restauración. El indicador final creado da un peso de 1 al indicador empleo, generado en el primer año, y un peso de 19 al indicador del empleo, generado al año del año 2 al 20.

58 Véase fichas técnicas de las acciones de restauración con sus respectivos mapas de imoacto potencial.

\subsubsection{Seguridad alimentaria}

En El Salvador parte de la población enfrenta inseguridad alimentaria de moderada a severa (UNDP 2015, DIGESTYC 2015, Morris et al. 2013). La restauración puede, potencialmente, tener un impacto positivo en este aspecto por medio del aumento en la producción agrícola. Este incremento puede tener una incidencia positiva específicamente para aquellos hogares que producen para su propio consumo. Para poder medir el impacto potencial de las acciones de restauración en la seguridad alimentaria se creó un indicador que consiste de dos partes, (i) porcentaje promedio de la producción total de los diferentes cultivos destinados al consumo de subsistencia; y (ii) incremento en la producción con respecto al escenario de uso actual del suelo. El indicador creado (Anexo 9, Cuadro A22), es la suma de ambos indicadores normalizados (véase 3.5 Análisis multicriterio para una mayor explicación).

\subsubsection{Medios de vida}

El último indicador que se analizó en este estudio es el impacto potencial de las acciones de restauración sobre los ingresos de los hogares productores. Para esto se utilizan dos indicadores, (i) la diversificación agrícola, que puede aumentar la resiliencia de los medios de vida de los hogares productores; y (ii) los beneficios netos de las acciones de restauración al considerar que la mano de obra familiar también tiene un costo.

\section{Mano de obra familiar}

Si se estima que en El Salvador la mayoría de la mano de obra para la agricultura es familiar, tanto para el cultivo de granos básicos, cacao y café, como para la ganadería (MAG 2016a), se debe reflejar el impacto que su inclusión, como un costo, tiene sobre los ingresos. Las familias que dependen de la agricultura no siempre valoran la mano de obra familiar invertida en sus fincas. Por este motivo, se propone ofrecer un enfoque más cercano a la rentabilidad real de la agricultura de subsistencia, al reflejar un pago de toda la mano de obra requerida. Según el criterio de la Asociación Fundación para la Cooperación y el Desarrollo Comunal (CORDES), en el caso de productores de 
subsistencia, el costo de mano de obra familiar representa el 50\% de la mano de obra total (Gutiérrez 2014). Por lo tanto, se refleja el impacto que puede tener la consideración de pagar, por lo menos, el sueldo mínimo a la mano de obra familiar, sobre los beneficios netos generados por la restauración.

El indicador creado (Anexo 9, Cuadro A22) es la suma de ambos indicadores normalizados.

\subsection{Análisis multicriterio}

Para poder analizar los datos del estudio financiero junto con los datos biofísicos, o de otro tipo, se llevó a cabo una interpretación multicriterio. Este criterio se puede utilizar cuando no se pueden agregar múltiples beneficios. Es un marco que permite integrar datos monetarios con datos ecológicos y sociales no monetarios (Favretto et al. 2016). Similar a un análisis costobeneficio, un análisis multicriterio es capaz de clasificar y, por lo tanto, priorizar entre múltiples opciones (Noleppa 2013). Esto permite clasificar las opciones alternativas mediante la cuantificación, puntuación y ponderación de una serie de pautas (Favretto et al. 2016).

Una característica estándar del análisis multicriterio es la matriz de rendimiento, o tabla de consecuencias, en la que cada fila describe una opción y cada columna describe el rendimiento de las opciones, en función de cada criterio. Las evaluaciones individuales de rendimiento son a menudo numéricas. En una forma básica de análisis multicriterio esta matriz de rendimiento puede ser el producto final del análisis. Se asigna una puntuación numérica para cada resultado de cada opción (de restauración) en una escala de intensidad de preferencia para cada opción y criterio. Las alternativas preferidas tienen un puntaje más alto en la escala, y las menos preferidas tienen una puntuación más baja (Department for Communities and Local Government 2009).

Para poder sumar los datos financieros en US\$ con otros datos como $\mathrm{TCO}_{2}$ e o porcentajes, los datos son normalizados en una escala donde 1 es el máximo y los otros valores son expresados en relación con este máximo. Para llegar a esto se dividen todos los valores por el mejor valor. Puede ser un valor positivo, como en el caso de ingresos netos, o negativos, como en el caso de la reducción de la erosión. Al final de la normalización todos los indicadores tendrán un valor máximo de 1. Para el análisis multicriterio estos valores se suman.

Se llevaron a cabo dos análisis multicriterio. Uno que excluye los indicadores espaciales y, por lo tanto, incluye la restauración de manglar. Otro en el cual se se incluyen los criterios espaciales, sin considerar la restauración de manglar.

Los diferentes criterios tomados en cuenta en el análisis multicriterio son:

Criterios financieros (5):

1. VAN marginal, RBC y $\mathrm{ROI}$ con $r=10 \%$.

2. VAN marginal con $r=15 \%$.

3. VAN marginal con $r=5 \%$.

4. VAN marginal con escenario 'pesimista'.

5. VAN marginal con escenario 'optimista'.

Criterios ambientales no espaciales (3):

1. Balance de carbono.

2. Conectividad.

3. Producción de leña.

Criterios ambientales espaciales, servicios ecosistémicos espaciales (3):

1. Impacto sobre la erosión.

2. Cambio en la exportación de sedimentos.

3. Cambio en la exportación de nitrógeno y fósforo.

Criterios sociales (3):

1. Creación de empleo.

2. Seguridad alimentaria.

3. Impacto sobre los medios de vida. 



\section{Resultados análisis costo-beneficio de las acciones de restauración}

El análisis multicriterio final es la suma de cada uno de los indicadores anteriormente mencionados. Cada indicador normalizado tiene igual peso en la suma total. Primero, se presentan los diferentes resultados del análisis financiero; segundo, se da a conocer el análisis de los cobeneficios ambientales (espaciales y no espaciales); y tercero, se muestran los resultados de los cobeneficios sociales.

\subsection{Costos y beneficios brutos, incrementales y netos}

Los costos y beneficios fueron estimados para un periodo de 20 años. A modo de ejemplo el SSP59 puede ilustrar uno de los modelos de estimación de los costos y los beneficios del uso actual del suelo (Figura 5) y la estimación de los costos y beneficios de la restauración (Figura 6). En la Figura 6, se puede apreciar el aumento del ingreso a partir del mejoramiento de la genética del hato (aumento de venta de carne en pie) y los aumentos productivos en leche por vaca, a partir del año 2 para estabilizarse en el año 8. El ingreso proveniente de madera se observa al final, en el año 20. Se estima que generaría alrededor del $41 \%$ de los ingresos de este año.

Los modelos de estimación de los costos y beneficios generan tres resultados principales: (1) beneficios netos de la restauración, (2) beneficios netos del uso actual, y (3) beneficio incremental, VAN marginal de la restauración.

En el Cuadro 3 se presenta la comparación entre los costos de la restauración y el uso actual del suelo. En el Anexo 4, Cuadro A7,

59 Se pueden encontrar más detalles sobre los supuestos y acciones de restauración en las fichas técnicas de cada opción de restauración. En este caso la ficha técnica "Sistema silvopastoril y agrosilvopastoril" (Nello et al., 2018c). se presenta el desglose de las diferentes categorías de los costos relativos a cada acción de restauración.

Se observa un aumento promedio del $100 \%$ de los costos por hectárea. Con la excepción de la restauración en bosque de galería, los costos de implementación y mantenimiento de la restauración son más altos que los costos asociados a los usos actuales de suelo. Las acciones de restauración con incrementos más marcados (más de 400\% en relación con el uso actual) son la renovación de café de bajío y la implementación de un SAF de cacao en café. Las acciones de restauración donde se incurre en mayores costos incrementales son: la siembra de árboles por requerir mayor cantidad de mano de obra y materiales.

En el Cuadro 4 se muestran las estimaciones de los beneficios brutos asociados a las acciones de restauración, y los beneficios brutos generados, si se continúa con el uso actual del suelo.

Las acciones de restauración que más beneficios monetarios incrementales traen son la implementación de un SAF de cacao en café por debajo de 900 msnm (incremento de 623\%) y la renovación de los cafetales (incremento promedio de 330\%). Estos incrementos se deben a la baja productividad actual en cafetales (especialmente café de bajío). ${ }^{60}$ Se destaca también la restauración de manglar que permite el establecimiento de un marco sostenible de extracción de recursos, que hoy en día no se aprovechan, por el alto nivel de degradación del ecosistema.

La Figura 7 muestra el VAN del uso actual del suelo y de la restauración (Anexo 4, Cuadro A8). Casi todas las acciones de restauración tienen un VAN estimado positivo, pero con gran variabilidad entre ellos. La restauración con mayor beneficio neto estimado es el SSP.

60 Para mayores detalles, véase la ficha técnica "Renovación de cafetales" (Fonseca et al., 2018b). 

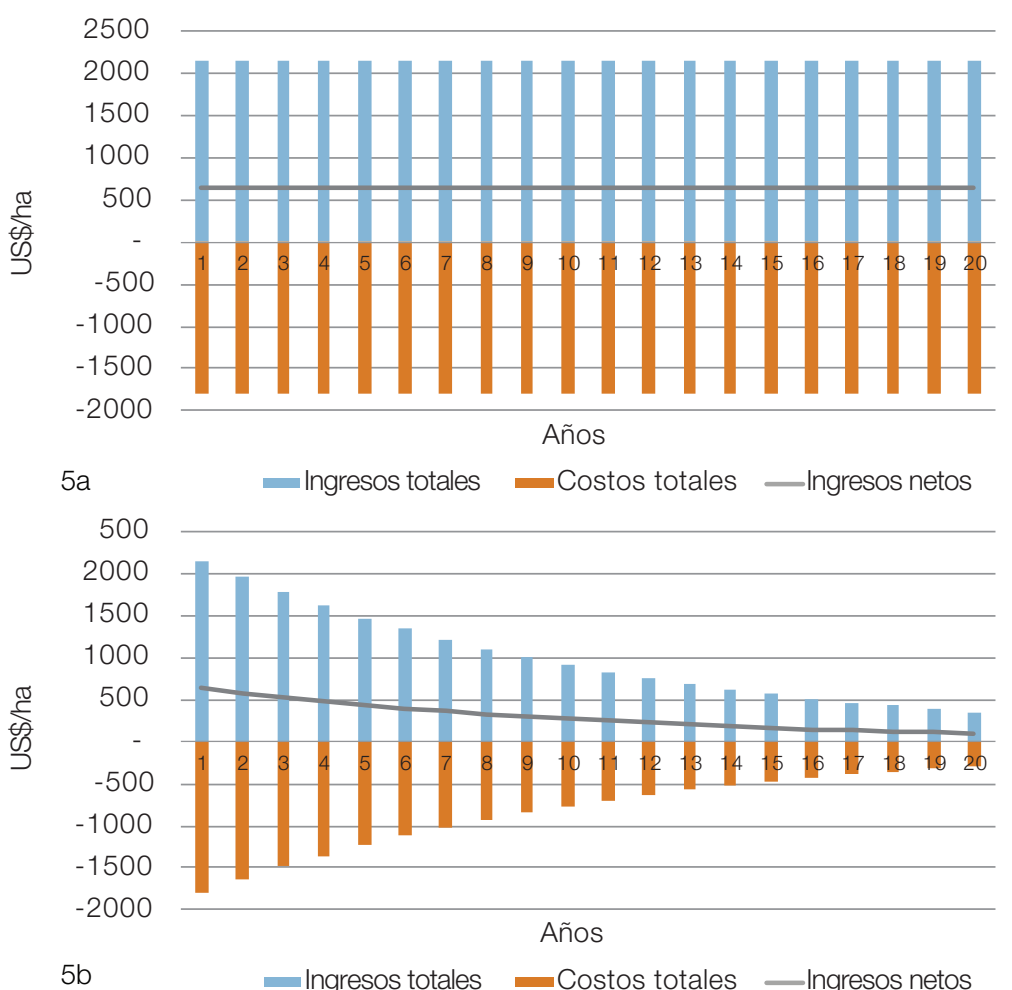

Figura 5 Costo de oportunidad-pasto natural en US\$/ha en valor presente (5a), y con la aplicación de la tasade descuento (5b). Fuente: Elaboración propia a partir de IICA (2011) y Benavides Martínez et al. (2007).
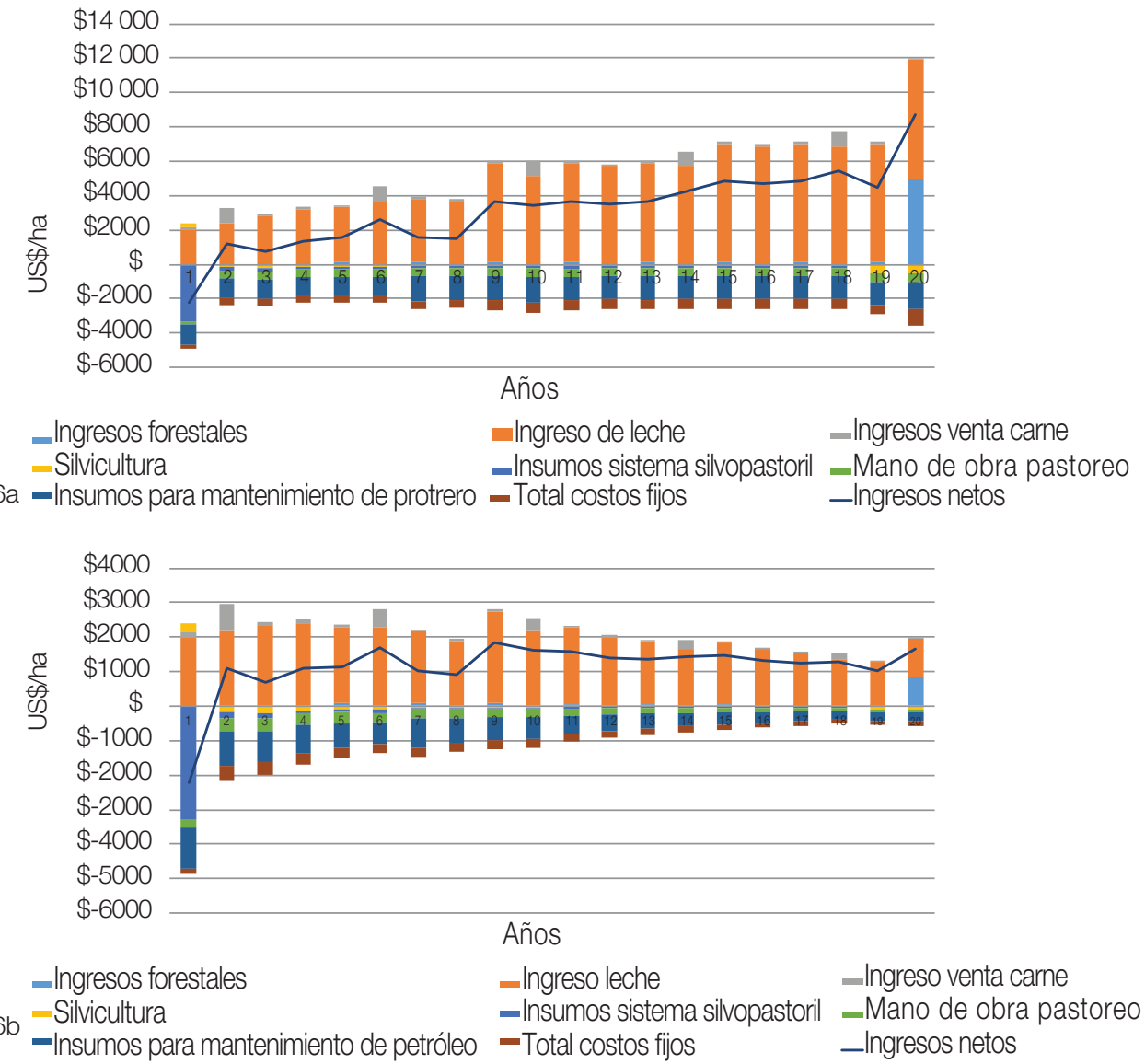

Figura 6 Costos y beneficios de la restauración de pasto natural mediante el sistema silvopastoril en US\$/ha en valor presente (6a), y con la aplicación de la tasa de descuento (6b).

Fuente: Elaboración propia. 
Cuadro 3 Costos de la restauración, del uso actual y costos incrementales de la restauración (r=10\%)

\begin{tabular}{|c|c|c|c|c|}
\hline Acción de restauración & $\begin{array}{l}\text { Costos restauración }{ }^{a /} \\
\text { (US\$/ha) }\end{array}$ & $\begin{array}{l}\text { Costos uso actual } \\
\text { (US\$/ha) }\end{array}$ & $\begin{array}{l}\text { Costos incrementales } \\
\text { (US\$/ha) }\end{array}$ & Incremento (\%) \\
\hline Restauración de manglar & 15420 & - & 15420 & $\mathrm{n} / \mathrm{a}$ \\
\hline Restauración bosque de galería en granos básicos & 5166 & 8429 & -3263 & -39 \\
\hline Restauración bosque de galería en pasto natural & 5166 & 16856 & -11690 & -69 \\
\hline Restauración bosque de galería en ca ña de azúcar & 5166 & 17581 & -12415 & -71 \\
\hline Restauración bosque de galería en mosaico de cultivos y pasto & 5166 & 16896 & -11.730 & -69 \\
\hline $\begin{array}{l}\text { Restauración bosque de galería en mosaico de cultivos, pastos } \\
\text { y vegetación }\end{array}$ & 5166 & 11410 & -6244 & -55 \\
\hline Sistema agroforestal de granos básicos & 17632 & 8429 & 9202 & 109 \\
\hline Sistema silvopastoril & 24543 & 16856 & 7687 & 46 \\
\hline Sistema agrosilvopastoril & 19802 & 16896 & 2906 & 17 \\
\hline Zafra verde en caña & 20639 & 17581 & 3058 & 17 \\
\hline Sistema agroforestal de cacao en café (cacao 1) & 20148 & 3619 & 16529 & 457 \\
\hline $\begin{array}{l}\text { Sistema agroforestal de cacao en mosaico de cultivos, pastos } \\
\text { y vegetación (cacao 2) }\end{array}$ & 22372 & 11410 & 10962 & 96 \\
\hline Renovación de los cafetales de bajio & 18695 & 3289 & 15406 & 468 \\
\hline Renovación de los cafetales de mediana altura & 18695 & 4115 & 14580 & 354 \\
\hline Renovación de los cafetales de altura & 18695 & 6826 & 11869 & 174 \\
\hline
\end{tabular}

a/ No incluye costos de oportunidad.

Fuente: Elaboración propia.

Cuadro 4 Beneficios brutos de la restauración, del uso actual e incrementales de la restauración (r=10\%)

\begin{tabular}{|c|c|c|c|c|}
\hline Acción de restauración & $\begin{array}{l}\text { Beneficios brutos } \\
\text { restauración } \\
\text { (US\$/ha) }\end{array}$ & $\begin{array}{l}\text { Beneficios brutos uso actual } \\
\text { (US\$/ha) }\end{array}$ & $\begin{array}{l}\text { Beneficios brutos } \\
\text { incrementales } \\
\text { (US\$/ha) }\end{array}$ & $\begin{array}{l}\text { Incremento } \\
(\%)\end{array}$ \\
\hline Restauración de manglar & 19481 & - & 19481 & $\mathrm{n} / \mathrm{a}$ \\
\hline Restauración bosque de galería en granos básicos & 0 & 12559 & -12559 & -100 \\
\hline Restauración bosque de galería en pasto natural & 0 & 24409 & -24409 & -100 \\
\hline Restauración bosque de galería en caña de azúcar & 0 & 20803 & -20803 & -100 \\
\hline Restauración bosque de galería en mosaico de cultivos y pasto & 0 & 21534 & -21534 & -100 \\
\hline $\begin{array}{l}\text { Restauración bosque de galería en mosaico de cultivos, } \\
\text { pastos y vegetación }\end{array}$ & 0 & 14510 & -14510 & -100 \\
\hline Sistema agroforestal de granos básicos & 22070 & 12559 & 9511 & 76 \\
\hline Sistema silvopastoril & 42812 & 24409 & 18404 & 75 \\
\hline Sistema agrosilvopastoril & 31926 & 21534 & 10392 & 48 \\
\hline Zafra verde en caña & 24706 & 20803 & 3903 & 19 \\
\hline Sistema agroforestal de cacao en café (cacao 1) & 34915 & 4826 & 30089 & 623 \\
\hline $\begin{array}{l}\text { Sistema agroforestal de cacao en mosaico de cultivos, pastos } \\
\text { y vegetación (cacao 2) }\end{array}$ & 37845 & 14510 & 23335 & 161 \\
\hline Renovación de los cafetales de bajío & 21589 & 4385 & 17204 & 392 \\
\hline Renovación de los cafetales de mediana altura & 24698 & 5487 & 19211 & 350 \\
\hline Renovación de los cafetales de altura & 31771 & 9101 & 22670 & 249 \\
\hline
\end{tabular}

Fuente: Elaboración propia. 


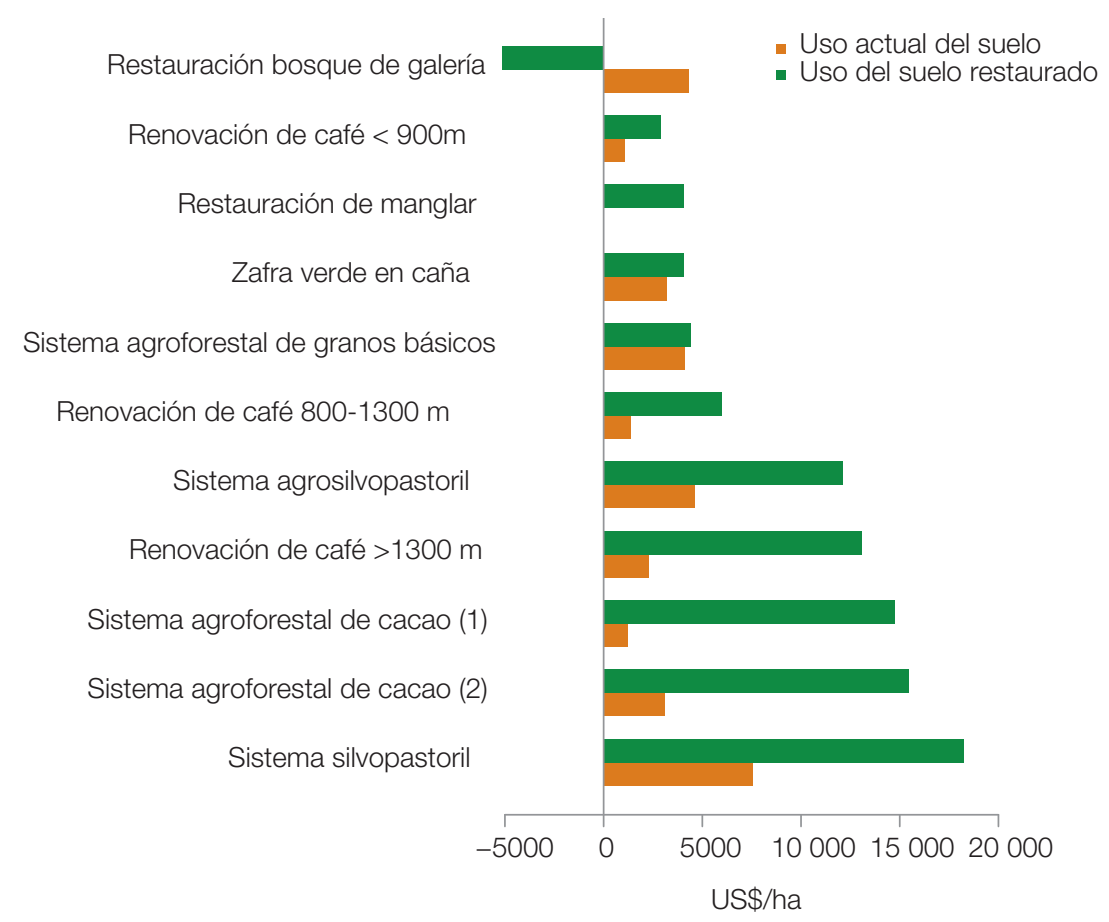

Figura 7 Valor actual neto del uso del suelo y de la restauración ( $r=10 \%)$.

Fuente: Elaboración propia.

\subsection{Indicadores de desempeño de las acciones de restauración}

En el Cuadro 5 se presentan los diferentes indicadores financieros desarrollados para analizar el desempeño de las acciones de restauración. Las que muestran mayores beneficios incrementales son el SAF de cacao, tanto si se implementa donde actualmente hay café como en áreas de mosaico de cultivo, pasto y vegetación.

Los beneficios netos marginales son los más bajos en el caso de la implementación del SAF en granos básicos, y son negativos en el caso de la restauración del bosque de galería. El último valor se debe a que en la restauración de este bosque solo se incurre en costos, a los que hay que añadir los costos de oportunidad por el abandono del uso actual del suelo.

Al analizar los resultados de la razón beneficio-costo, las acciones de restauración que generan más beneficios en relación con el uso actual y los costos relacionados con la restauración, son los sistemas agroforestales de cacao en mosaico de cultivos, pasto y vegetación; y la renovación de café de altura. Según las estimaciones presentadas, la implementación de estas acciones de restauración generarían respectivamente 1,63 y 1,52 veces más que la suma de los ingresos generados con la continuación del uso actual del suelo y los costos de la restauración.
Por otra parte, la implementación de un SAF de granos básicos trae beneficios apenas superiores a la suma de los ingresos y los costos antes mencionados ( $\mathrm{RBC}=1,01)$.

Si se considera el retorno incremental de la inversión, ${ }^{61}$ las acciones de restauración presentan valores entre un máximo de 6,77 (restauración de manglar), un mínimo positivo de 0,25 (zafra verde en caña de azúcar), y un mínimo de -3,22 (restauración de bosque de galería en pasto natural).

El nivel promedio del $\mathrm{ROI}$ de las restauraciones productivas ${ }^{62}$ es de 1,67. Esto significa que por cada dólar invertido en la restauración se generaría US\$1,67 de ingresos adicionales, valor actual.

\subsection{Análisis de sensibilidad}

\subsubsection{Sensibilidad a la tasa de descuento}

Para reflejar la sensibilidad de los resultados presentados con la tasa de descuento, se muestran los resultados del VAN de las acciones de restauración y los usos de suelo actual con tasas de $5 \%$ y 15\% (Figuras 8 y 9). Las líneas adicionales en las barras de la figura representan el VAN con tasa de descuento bajo en las partes

61 Este número toma en cuenta los ingresos del uso actual del suelo.

62 Todas las acciones de restauración, salvo de bosque de galería. 
Cuadro 5. Beneficios marginales de la restauración, razón beneficio-costo (RBC) y retorno de la inversión (ROI) (r=10\%)

\begin{tabular}{|c|c|c|c|}
\hline Acciones de restauración & Beneficios netos marginales (US\$/ha) & RBC & $\mathrm{R}$ 이 \\
\hline Restauración de manglar & 4061 & 1,26 & 6,77 \\
\hline Restauración bosque de galería en granos básicos & -9296 & 0,00 & $-2,35$ \\
\hline Restauración bosque de galería en pasto natural & -12719 & 0,00 & $-3,22$ \\
\hline Restauración bosque de galería en caña de azúcar & -8388 & 0,00 & $-2,12$ \\
\hline $\begin{array}{l}\text { Restauración bosque de galería en mosaico de cultivos y } \\
\text { pasto }\end{array}$ & -9804 & 0,00 & $-2,48$ \\
\hline $\begin{array}{l}\text { Restauración bosque de galería en mosaico de cultivos, } \\
\text { pastos y vegetación }\end{array}$ & -8266 & 0,00 & $-2,09$ \\
\hline Sistema agroforestal de granos básicos & 309 & 1,01 & 0,08 \\
\hline Sistema silvopastoril & 10717 & 1,33 & 1,87 \\
\hline Sistema agrosilvopastoril & 7486 & 1,31 & 1,59 \\
\hline Zafra verde en caña & 845 & 1,04 & 0,25 \\
\hline Sistema agroforestal de cacao en café (cacao 1) & 13560 & 1,63 & 1,72 \\
\hline $\begin{array}{l}\text { Sistema agroforestal de cacao en mosaico de cultivos, pastos } \\
\text { y vegetación (cacao 2) }\end{array}$ & 12373 & 1,49 & 1,48 \\
\hline Renovación de los cafetales de bajío & 1798 & 1,09 & 0,31 \\
\hline Renovación de los cafetales de mediana altura & 4631 & 1,23 & 0,79 \\
\hline Renovación de los cafetales de altura & 10801 & 1,52 & 1,85 \\
\hline
\end{tabular}

Fuente: Elaboración propia.

superiores, y el VAN con tasa de descuento alta en las partes inferiores. Las excepciones son las líneas adicionales a las dos barras del VAN de bosque de galería, donde es al revés. Los resultados de los diferentes valores actuales y los indicadores de desempeño se pueden visualizar en los cuadros compilados en los Anexos 5 y 6.

En relación con los beneficios netos actuales (Figura 8), se observa que al considerar las tasas de descuento más bajas, se reajustan los beneficios netos de la restauración de manglar y de la renovación de café de bajío, así, se convierten más atractivas que la zafra verde en caña, por sus beneficios productivos estables en un plazo más corto. También la estimación del VAN de la implementación de un SAF de cacao en café se vuelve ligeramente más alto que la implementación del SAF de cacao en el mosaico de cultivos, pasto y vegetación.

Debido a un incremento paulatino y constante ${ }^{63}$ de los beneficios futuros esperados en los sistemas silvopastoriles, se destaca que esta restauración pasa de ser la cuarta a la segunda acción

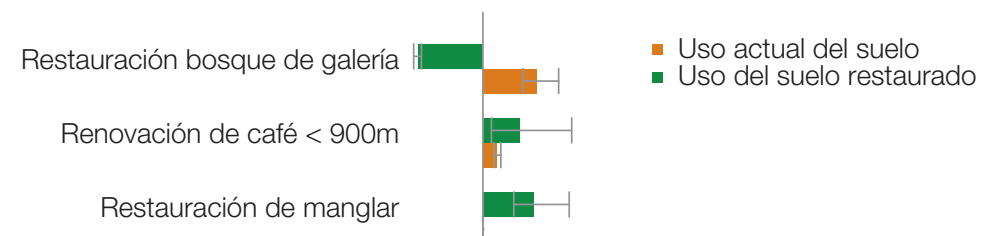

Zafra verde en caña

Sistema agroforestal de granos básicos

Renovación de café 800-1300 m

Sistema agrosilvopastoril

Renovación de café >1300 m

Sistema agroforestal de cacao (1)

Sistema agroforestal de cacao (2)

Sistema silvopastoril

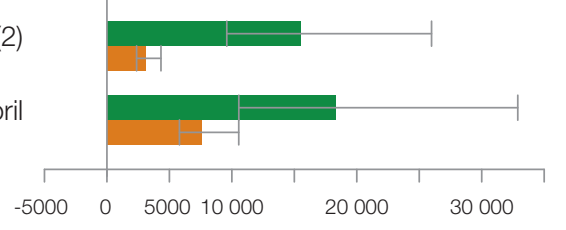

US\$/ha

Figura 8 Valor actual neto del uso actual del suelo y del uso del suelo restaurado con incertidumbre por tasa de descuento ( $r=5,10$ y 15\%)

63 Los beneficios productivos en rendimiento de leche alcanzan su tope al año 8. 
más rentable, cuando la tasa de descuento sube de 10 a 15\%. Por otro lado, con una tasa de descuento más alto, el VAN estimado de la renovación de cafetales de mediana altura se vuelve menor que implementar la zafra verde en caña de azúcar. Lo mismo ocurre con la implementación de un sistema agroforestal de granos básicos, con un VAN en este caso menor que la zafra verde en caña de azúcar y la restauración de manglares. Estos cambios se observan mejor en la figura con los VAN marginales.

La Figura 9 muestra la diferencia entre el VAN estimado de la restauración y el uso actual del suelo. Las líneas adicionales tienen el mismo significado que en la figura anterior. EI SAF de granos básicos tiene un VAN especialmente sensible a la tasa de descuento. En el escenario intermedio ( $r=10 \%)$ esta acción de restauración brinda beneficios netos marginales estimados en US\$309/ha. El beneficio marginal se vuelve negativo con $r=15 \%$ (US\$ $-1413 / \mathrm{ha}$ ), pero se multiplica por diez con un $r=5 \%$ (US\$ 4649/ha). Esto es una indicación de beneficios futuros altos, pero con más costos que beneficios a corto plazo (Figura 9).

Otra acción sensible a una tasa de descuento alta (con r=15\%) es la renovación de cafetales de bajío, que también trae beneficios marginales negativos. Puede ser una indicación de que no sería rentable esta acción de restauración bajo las condiciones de financiamiento ofrecido por el sector privado.

\subsubsection{Sensibilidad a nivel de precio y rendimiento}

En las Figuras 10 y 11 se muestra los impactos del escenario optimista y pesimista sobre el VAN, presentado en el punto
3.1.5. Las líneas adicionales a las barras, en este caso, ilustran el escenario optimista (partes superiores) y pesimistas (inferiores), con la excepción de las barras con los VAN y VAN marginal de la restauración de bosque de galería, donde es al revés. En los Anexos 7 y 8 se presentan los costos, los beneficios brutos y netos, al igual que los indicadores de desempeño de los usos de suelo actual y de las acciones de restauración para ambos escenarios.

En la Figura 10 se puede observar que con el escenario pesimista (precios y rendimientos más bajos), la renovación de cafetales en mediana altura y de bajío, así como el SAF de granos básicos, ya no serían rentables por tener beneficios netos negativos. Estas acciones de restauración son, según estas estimaciones, las más sensibles a una disminución en los precios y/o los rendimientos.

También cabe destacar la renovación de café de altura que, en el escenario optimista, se convierte en la restauración más rentable desde el punto de vista del VAN. No obstante, es menos rentable que cuatro acciones de restauración en el escenario pesimista (la implementación de los sistemas agroforestales de cacao, y los sistemas silvopastoril y agrosilvopastoril). Las altas fluctuaciones en los VAN de las renovaciones de cafetales evidencian la sensibilidad de estos sistemas a los precios de los mercados internacionales. Al considerar el escenario pesimista, la implementación del sistema agroforestal de granos básicos y la renovación de los cafetales de bajío, son las acciones de restauración más sensibles a los factores precio y rendimiento. La Figura 11 de los VAN marginales en los diferentes escenarios evidencia también las observaciones hechas anteriormente

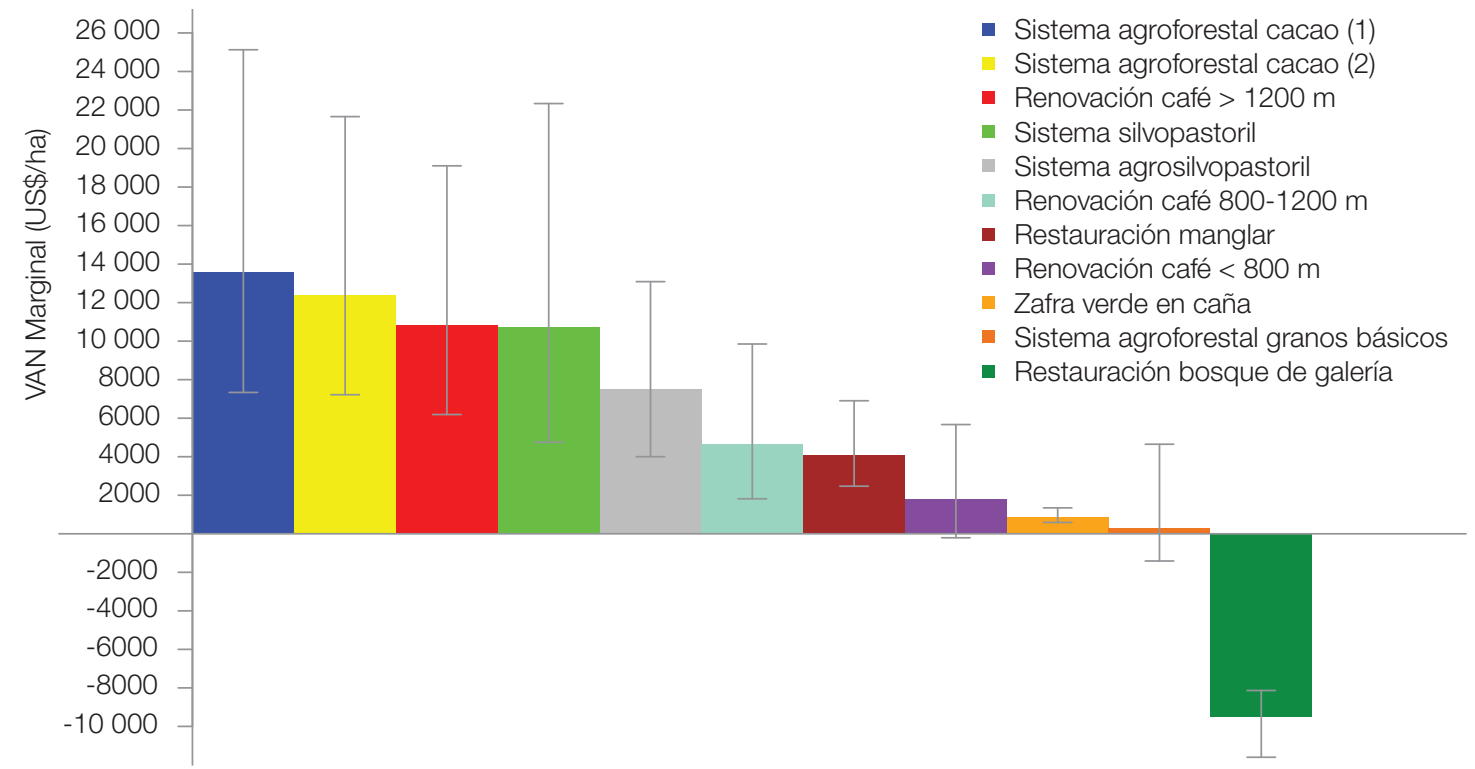

Figura 9 VAN marginal de las acciones de restauración con incertidumbre por tasa de descuento $(r=5,10,15 \%)$. Fuente: Elaboración propia. 


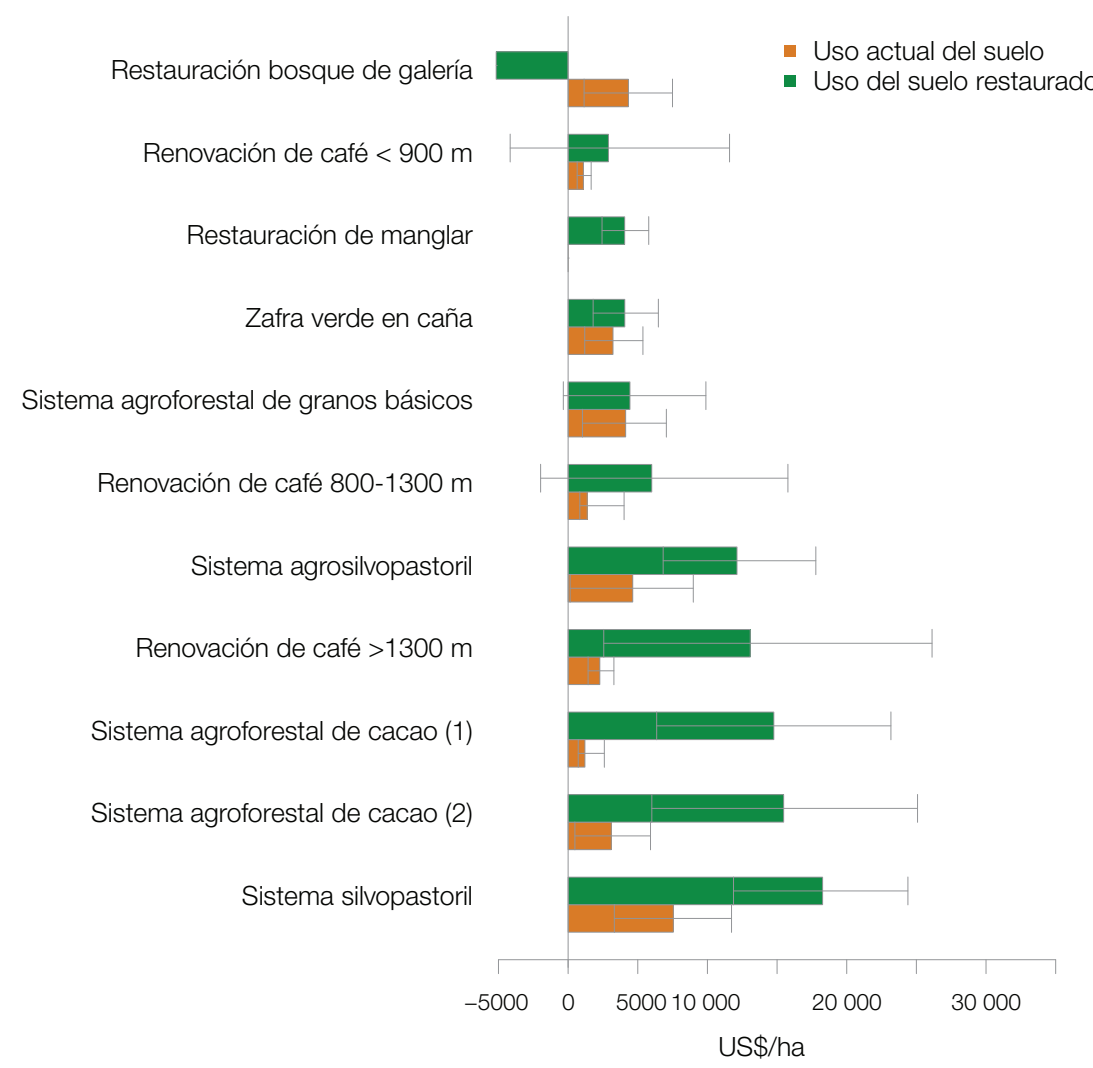

Figura 10 VAN uso actual y acciones de restauración con precios y rendimientos altos y bajos ( $r=10 \%)$.

Fuente: Elaboración propia.

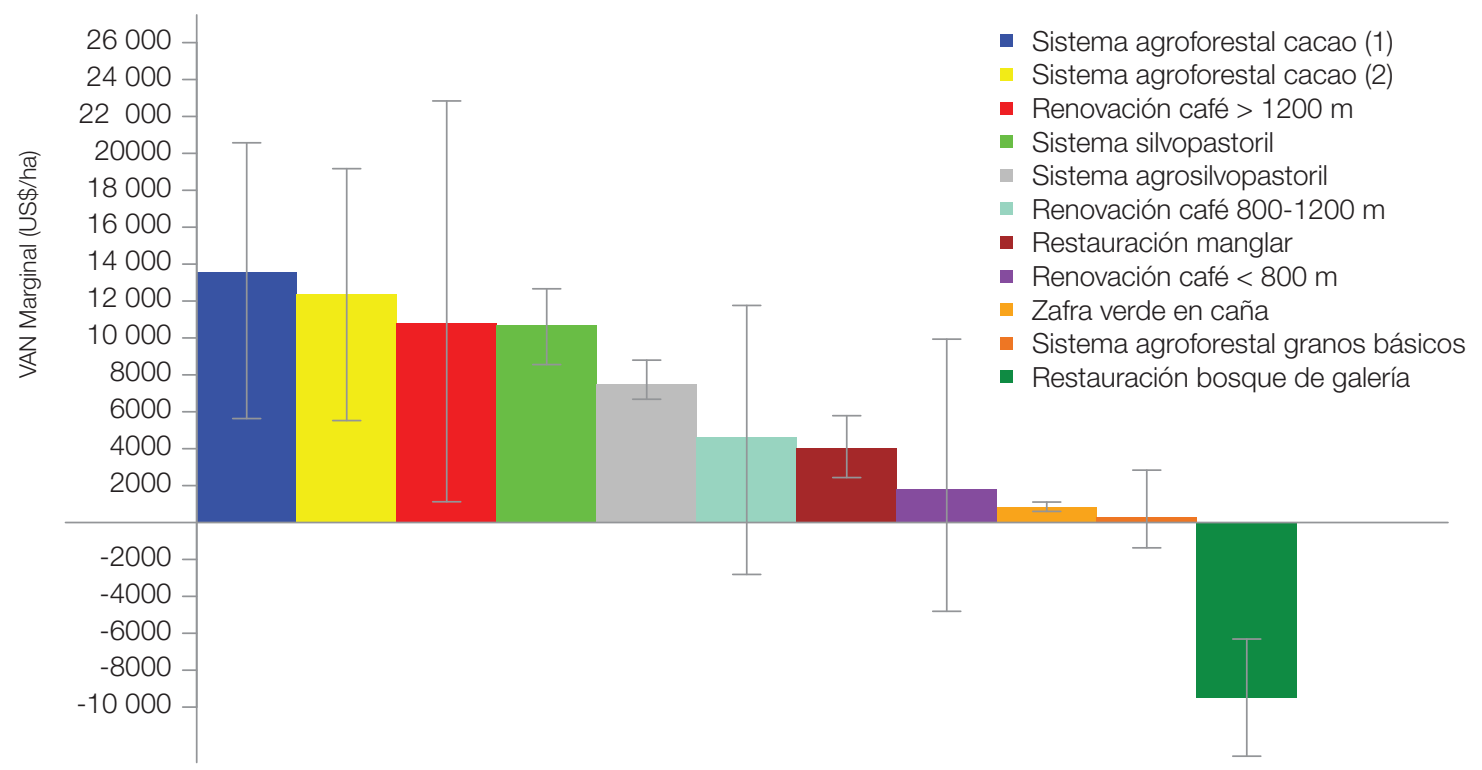

Figura 11 VAN marginal de las acciones de restauración con precios y rendimientos altos y bajos ( $r=10 \%)$.

Fuente: Elaboración propia 


\subsection{Balance de gases de efecto invernadero}

La Figura 12 presenta a veinte años los resultados del balance de carbono de las distintas acciones de restauración. Las acciones que tendrían más potencial de mitigación de cambio climático son las técnicas que se enfocan en la restauración de ecosistemas naturales, como la restauración de manglar (134 $\mathrm{TCO}_{2} \mathrm{e} / \mathrm{ha}$ ) y bosque de galería (127 $\mathrm{TCO}_{2} \mathrm{e} / \mathrm{ha}$ ).

Después viene la implementación de los sistemas agroforestales de granos básicos y de cacao. La adopción de la zafra verde en caña (el abandono de la quema) se destaca también por el aporte en términos de mitigación del cambio climático. La renovación de café trae beneficios más bajos porque en el uso actual ya existen especies arbóreas en los cafetales. Por ende, el balance de GEI de los sistemas silvopastoriles son los que menos beneficios traen, en términos de mitigación, porque al aumentar las cabezas de ganado suben las emisiones por hectárea. A continuación se describen los impactos de las diferentes acciones de restauración sobre los usos de suelo, a nivel de balance de GEl.

\subsubsection{Balance GEl restauración de manglar}

Debido a su alta actividad biológica el ecosistema de mangle tiene capacidad de fijación de carbono en condiciones adversas
(Sappal et al. 2016). La mayor parte del carbono almacenado se ubica en los sedimentos, seguido por el carbono fijado en la biomasa aérea y subterránea (Pendleton et al. 2012). En el caso de la restauración, se valora una pérdida neta de 18,33 $\mathrm{TCO}_{2} \mathrm{e} /$ ha/año por remoción de sedimentos a 1 metro de profundidad. Se trata de sedimentos que provienen de las áreas de cultivo en las partes más altas de la cuenca, alrededor de la zona de mangle, y no del propio sedimento generado por el ecosistema. ${ }^{64}$ Se usó un factor de emisión de nivel 2 basado en el contenido de carbono del suelo cercano al mangle. Con base en el análisis de suelo de las regiones de Usulatán, La Libertad, y La Unión, se corrigió el factor de emisión en un promedio de 41 $\mathrm{TCO}_{2}$ e/ha en lugar de los $471 \mathrm{TCO}_{2}$ e que se usa como factor predeterminado con sedimentos propios del mangle.

Por otra parte, la recuperación del área de mangle correspondiente al desazolvamiento, permite la rehumidificación y la regeneración del ecosistema (Feble-Patrón et al. 2009), lo cual conlleva el aumento de su reserva de carbono. Asimismo, con base en los estudios de carbono fijado (Cifuentes y Rivera 2016) y la evaluación de la densidad arbórea de mangle (Trejos 2011), se calculó que la rehumidificación permite una fijación de $\mathrm{CO}_{2}$ de 26,83 $\mathrm{TCO}_{2}$ e usando factores de emisión de nivel 2. Por ende, el dezasolvamiento de mangle y su respectiva recuperación permite una fijación de 8,48 $\mathrm{TCO}_{2} \mathrm{e} / \mathrm{ha} / \mathrm{año}$.

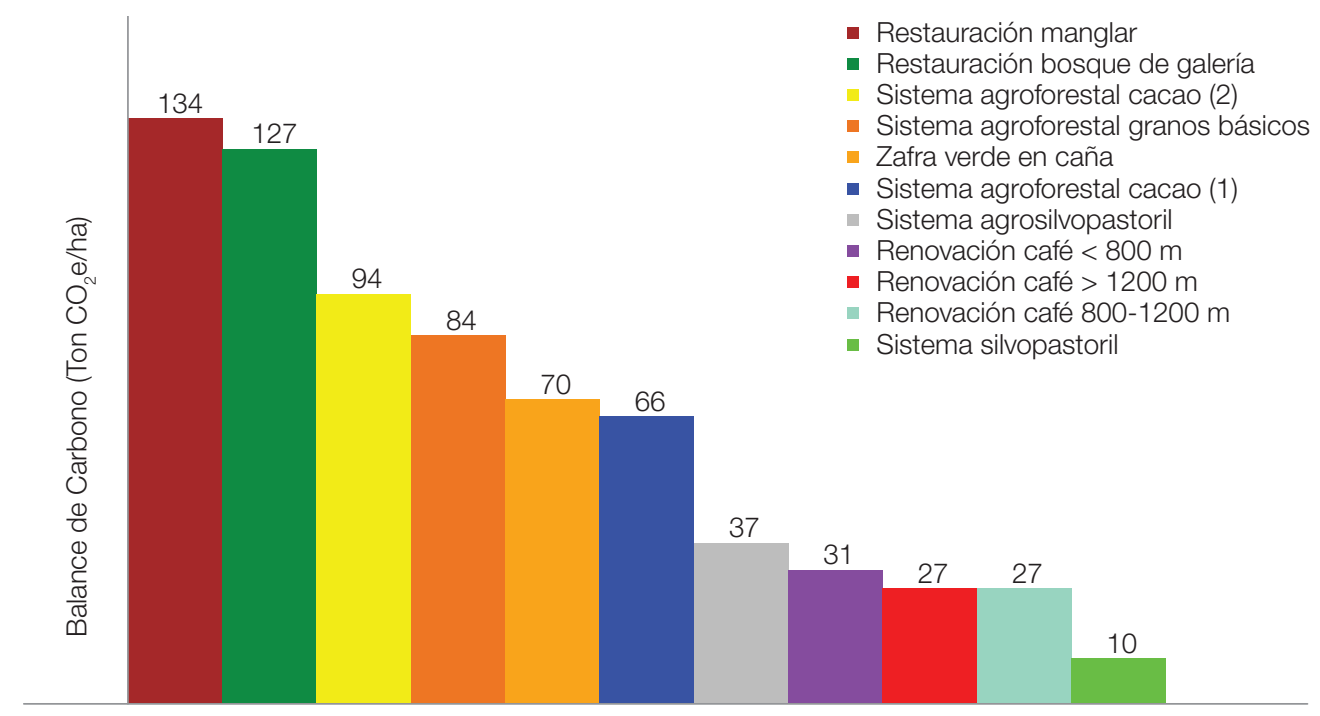

Figura 12 Balance de GEl en las acciones de restauración ( $\left.\mathrm{TCO}_{2} \mathrm{e} / \mathrm{ha}\right)$. 


\subsubsection{Balance GEl restauración de bosque de galería}

Por tener una mayor tasa de aplicación y prácticas más dañinas para el ambiente (quema) se observa una mayor reducción de emisiones de $\mathrm{CO}_{2}$ e cuando se hace la restauración de bosque de galería donde hoy en día hay cultivos anuales. La restauración de área con regeneración natural es la que menos contribuye a la reducción de emisiones con una tasa promedia de 4,07 $\mathrm{TCO}_{2}$ e/ha/año. En conjunto, la restauración de bosque de galería en espacios agrícolas ubicados en una franja de 25 metros de los principales ríos, permitiría la reducción de 6,03 $\mathrm{TCO}_{2} \mathrm{e} / \mathrm{ha} / \mathrm{año}$.

\subsubsection{Balance GEl sistema agroforestal de granos básicos}

La incorporación de árboles dentro de los cultivos de granos básicos aumenta los niveles de carbono orgánico en biomasa y suelo (Kaonga y Bayliss-Smith 2009). Se confirma esta tendencia para la implementación de un SAF en granos básicos, ya que según cálculos realizados con Ex Act, generaría una reducción de 5,34 TCO 2 e/ha/año. Un 88\% (4,7 TCO 2 e/ha/año) proviene de un incremento de carbono en biomasa arbórea y un 8\% por incremento de carbono orgánico de suelo. Se destaca un incremento relativamente poco significativo de 0,14 $\mathrm{TCO}_{2} \mathrm{e} /$ ha/año por la mayor tasa de aplicación de fertilizantes. El abandono de la quema en granos básicos generaría un beneficio de $0,5 \mathrm{TCO}_{2} \mathrm{e} / \mathrm{ha} / \mathrm{año}$.

\subsubsection{Balance GEl sistema silvopastoril}

A nivel de Centroamérica, la incorporación de árboles en potreros se ha reportado también como un potencial sumidero de carbono, tanto en biomasa como en suelo (Chacón-León y Harvey 2013). Los pastos que ocupan la mayor parte del área agrícola a nivel mundial tienen el mayor potencial de fijación de carbono en el suelo (Watson et al. 2000). Los suelos de pastizales, en particular en el caso de sobrepastoreo, constituye un significativo sumidero potencial (Zhou et al. 2007, Conant y Paustian 2002).

La implementación del SSP se caracteriza por tener un balance positivo neto gracias al aumento de fijación de carbono en el suelo. Cuando se implementó la restauración de pastos naturales, se determinó un incremento de carbono de suelo equivalente a 0,67 $\mathrm{TCO}_{2}$ e/ha/año y a 2,33 $\mathrm{TCO}_{2}$ e/ha/año en mosaico de cultivo y pasto. Estos incrementos se deben a la reversión de la degradación de los pastos sin quema. Por otra parte, el incremento de carbono de biomasa arbórea es de 2,22 $\mathrm{TCO}_{2} \mathrm{e} /$ ha/año. Sin embargo, el aumento de la capacidad de carga de 4 a 5 animal/hectárea del SSP se traduce en una mayor intensidad de GEl de 1,66 $\mathrm{TCO}_{2}$ e/ha/año.

En cuanto a la fertilización, se observa un aumento neto de emisiones de GEl de 0,58 $\mathrm{TCO}_{2}$ e/ha/año para ambos usos de suelo actual. En este sentido, al tomar en cuenta este rebote de emisiones por mayor producción lechera, se obtiene una reducción neta de GEl de 0,66-2,30 TCO 2 e/ha/año, si se establecen sistemas silvopastoriles en pasto natural o en los pastos del mosaico de cultivo y pasto.

\subsubsection{Balance GEl zafra verde en caña de azúcar}

La implementación de la zafra verde aumenta las reservas de carbono de suelo (Galdos et al. 2009) de hasta 30\% en el caso de cultivos de caña donde hayan adoptado la no quema por más de ocho años. En Brasil, se valoró que la quema de residuos ocupa el primer puesto de emisiones por generar 44\% de GEl a lo largo del ciclo productivo de la caña (de Figueiredo et al. 2010). Por lo tanto, la adopción de la zafra verde, a nivel del sector azucarero, puede proporcionar una reducción significativa de emisiones. En el caso de El Salvador, se determina una reducción neta de $\mathrm{GEI}$ de 3,35 $\mathrm{TCO}_{2}$ e/ha/año por la ausencia de quema y la eliminación de emisiones por el manejo de la caña bajo zafra verde.

\subsubsection{Balance GEl sistema agroforestal de cacao}

Para el establecimiento de un cacaotal diversificado dentro del cafetal, se observa un aumento neto del secuestro de carbono de 4,8 $\mathrm{TCO}_{2}$ e/ha/año, frente al uso actual. En Centroamérica los árboles de sombra concentran el 70\% del carbono orgánico, según se reporta en los sistemas agroforestales de cacao (Somarriba et al. 2013). El rebote de emisiones por aplicación de fertilizante es de 0,63 $\mathrm{TCO}_{2}$ e/ha/año, lo cual se resta al aumento total de secuestro de carbono anual, como resultado se da un balance neto anual de 4,17 $\mathrm{TCO}_{2} \mathrm{e} / \mathrm{ha}$. El cálculo del balance de GEl para el establecimiento de mosaico de cultivo de pasto y vegetación hacia cacaotal se hace siguiendo la misma lógica, con la diferencia de que se determina una ligera disminución de las emisiones por aplicación y producción de fertilizantes $\left(-0,11 \mathrm{TCO}_{2} \mathrm{e} / \mathrm{ha} / \mathrm{año}\right)$ frente a otros usos de suelo como granos básicos y caña. Asimismo, se valora que el establecimiento de cacao en zona idóneas para su cultivo, en El Salvador, resultaría en una mayor fijación de carbono de 5,94 
$\mathrm{TCO}_{2} \mathrm{e} / \mathrm{ha} / \mathrm{año}$. Esta diferencia con el establecimiento de cacao en cafetales se debe al hecho de que los cafetales ya tienen un dosel de sombra que no permite aumentarlo de manera tan significativa.

\subsubsection{Balance GEl renovación de los cafetales}

El Plan de Acción permite consolidar los esfuerzos de renovación del parque cafetalero a nivel nacional al complementar la reforestación y la diversificación con cultivos frutales y árboles maderables. Esta práctica permite aumentar el secuestro anual de carbono entre 2,78 $\mathrm{TCO}_{2}$ e y 2,5 $\mathrm{TCO}_{2} \mathrm{e}$, si el café está ubicado en zonas de mediana altura, de altura o de bajío. La extracción de nutrientes asociada a cada cosecha que va en aumento en el tiempo, implica un incremento de la fertilización, lo cual se traduce en un aumento de emisiones de 0,85 $\mathrm{TCO}_{2}$ e. Si las otras condiciones se mantienen iguales, se proyecta un aumento de 1,94 a 1,68 TCO $\mathrm{TC}_{2} \mathrm{ha} /$ año, si la diversificación y modernización del parque cafetalero se implementa en zona de bajío o en zona de altura.

\subsubsection{Curva marginal de reducción de carbono}

Contener la degradación del ambiente y cubrir las necesidades de desarrollo económico son dos prioridades para el Gobierno de El Salvador (GOES 2012a). Este estudio se propone ilustrar cuáles son las acciones de restauración más efectivas para regenerar las capacidades funcionales de los ecosistemas que permiten sostener los medios de vida (p. ej. producción agrícola, forestal, entre otros), y al mismo tiempo, mitigar las emisiones de GEl (Verdone 2015). Bajo este enfoque, las acciones de restauración que más beneficios económicos traen y, al mismo tiempo, mantienen un alto potencial de mitigación del cambio climático, son la implementación de sistemas agroforestales de cacao y agrosilvopastoriles (Figura 13). Los sistemas silvopastoriles y la renovación de café de altura mantienen un balance económico altamente positivo, pero con un menor potencial de fijación y almacenamiento de carbono.

Las acciones de restauración que tienen el mejor desempeño de GEl tienen un balance económico mediano como en el caso de la restauración de manglar (VAN marginal = US\$ 4061/ha), o negativo en el caso de la restauración de bosque de galería (VAN marginal promedio = US\$ -9495/ha).

Si se consideran los beneficios marginales obtenidos por toneladas de $\mathrm{CO}_{2}$ e reducido, la implementación de un SSP es la que mejor clasifica al generar US\$51,4 por $\mathrm{TCO}_{2}$ e reducida.

En comparación, las acciones de restauración rentables que más carbono fijan por hectárea son la restauración ecológica de manglar (134 $\mathrm{TCO}_{2} \mathrm{e} / \mathrm{ha}$ ) y el SAF de cacao en mosaico de cultivos anuales, pasto y vegetación (94 $\mathrm{TCO}_{2} \mathrm{e} / \mathrm{ha}$ ), que generan beneficios marginales estimados en US\$1,5/TCO 2 e y US\$ 6,6 $\mathrm{TCO}_{2} \mathrm{e}$, respectivamente. Finalmente, la restauración de bosque de galería tiene un costo de US\$ 3,7 por $\mathrm{TCO}_{2} \mathrm{e}$.

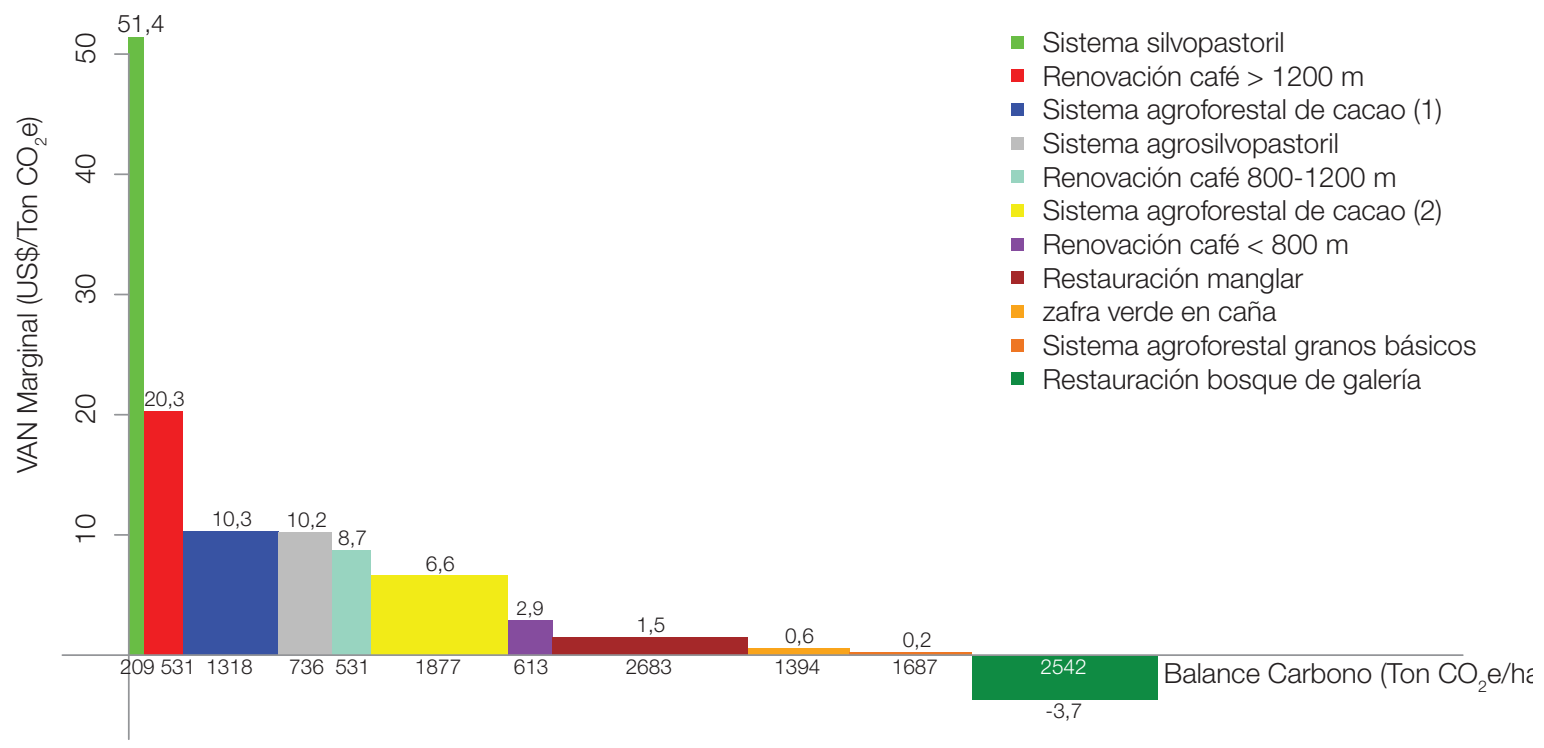

Figura 13 Curva de costo marginal de reducción de $\mathrm{CO}_{2} \mathrm{e}(\mathrm{r}=10 \%)$. 


\subsection{Impacto sobre conectividad}

La restauración de los ecosistemas naturales (manglar y bosque de galería) tiene la mayor puntuación en el índice de conectividad. Todas las acciones de restauración mejoran la conectividad, con la excepción de la zafra verde en caña, ya que el sistema analizado carece de árboles (Cuadro 6).

\subsection{Impacto en producción de leña}

\section{Cuadro 6 Índice de conectividad}

\begin{tabular}{ll} 
Acciones de restauración & Índice \\
Restauración del manglar & 1,00 \\
\hline Restauración bosque de galería & 1,00 \\
\hline Sistema agroforestal de granos básicos & 0,94 \\
\hline Sistema silvopastoril & 0,82 \\
\hline Sistema agrosilvopastoril & 0,94 \\
\hline Zafra verde en caña de azúcar & 0,00 \\
\hline $\begin{array}{l}\text { Sistemas agroforestales con cacao en café } \\
\text { (cacao 1) }\end{array}$ & 0,75 \\
\hline $\begin{array}{l}\text { Sistemas agroforestales con cacao en mosaico } \\
\text { de cultivo, pasto y vegetación (cacao 2) }\end{array}$ & 0,83 \\
\hline Renovación de café de bajío & 0,90 \\
\hline Renovación de café de mediana altura & 0,79 \\
\hline Renovación de café de altura & 0,90 \\
\hline
\end{tabular}

Finalmente, como cobeneficio ambiental (no espacial) se considera la producción de leña. El manglar proveería la mayor cantidad de leña, mientras que dos acciones de restauración no la proveen, ya sea porque el propósito es conservación (restauración bosque de galería), o porque la restauración no incluye la siembra de árboles (zafra verde en caña de azúcar (Figura 14).

\subsection{Cambio en erosión y exportación de sedimentos y de nutrientes}

Con los modelos del InVEST se generaron cuatro mapas por cada acción de restauración: (1) cambio en la erosión y (2) exportación de sedimentos del modelo SDR, (3) cambio en la exportación de N, y (4) P del modelo NDR. Se procedió a realizar el análisis de impacto sobre la provisión de servicios ecosistémicos.

Los mapas (3-6) muestran ejemplos de los mapas de diferencia entre el uso actual del suelo y la implementación de la restauración

A partir de los valores diferenciados, a nivel espacial, se puede calcular el impacto promedio de cada acción de restauración (Cuadro 7). La implementación del SAF de cacao en el mosaico de cultivos, pasto y vegetación tiene el mayor impacto promedio sobre la disminución de la erosión, mientras que el SAF de cacao en los cafetales tiene el mayor impacto sobre la reducción en la exportación de sedimentos. La mayor disminución

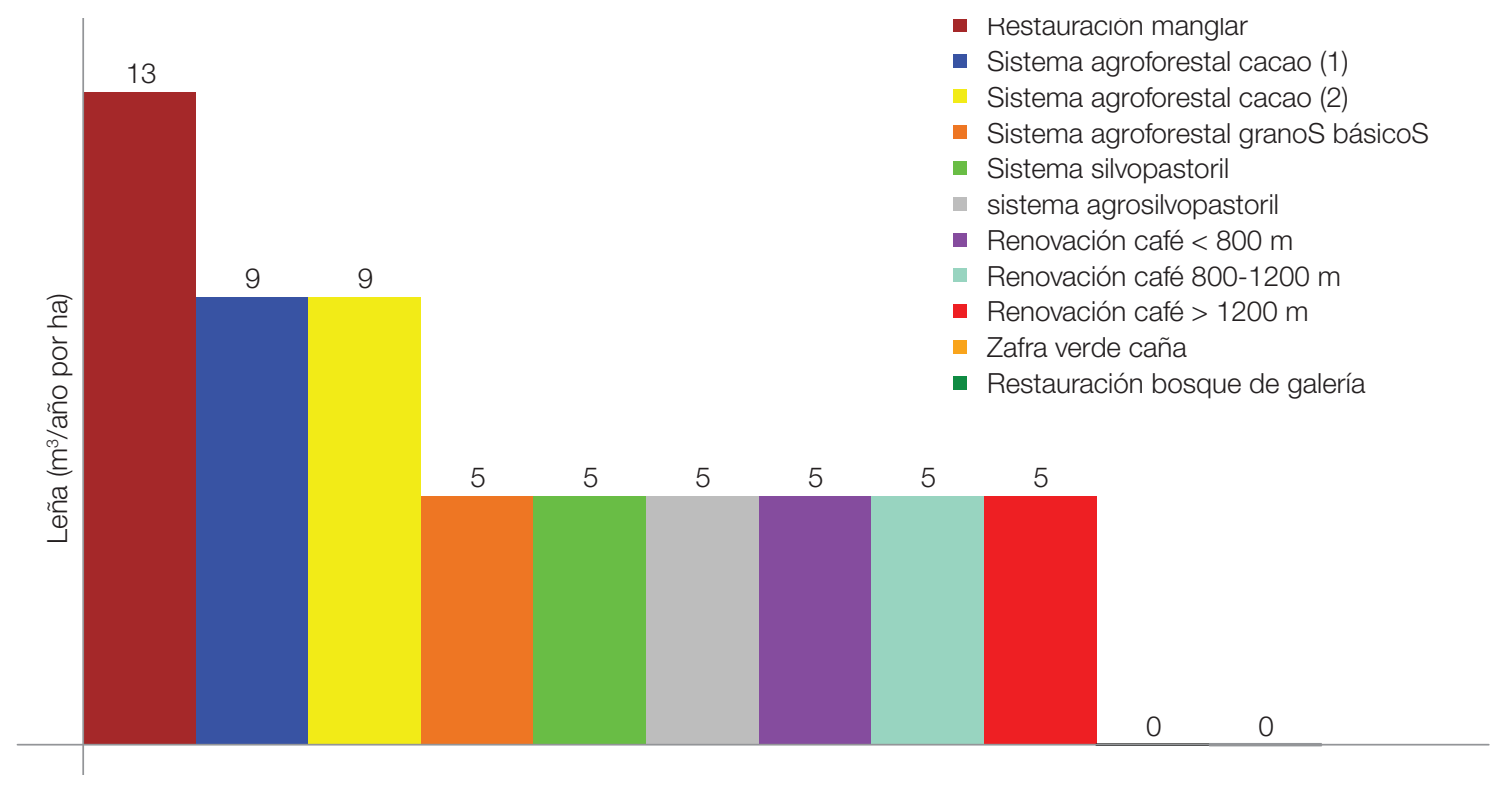

Figura 14 Producción de leña por cada acción de restauración (m³/año). 
promedio sobre la exportación de nitrógeno y fósforo se consigue con la restauración del bosque de galería. sobre todo, un efecto del incremento en el número de cabezas de ganado, por hectárea, en los sistemas propuestas.

El mayor incremento promedio en la exportación de estos nutrientes proviene de la implementación de los SSP y SASP; y es

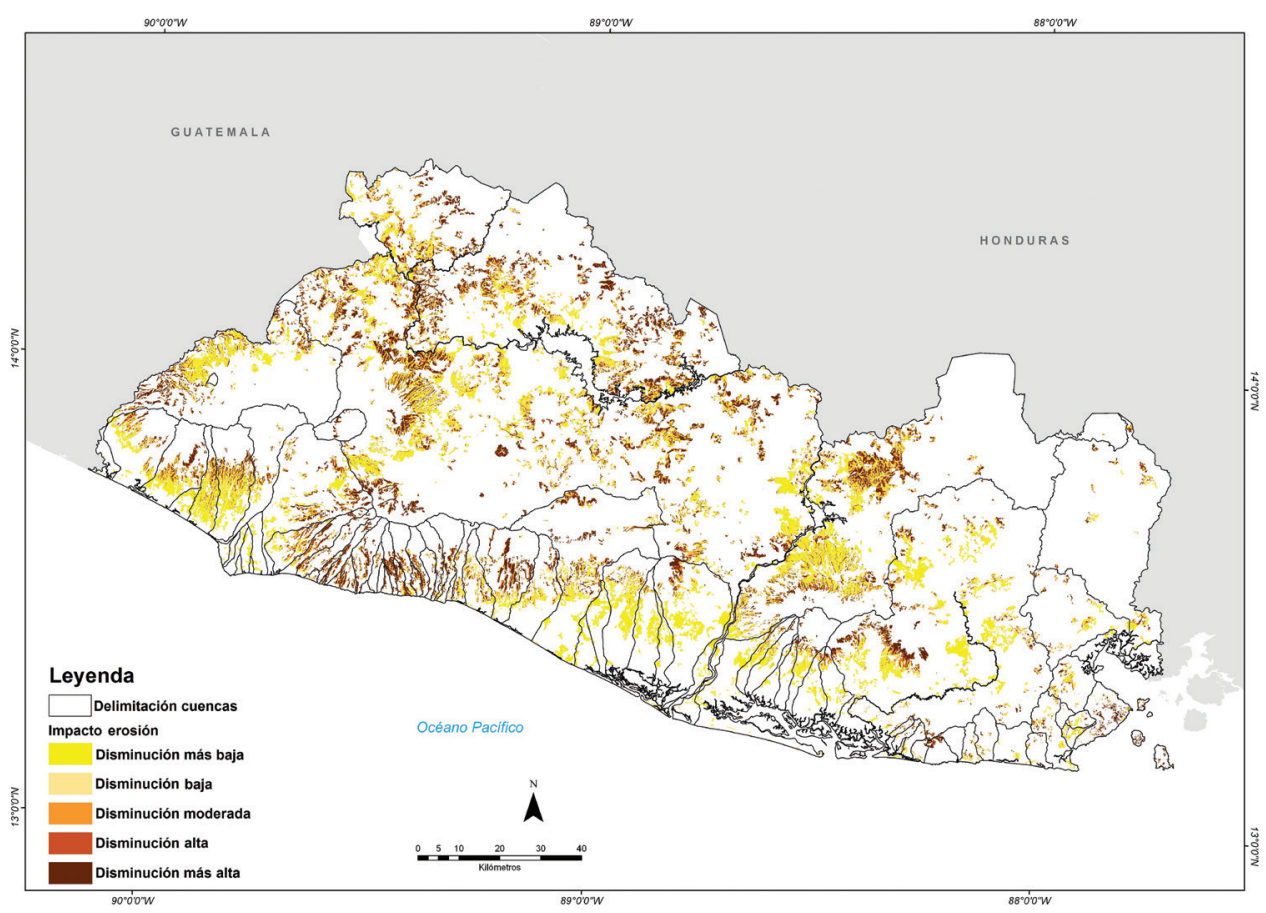

Mapa 3 Cambio en la erosión por la implementación del SAF de granos básicos.

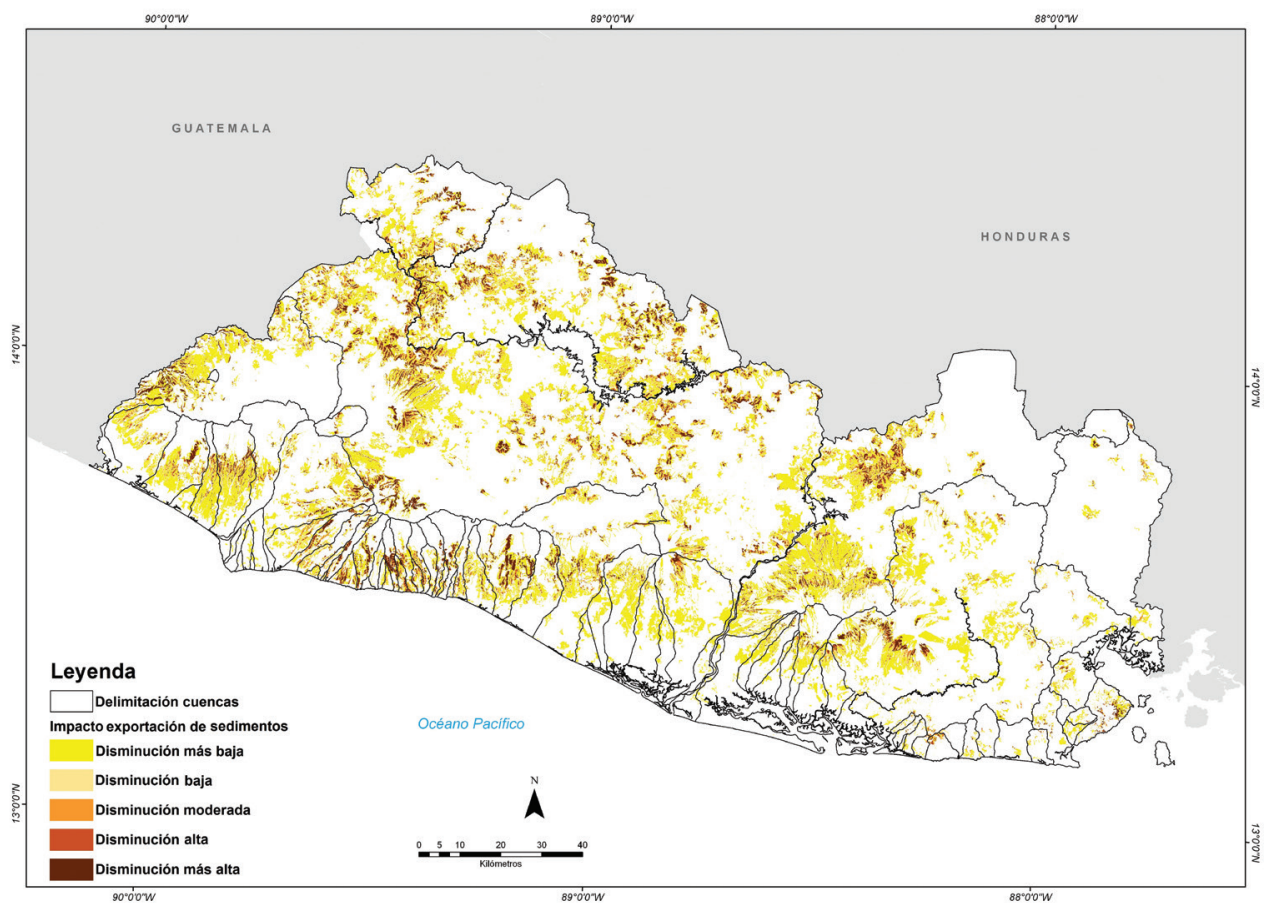

Mapa 4 Cambio en la exportación de sedimentos por la implementación del SAF de granos básicos. 


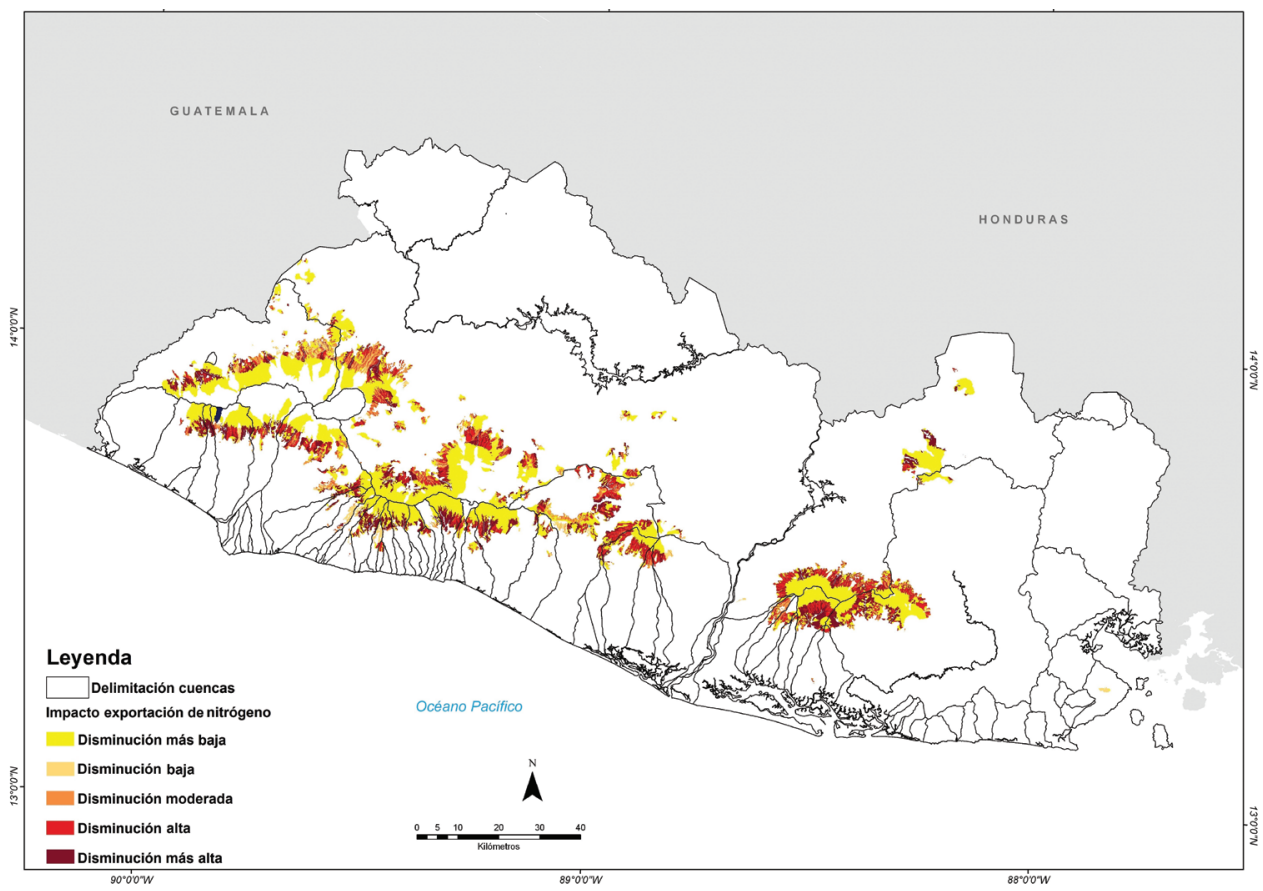

Mapa 5 Cambio en la exportación de N por la renovación del café de mediana altura.

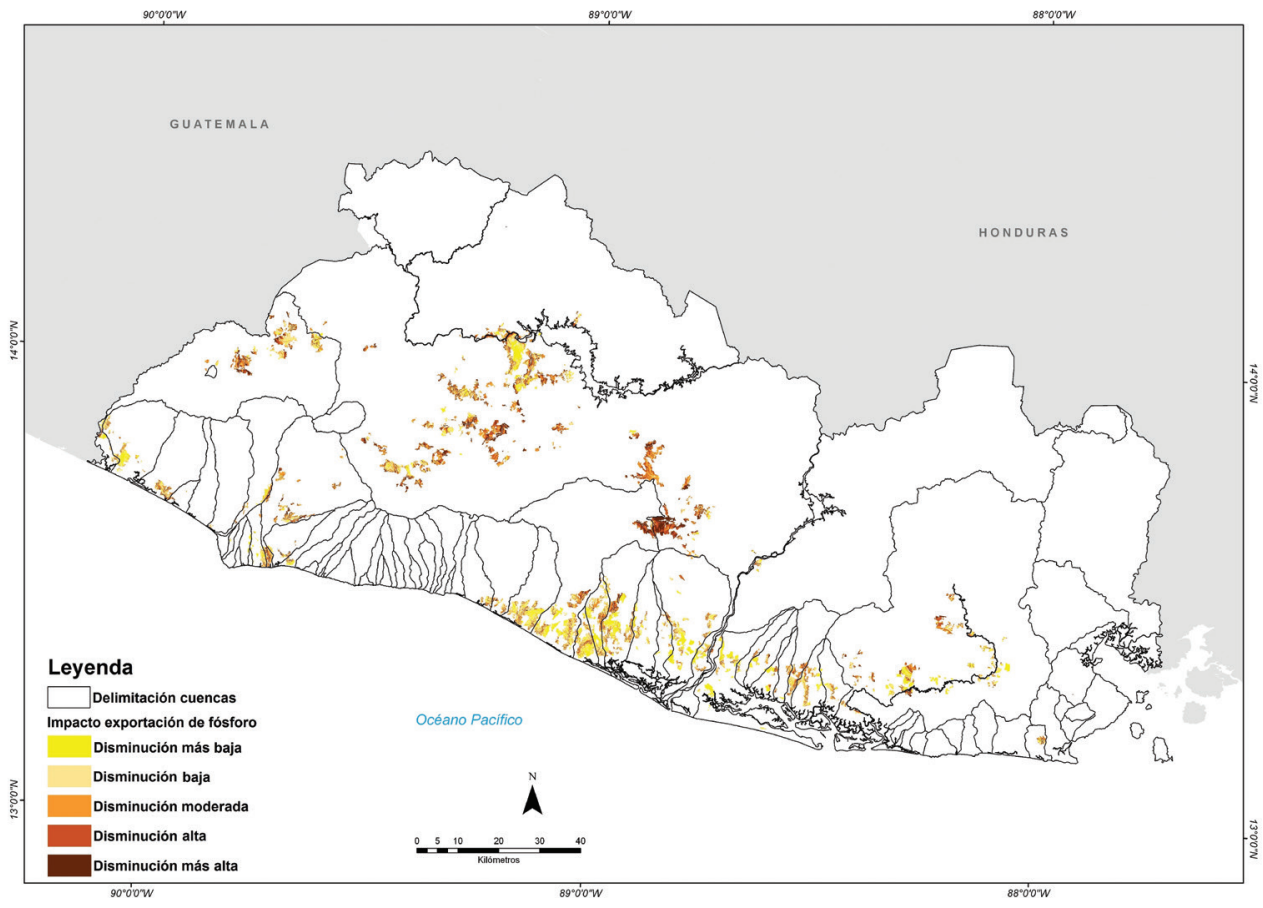

Mapa 6 Cambio en la exportación de P por la adopción de la zafra verde en caña de azúcar. 
Cuadro 7 Impacto promedio por la restauración modelado con InVEST

\begin{tabular}{|c|c|c|c|c|}
\hline Acciones de restauración & Cambio erosión & $\begin{array}{l}\text { Cambio exportación } \\
\text { sedimentos }\end{array}$ & Cambio exportación nitrógeno & Cambio exportación fósforo \\
\hline Restauración del manglar & $\mathrm{n} / \mathrm{a}$ & $\mathrm{n} / \mathrm{a}$ & $\mathrm{n} / \mathrm{a}$ & $\mathrm{n} / \mathrm{a}$ \\
\hline Restauración de bosque de galería & $\downarrow$ & $\downarrow$ & $\downarrow \downarrow \downarrow$ & $\downarrow \downarrow \downarrow$ \\
\hline Sistemas agroforestales con granos básicos & $\downarrow \downarrow$ & $\downarrow \downarrow \downarrow$ & $\uparrow$ & $\uparrow \uparrow$ \\
\hline Sistema silvopastoril & $\downarrow \downarrow$ & $\downarrow \downarrow$ & $\uparrow$ & $\uparrow \uparrow$ \\
\hline Sistema agrosilvopastoril & $\downarrow$ & $\downarrow \downarrow$ & $\uparrow$ & $\uparrow \uparrow$ \\
\hline Zafra verde en caña de azúcar & $\downarrow$ & $\downarrow$ & $\downarrow$ & $\downarrow$ \\
\hline $\begin{array}{l}\text { Sistemas agroforestales con cacao en mosaico } \\
\text { de cultivo, pasto y vegetación (cacao 2) }\end{array}$ & $\downarrow \downarrow \downarrow$ & $\downarrow \downarrow \downarrow$ & $\downarrow$ & $\downarrow$ \\
\hline $\begin{array}{l}\text { Sistemas agroforestales con cacao en café } \\
\text { (cacao 1) }\end{array}$ & $\downarrow \downarrow$ & $\downarrow \downarrow \downarrow$ & $\uparrow$ & $\downarrow$ \\
\hline Renovación de café de bajío & $\downarrow$ & $\downarrow$ & $\downarrow$ & $\downarrow$ \\
\hline Renovación de café de mediana altura & $\downarrow$ & $\downarrow \downarrow$ & $\downarrow$ & $\downarrow$ \\
\hline Renovación de café de altura & $\downarrow$ & $\downarrow \downarrow$ & $\downarrow$ & $\downarrow$ \\
\hline
\end{tabular}

Además de los cobeneficios ambientales, se consideran una serie de beneficios sociales (o impactos sociales) que la implementación y las acciones de restauración podrían generar.

\subsection{Creación de empleo}

Con la excepción de la restauración de bosque de galería, todas las acciones de restauración generan empleos adicionales durante la fase de implementación (Figura 15.1). Adicionalmente, mantendrá un aumento constante por la demanda de mano de obra al incrementar la productividad o el fomento de nuevas cadenas en todas las acciones de restauración, salvo, de nuevo, en el caso de la restauración de bosque de galería (Figura 15.2).

La renovación de cafetales es la acción que más empleo genera durante la fase de implementación con 0,9 empleo/ha/año. La actividad ganadera y la implementación de la zafra verde crean, respectivamente, 0,56 y 0,54 empleo/ha/año. Estos dos sistemas son los que mantienen el nivel de creación de empleo más alto a lo largo del año 2 al 20. Se destaca en particular la adopción de la zafra verde que mantiene un aumento de 0,48 empleo/ ha año, lo cual se explica por el abandono de la quema que conlleva una mayor demanda de mano de obra.

\subsection{Seguridad alimentaria}

El indicador de seguridad alimentaria consiste de dos partes: (i) porcentaje de la producción para subsistencia (Figura 16), y (ii) incremento en la producción con respecto al escenario de uso actual del suelo (Cuadro 8).

El SAF de granos básicos es el sistema donde una mayor parte de la producción es para el consumo de subsistencia, seguido del SSP y SASP. En los SAF de cacao y la renovación de los cafetales, el bajo porcentaje de subsistencia se debe al hecho que el principal cultivo es un cultivo comercial, en buena parte para la exportación.

No se considera extracción para la subsistencia con la restauración del manglar, bosque de galería ni en la zafra verde en caña de azúcar. En el caso de la restauración del manglar esto podría ser una subestimación del aporte de esta acción. No se tuvo acceso a los datos sobre el porcentaje de cangrejos extraídos que podrían ser para el autoconsumo, por lo tanto, no se incluyó en este análisis. No obstante, en el caso de la restauración del manglar, el dato del aporte a la seguridad alimentaria debe ser interpretado desde esta perspectiva.

El Cuadro 8 muestra el incremento en la producción considerada para cada una de las acciones de restauración. Como es imposible crear un solo indicador de incremento en la productividad para todos los diferentes cultivos, a partir de los incrementos en kilogramos, se utiliza el incremento (o disminución) de los ingresos brutos de cada acción de restauración como proxy (Figura 17).

La implementación del SAF de cacao en café produce el mayor incremento en la producción, la zafra verde en caña de azúcar la menor. La restauración de bosque de galería tiene un impacto negativo sobre los beneficios brutos adicionales. 


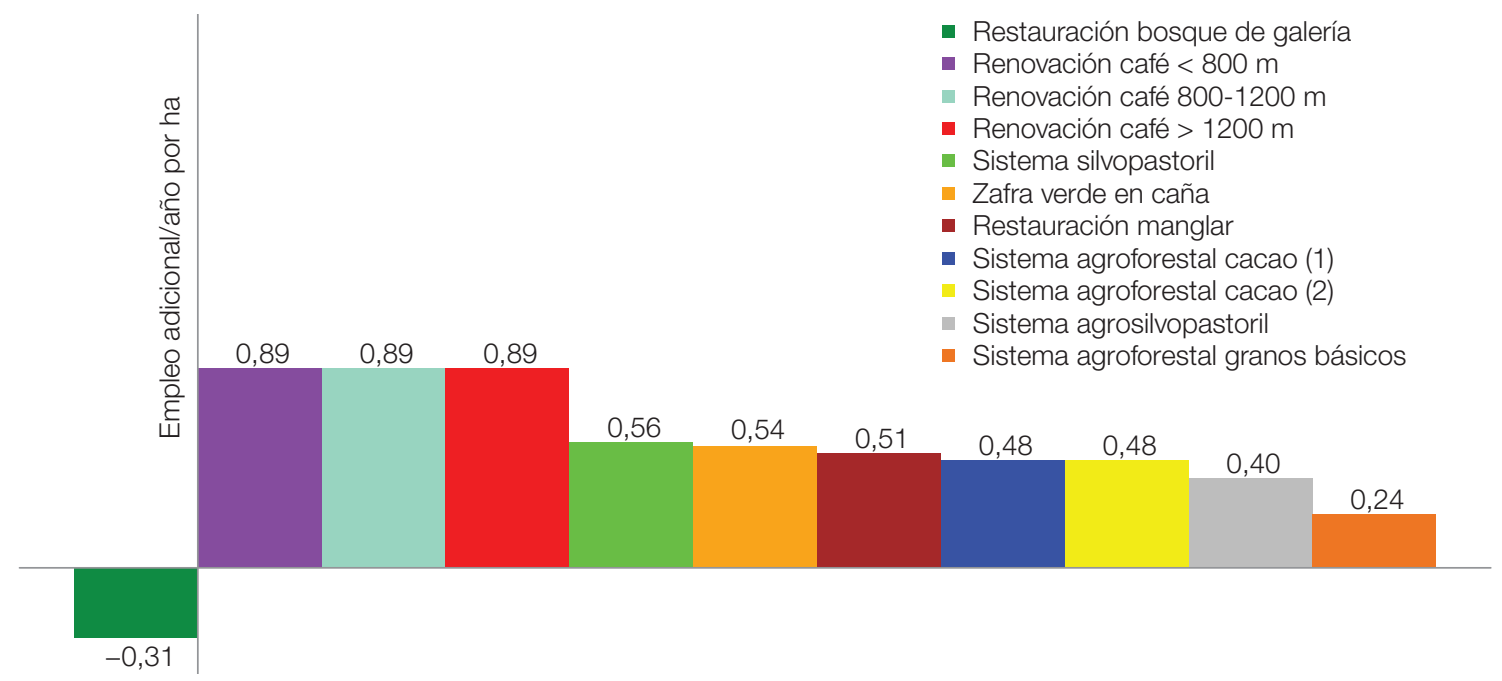

Figura 15.1 Creación de empleo en el primer año (establecimiento) por acción de restauración.

Fuente: Elaboración propia.

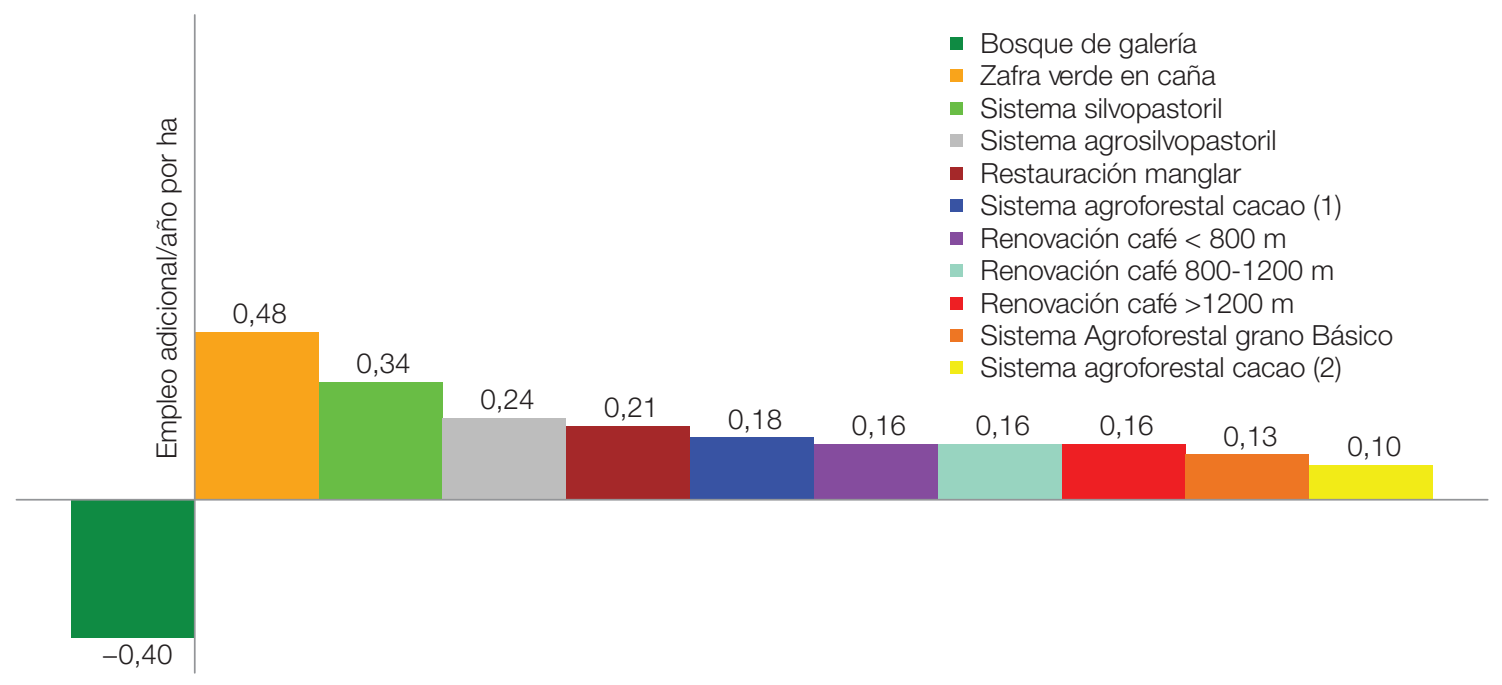

Figura 15.2 Creación de empleo del año 2 al 20 por acción de la restauración por año.

Fuente: Elaboración propia. 


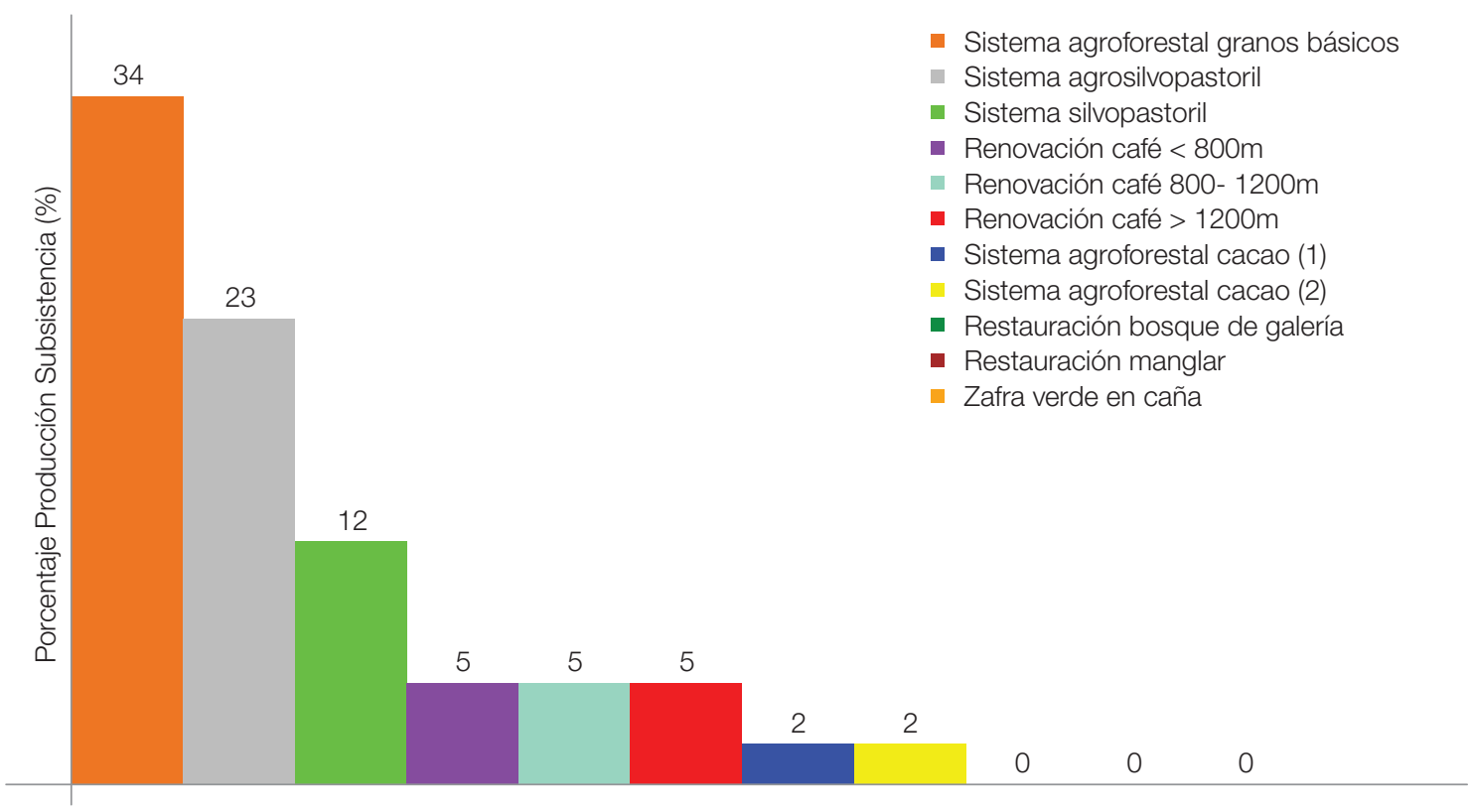

Figura 16 Porcentaje producción de subsistencia de los sistemas restaurados.

Cuadro 8 Incremento en la producción por la implementación de las acciones de restauración

\begin{tabular}{|c|c|c|c|c|}
\hline Acciones de restauración & Intervención & Cadenas & $\begin{array}{l}\text { Rendimiento promedio BAU } \\
\text { (Kg/ha/año) }\end{array}$ & $\begin{array}{c}\text { Rendimiento promedio bajo } \\
\text { restauración ( } \mathrm{Kg} / \mathrm{ha} / \mathrm{año})\end{array}$ \\
\hline \multirow[t]{2}{*}{ Restauración manglar } & Ampliación & Punches (Ucides occidentalis) & / & $1325^{\mathrm{a} /}$ \\
\hline & Ampliación & $\begin{array}{l}\text { Cangrejo Azul } \\
\text { (Cardissoma crassum) }\end{array}$ & / & $175^{\mathrm{b} /}$ \\
\hline \multirow[t]{4}{*}{ Sistema agroforestal granos básicos } & Productividad & Maíz & 2686 & 2901 \\
\hline & Productividad & Frijol & 867 & 841 \\
\hline & Diversificación & Jocote de verano & / & 403 \\
\hline & Diversificación & Marañón & / & 104 \\
\hline Sistema silvopastoril & Productividad & Leche & 3660 & 12360 \\
\hline \multirow[t]{5}{*}{ Sistema agrosilvopastoril } & Diversificación & Marañón & l & 52 \\
\hline & Diversificación & Jocote de verano & / & 202 \\
\hline & Productividad & Maíz & 1343 & 1450 \\
\hline & Productividad & Frijol & 433 & 420 \\
\hline & Productividad & Leche & 1830 & 6180 \\
\hline Zafra verde caña & Productividad & Azúcar & 8010 & 8470 \\
\hline \multirow[t]{4}{*}{ Sistema agroforestal de cacao } & Diversificación & Plátano & / & 1636 \\
\hline & Diversificación & Níspero (Manilkara zapota) & / & 2250 \\
\hline & Diversificación & Mango (Mangifera indica) & l & 1360 \\
\hline & Diversificación & Cacao & l & 889 \\
\hline \multirow[t]{5}{*}{ Renovación café } & Productividad & Café <800 msnm & 322 & 1472 \\
\hline & Productividad & Café $800<1200$ msnm & 368 & 1.610 \\
\hline & Productividad & Café >1200 msnm & 552 & 1.840 \\
\hline & Diversificación & Mango & I & 648 \\
\hline & Diversificación & Aguacate & I & 572 \\
\hline
\end{tabular}

a/ Se asume un peso promedio de 128 gr por unidad de Ucides occidentalis a partir de Rivera y Córdoba (2010).

b/ Se asume un peso promedio de 146 gr por unidad de cangrejo azul a partir de Uscocovich Garcés (2015). 


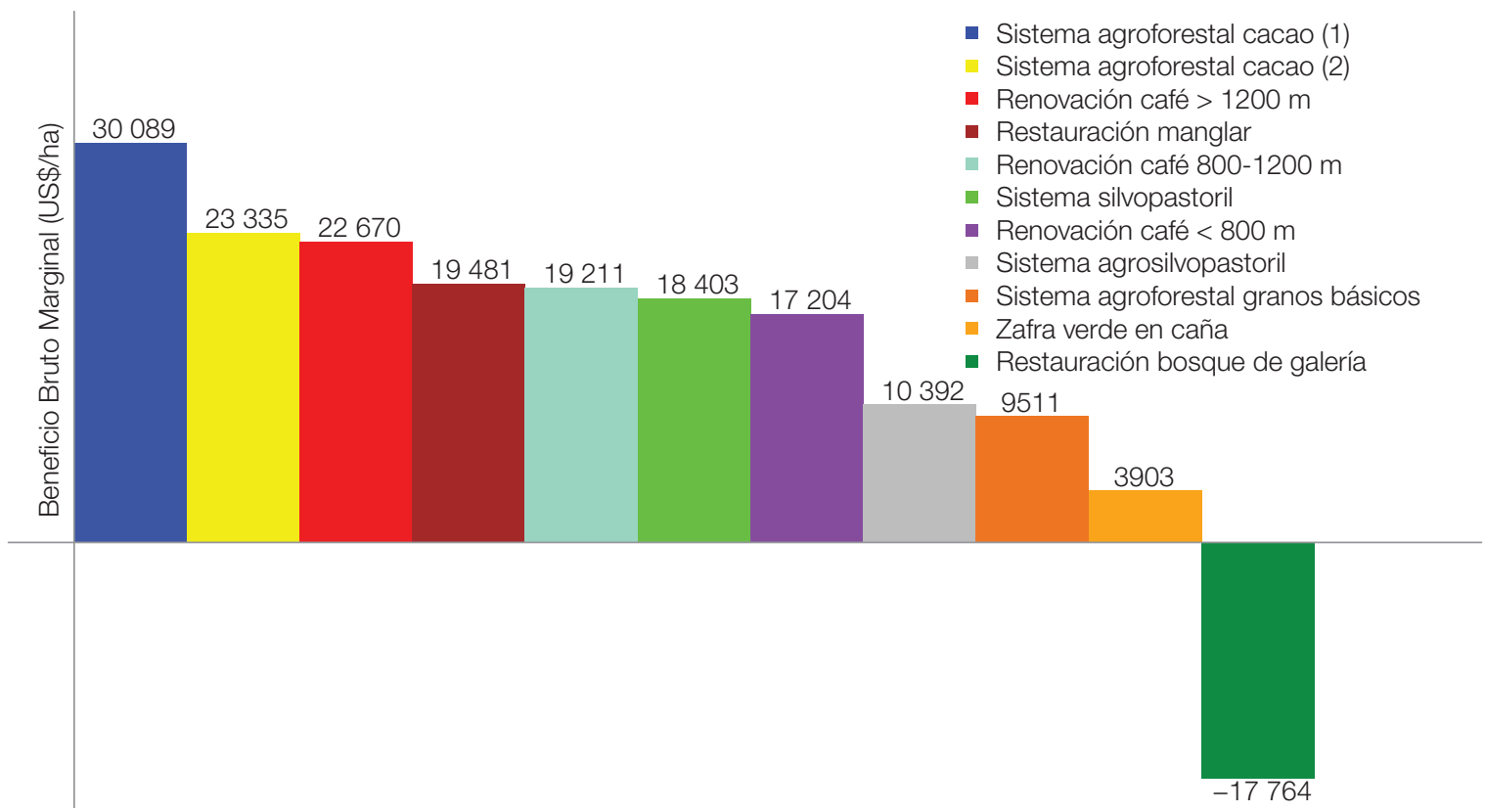

Figura 17 Beneficio bruto marginal de las acciones de restauración.

\subsection{Medios de vida}

Para estimar los impactos de la restauración sobre los medios de vida de los productores se utilizaron dos indicadores: (1) la diversificación agrícola, que puede fortalecer los medios de vida de los hogares productores, y (2) los beneficios netos de las acciones de restauración, pero teniendo en cuenta que la mano de obra familiar también tiene un costo. El indicador creado (Anexo 9, Cuadro A22) es la suma de ambos indicadores normalizadas (Cuadro 9).

Cabe destacar el SAF de granos básicos, que tiene un VAN negativo, si se retribuye toda la mano de obra familiar utilizada en la implementación y el mantenimiento de esta acción de

Cuadro 9 Ingresos que consideran la mano de obra familiar y el porcentaje de diversificación

\begin{tabular}{|c|c|c|}
\hline Acciones de restauración & $\begin{array}{l}\text { Beneficios netos restauración con costo mano } \\
\text { de obra familiar (US\$/ha) }\end{array}$ & $\begin{array}{c}\text { Porcentaje } \\
\text { de diversificación }\end{array}$ \\
\hline Restauración de manglar & 4061 & l \\
\hline Restauración bosque de galería en granos básicos & -5511 & l \\
\hline Restauración bosque de galería en pasto natural & -12717 & l \\
\hline Restauración bosque de galería en caña de azúcar & -8387 & / \\
\hline Restauración bosque de galería en mosaico de cultivos y pasto & -9804 & / \\
\hline Restauración bosque de galería en mosaico de cultivos, pastos y vegetación & -6021 & / \\
\hline Sistema agroforestal de granos básicos & -186 & 24 \\
\hline Sistema silvopastoril & 8034 & 7 \\
\hline Sistema agrosilvopastoril & 2914 & 20 \\
\hline Zafra verde en caña & 858 & 0 \\
\hline Sistema agroforestal de cacao en mosaico de cultivos, pastos y vegetación (cacao 2) & 11038 & 56 \\
\hline Sistema agroforestal de cacao en café (cacao 1) & 11806 & 42 \\
\hline Renovación de los cafetales de bajío & -142 & 36 \\
\hline Renovación de los cafetales de mediana altura & -141 & 28 \\
\hline Renovación de los cafetales de altura & 5273 & 19 \\
\hline
\end{tabular}

la Se calculó el beneficio de diversificación de ingreso, al comparar los ingresos generados por los cultivos y plantas maderables, sembrados como parte de las acciones de restauración, con los ingresos de la acción de restauración: donde Ix: sumatoria de los ingresos generados por cultivos y plantas maderables sembrados como parte de la restauración a 20 años; y I(t): ingresos totales (incluyendo $\mathrm{x}$ ) generados por la restauración a 20 años 
restauración. Aunque el nuevo VAN no es muy negativo, es un dato importante para considerar, ya que significa que no todo el esfuerzo de la mano de obra podrá ser retribuida si se consideran todos los costos de la restauración como costos para los hogares productores. En cuanto a la diversificación, los SAF de cacao tienen el mayor porcentaje en este sentido 


\section{Resumen del resultado por indicador}

El cuadro 10 resume los resultados obtenidos para los diferentes análisis llevados a cabo en este estudio. Muestra las restauraciones con el desempeño más alto y más bajo, según las estimaciones llevadas a cabo (Cuadros A18, A19, A20 y A21 señalan el desempeño para cada acción de restauración con un indicador normalizado para el análisis multicriterio que se muestra en el Cuadro 10).

Cuadro 10 Resumen de los resultados por cada indicador del análisis

\begin{tabular}{|c|c|c|c|}
\hline \multicolumn{2}{|l|}{ Indicador } & \multicolumn{2}{|c|}{ Acción de restauración } \\
\hline Desempeño más alto & & Desempeño más alto & Desempeño más bajo \\
\hline \multicolumn{4}{|l|}{ Indicadores financieros } \\
\hline \multirow[t]{3}{*}{ Indicador financiero ( $r=10 \%)$} & VAN marginal & Sistema agroforestal de cacao en café (cacao 1) & Restauración bosque de galería (en pasto natural) \\
\hline & $\mathrm{RBC}$ & Sistema agroforestal de cacao en café (cacao 1) & Restauración bosque de galería \\
\hline & $\mathrm{ROI}$ & Restauración de manglar & Restauración bosque de galería (en pasto natural) \\
\hline VAN marginal $(r=15 \%)$ & & Sistema agroforestal de cacao en café (cacao 1) & Restauración bosque de galería (en pasto natural) \\
\hline VAN marginal $(r=5 \%)$ & & Sistema agroforestal de cacao en café (cacao 1) & Restauración bosque de galería (en pasto natural) \\
\hline VAN marginal (escenario 'pesimista') & & Sistema silvopastoril & Restauración bosque de galería (en pasto natural) \\
\hline VAN marginal (escenario 'optimista') & & Renovación café de altura & Restauración bosque de galería (en pasto natural) \\
\hline \multicolumn{4}{|c|}{ Indicadores ambientales no espaciales } \\
\hline Balance de carbono & & Restauración de manglar & Sistema silvopastoril \\
\hline Conectividad & & Restauración de manglar y bosque de galería & Zafra verde en caña de azúcar \\
\hline Producción de leña & & Restauración de manglar & Restauración bosque de galería y zafra verde en caña de azúcar \\
\hline \multicolumn{4}{|l|}{ Indicadores ambientales espaciales } \\
\hline Impacto sobre la erosión & & $\begin{array}{l}\text { Sistema agroforestal de cacao en mosaico de cultivo, pasto y } \\
\text { vegetación (cacao 2) }\end{array}$ & Zafra verde en caña de azúcar \\
\hline Cambio exportación sedimentos & & Sistema agroforestal de cacao en café (cacao 1) & Zafra verde en caña de azúcar \\
\hline Cambio exportación nitrógeno y fósfor & & Restauración bosque de galería & Sistema agrosilvopastoril \\
\hline \multicolumn{4}{|l|}{ Indicadores sociales } \\
\hline Creación de empleo & & Zafra verde en caña de azúcar & Restauración bosque de galería (en caña de azúcar) \\
\hline Seguridad alimentaria & & Sistema agroforestal de granos básicos & Restauración bosque de galería \\
\hline Impacto sobre medios de vida & & $\begin{array}{l}\text { Sistema agroforestal de cacao en mosaico de cultivo, pasto y } \\
\text { vegetación (cacao 2) }\end{array}$ & Restauración bosque de galería (en pasto natural) \\
\hline
\end{tabular}





\section{Resultados análisis multicriterio}

Si se considera la puntuación en el análisis multicriterio de las acciones de restauración por tipo de criterio (Figura 18), destaca la implementación de los sistemas agroforestales de cacao. La implementación de estos sistemas tiene puntuaciones altas para los cuatro tipos de criterio.

El SAF de cacao en café tiene la puntuación más alta para el conjunto de criterios financieros y el conjunto de criterios sociales, mientras que el SAF de cacao en el mosaico de cultivos, pasto y vegetación tiene la puntuación más alta para el conjunto de criterios ambientales espaciales (servicios ecosistémicos). La excepción se da con el manglar que tiene la mayor puntuación para el indicador ambiental no espacial (carbono, conectividad y leña).

La restauración de bosque de galería tiene una puntuación alta (y positiva), tanto para el indicador ambiental, como para los servicios ecosistémicos espaciales. Al ser una acción de restauración con un enfoque de conservación no recibe una puntuación para el indicador de leña.

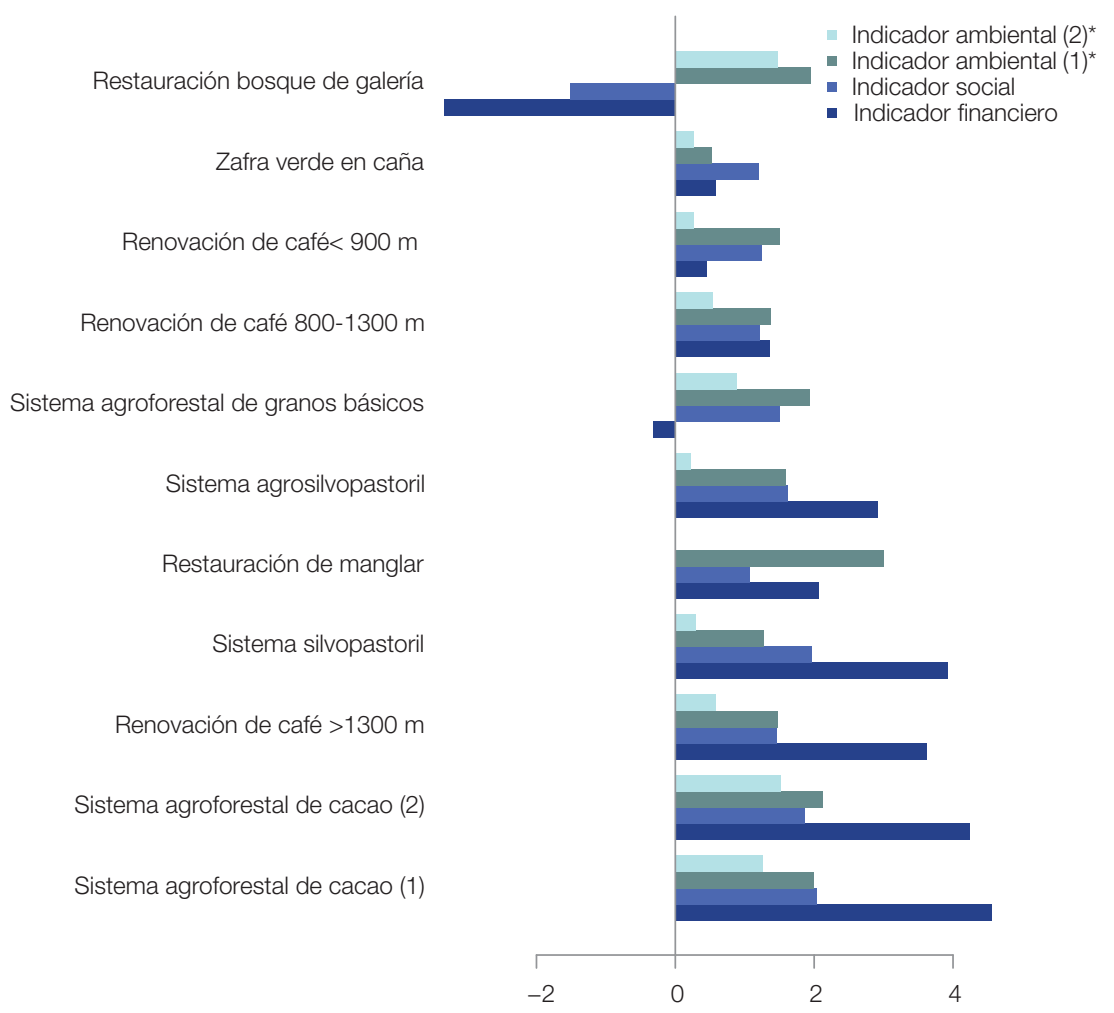

Figura 18 Indicadores del análisis multicriterio por tipo.

* (1) = indicador no espacial, (2) = indicador espacial. 
Como último paso de este análisis económico se suman todos los criterios del análisis para crear una clasificación general de las acciones de restauración consideradas.

Las acciones de restauración con mayor puntuación son la implementación de los SAF de cacao, seguido del sistema silvopastoril y la renovación de café de altura, tanto si se incluye el manglar (Indicador 1, Cuadro 11), como si no se incluye, debido a la incorporación de los servicios ecosistémicos modelados con InVEST (Indicador 2, Cuadro 11). Solo la restauración de bosque de galería tiene una puntuación negativa, pero mejora, si se incluye el impacto sobre la provisión de los servicios ecosistémicos modelados con InVEST.
El análisis multicriterio no solo muestra cuales acciones de restauración tienen, en general, el mayor impacto, sino que también señala que la priorización de las acciones dependerá del objetivo. Por ejemplo, un objetivo financiero prioriza un sistema agroforestal de cacao en café debajo de 900 m; un enfoque de creación de empleo prioriza la implementación de la zafra verde manual en caña; un enfoque de mejoramiento de la seguridad alimentaria prioriza los sistemas agroforestales de granos básicos, mientras que si se prioriza una disminución en los flujos de nutrientes, la restauración de bosque de galería sería en promedio la mejor opción.

Cuadro 11 Matriz de rendimiento de las acciones de restauración con (Indicador 1) y sin los indicadores ambientales espaciales (Indicador 2)

\begin{tabular}{|c|c|c|}
\hline Acciones de restauración & Indicador 1 & Indicador 2 \\
\hline Sistema agroforestal de cacao en café (cacao 1) & 8,61 & 9,86 \\
\hline Sistema agroforestal de cacao en mosaico de cultivo, pasto y vegetación (cacao 2) & 8,24 & 9,76 \\
\hline Sistema silvopastoril & 7,16 & 7,45 \\
\hline Renovación café de altura & 6,57 & 7,14 \\
\hline Restauración de manglar & 6,15 & / \\
\hline Sistema agrosilvopastoril & 6,12 & 6,34 \\
\hline Renovación del café de mediana altura & 3,95 & 4,49 \\
\hline Renovación del café de bajío & 3,19 & 3,45 \\
\hline Sistema agroforestal de granos básicos & 3,13 & 4,02 \\
\hline Zafra verde en caña & 2,29 & 2,55 \\
\hline Restauración bosque de galería & $-2,89$ & $-1,43$ \\
\hline
\end{tabular}




\section{Resumen resultado por acción de restauración}

La restauración de manglar es una acción con indicadores financieros de valores intermedios, es decir positivos, pero, en general, no con valores más altos. La excepción es el ROI donde el manglar tiene el valor más alto. La restauración de manglar se destaca sobre todo por el impacto positivo en los indicadores ambientales no espaciales considerados. Se confirma la capacidad del ecosistema de manglar como el mayor sumidero de carbono dentro de las acciones de restauración analizadas, en relación tanto con el paisaje forestal (Donato et al. 2011) como con el agrícola; adicionalmente, tiene un impacto muy positivo sobre la conectividad del paisaje (costero) y la producción de leña.

La restauración de bosque de galería no representa una rentabilidad financiera positiva por su enfoque hacia la conservación. A su vez, tiene un impacto negativo sobre los indicadores sociales. Algo que debe ser considerado a la hora de implementar esta restauración, es buscar mecanismos de pagos por las acciones de restauración y conservación, por ejemplo, compensaciones por servicios ecosistémicos. El desempeño positivo de la restauración de manglar en los indicadores ambientales (balance de carbono alto, mejora en la conectividad, reducción de la erosión y exportación de sedimentos, y reducción en la exportación de nitrógeno y fósforo) puede ayudar en el diseño de instrumentos de financiamiento para apoyar la restauración de bosque de galería, basados en estos impactos positivos.

La implementación de un SAF de granos básicos es rentable siempre y cuando se mantengan las condiciones favorables ${ }^{65}$ de producción y de mercado. Se vuelve más rentable que el uso actual del suelo, cuanto más valor se da a los beneficios futuros ( $r=10$ y $5 \%)$. Las razones sociales, sobre todo la importancia

65 Se entiende por condiciones favorables o desfavorables los niveles de precios y rendimientos históricos altos (véase sección metodológica). para la seguridad alimentaria de la producción de granos básicos, es una razón de peso para apoyar la implementación de SAF de granos básicos. No obstante, además de su sensibilidad a los costos de implementación, los precios y los rendimientos bajos, es clave considerar que la implementación de este sistema podría no cubrir todos los costos del total de la mano de obra familiar utilizada, si no se incluye apoyo e instrumentos financieros adecuados. Finalmente, se debe tomar en cuenta que, aunque es un sistema con un desempeño positivo en la mayoría de los indicadores ambientales considerados, un mejoramiento del sistema productivo puede llevar a una mayor exportación de nitrógeno y fósforo y su consecuente impacto negativo sobre la calidad del agua.

La implementación de sistemas silvopastoriles y agrosilvopastoriles tienen una alta rentabilidad financiera por su nivel de beneficios netos (marginales) generados a lo largo del periodo considerado. Con estos beneficios y con retornos a la inversión del $159 \%$ al $187 \%$, respectivamente, podrían ser buenos candidatos para recibir financiamiento desde sistemas bancarios nacionales. Además, no muestran una sensibilidad tan alta a los supuestos financieros utilizados como otros sistemas valorados. No obstante, no generan impactos significativos para la mitigación del cambio climático, y la intensificación propuesta incrementa, al igual que la implementación del SAF de granos básicos considerado, la exportación de nitrógeno y fósforo.

La adopción de la zafra verde en caña de azúcar es rentable, incluso bajo condiciones productivas y de mercado más desfavorables. ${ }^{66}$ Ofrece beneficios productivos a corto plazo y sigue siendo rentable cuando se asigna un mayor valor a los beneficios netos presentes ( $r=15 \%)$. Adicionalmente, es la acción de

66 Se entiende por condiciones favorables o desfavorables los niveles de precios y los rendimientos históricos bajos. 
restauración que más empleo crea por hectárea de terreno restaurado (0,48 empleo/ha/año) con un balance de carbono alto (70 $\mathrm{TCO}_{2} \mathrm{e} / \mathrm{ha}$ ), que impacta de forma positiva la provisión de los servicios ecosistémicos considerados. Sin embargo, no tiene incidencia alguna sobre otros indicadores (conectividad, producción de leña, y los indicadores intermedios de importancia para la agricultura de subsistencia, y la diversificación de la producción).

Como ya se mostró en el capítulo anterior, los sistemas agroforestales de cacao son las acciones de restauración que mayores beneficios generan, aunque en relación con las demás acciones de restauración analizadas, tiene un balance de GEI en la mitad superior de la clasificación, mientras que la creación marginal de empleo, se ubica en la mitad inferior de la clasificación. Por otra parte, la implementación de este sistema puede incrementar la exportación de los nutrientes analizados. Por ultimo, cabe mencionar que aunque es un sistema que, según este análisis, debe formar parte de los planes de restauración, un incremento muy alto en la producción de cacao puede tener un impacto sobre los precios si no es seguido por un incremento en la demanda. Estos efectos negativos potenciales no han sido considerados en este estudio. Esto podría disminuir el desempeño de los SAF de cacao en los indicadores financieros, por lo que los datos muy positivos deben ser interpretados con cierta cautela.

La renovación de cafetales ofrece resultados económicos distintos según la altura del área restaurada. La renovación de café de altura es rentable bajo todos los diferentes escenarios de tasa de descuento y condiciones de mercado. Sin embargo, la renovación de café de bajío ya no sería viable si se da mayor importancia a los beneficios netos presentes $(r=15 \%)$ o con condiciones productivas y de mercado adversas, mientras que el desempeño de la renovación de café de mediana altura se sitúa entre el desempeño de los otros dos. La renovación de cafetales crearía alrededor de 0,18 empleo/ ha adicionales y ofrecería un balance de GEI positivo (27 a 31 $\mathrm{TCO}_{2} \mathrm{e} / \mathrm{ha}$ ) al considerar meramente el incremento de carbono biológico, resultado de la reforestación de los cafetales. En general, la renovación de los cafetales debe ser considerada en los planes de restauración, aunque en el caso de café de bajío, se podría priorizar la sustitución de este cultivo por el cultivo de cacao bajo un SAF. 


\section{Conclusiones}

El presente estudio determinó los costos de implementación y beneficios esperados en las acciones de restauración como parte de la metodología ROAM. De la misma manera, se cuantificó el efecto que la restauración tendría sobre la producción de granos básicos, leche y carne que proveen la base de la dieta del país (Menchú et al. 2011). Al mismo tiempo, se determinaron las acciones de restauración sobre los recursos energéticos (leña) y la balanza comercial (producción de café, frutales y madera).

Las estimaciones de los costos y los beneficios de las acciones de restauración realizadas para el análisis financiero mostraron que la mayoría de las acciones son rentables, aunque algunas son susceptibles al cambio en la tasa de descuento, y a los precios y rendimientos bajos.

Con la ayuda de una herramienta reconocida se cuenta con estimaciones sobre el aporte de cada acción a la mitigación del cambio climático. Las acciones de restauración como restauración de mangle y bosque de galería son las acciones con el mejor desempeño de carbono. Existe otro grupo que se destaca por su alta rentabilidad por tonelada de $\mathrm{CO}_{2}$ reducido que abarca la expansión de SAF de cacao y la renovación de café de altura.

Se complementó la evaluación de los ingresos generados por aquellas acciones de restauración al valorar, de manera espacial el impacto sobre la provisión de servicios ecosistémicos.

La tasa de exportación marginal de sedimentos da elementos a los tomadores de decisión sobre cuáles técnicas son más apropiadas para conservar el suelo si se tiene en cuenta la diversidad climática y topográfica del país. Se podría traducir tanto a nivel de costo evitado de drenaje de ríos y estuarios (beneficio fuera del área restaurada) como en términos de conservación de la fertilidad del suelo a nivel de finca.
Las tasas de exportación de nitrógeno y fósforo indican el impacto de la restauración, en cuanto a la descarga de fosfato y nitrato en los recursos acuíferos, y en caso de un incremento, se debe proceder con cautela, sobre todo en áreas de captación de agua para consumo humano o en áreas de importancia para la biodiversidad acuática. Adicionalmente, se podría considerar incrementar la capacidad de retención de estos sistemas con la plantación de más cultivos o cambiar el sistema de aplicación de fertilizantes, aunque se debe recordar que esta decisión también puede influir en los valores de los otros indicadores señalados.

Los datos que se generaron, como parte de este estudio, aportan elementos para orientar las propuestas de financiamiento de los inversionistas privados (p. ej. con el ROI) y a tomadores de decisión para asignar fondos limitados hacia la restauración ambiental más eficaz por su retorno absoluto (VAN marginales), por su eficiencia (RBC), o por su impacto ambiental o social.

El análisis multicriterio no espacial arrojó una primera clasificación de las acciones de restauración. No obstante, a la hora de implementar las acciones de restauración en el campo, faltaría conectar el impacto en las áreas donde mayor efecto podrían tener, ya sea por nivel de desempleo según área, consumo de leña por municipio o la existencia de hidroeléctricas que podrían beneficiarse de una reducción en la sedimentación.

Este último paso facilitaría no solo clasificar las acciones de restauración, según su desempeñó en una serie de indicadores, sino que también permitiría identificar cuáles áreas son prioritarias para la restauración y con qué técnicas y acciones de restauración realizarlas, información de utilidad para los tomadores de decisiones y para la formulación del Plan de Acción de Restauración.

Finalmente, los datos generados con este análisis muestran estimaciones de impacto promedio a nivel nacional y sin 
considerar una serie de diferentes impactos potenciales (degradación del suelo, cambio climático, innovación tecnológica, entre otros) que pueden impactar los beneficios generados por los usos actuales del suelo o por las diferentes acciones de restauración. Durante la implementación de acciones de restauración, los modelos generados aquí deben ser adaptados a las circunstancias locales. Asimismo, los resultados arrojan una luz sobre los impactos potenciales de acciones de restauración que pueden ser refinados con la inclusión de datos sobre el impacto de la productividad en el futuro u otros aspectos ambientales, sociales o financieros que van a tener una influencia sobre los sistemas productivos en el futuro. 


\section{Bibliografía}

Aimin, H. 2010. Uncertainty, risk aversion and risk management in agriculture. Agriculture and Agricultural Science Procedia, 1, 152-156 http://dx.doi.org/10.1016/j. aaspro.2010.09.018

Banco Mundial, CIAT, CATIE. 2015. Climate-Smart Agriculture in El Salvador. CSA Profiles for Latin America Series. 2nd. Ed. Grupo del Banco Mundial, Washington D.C., EE.UU. Disponible en: http://sdwebx.worldbank.org/climateportal/documents/CLIMATE_SMART_SLV.pdf

Benavides L., García Campos, J. C. 2007. Evaluación del rendimiento económico de hatos lecheros con diferentes niveles de manejo en el departamento de San Miguel. Universidad de El Salvador, San Salvador, El Salvador.

Benitez, P.C., Kuosmanen, T., Olschewski, R., van Kooten, G.C. 2006. Conservation payments under risk: a stochastic dominance approach. American Journal of Agricultural Economics, 88 (1),1-15, http://dx.doi. org/10.1111/j.1467-8276.2006.00835.x

Bernoux, M., Branca, G., Carro, A., Lipper, L., Smith, G., Bockel, L. 2010. Ex-ante greenhouse gas balance of agriculture and forestry development programs. Scientia Agricola 67, p. 31-40. doi:10.1590/S0103-90162010000100005

Banco Mundial. 2016. Agricultura, valor agregado y \% del PIB [en línea]. Disponible en: http://datos.bancomundial.org/ indicador/NV.AGR.TOTL.ZS [2016, 25 de agosto].

Cordero y Boshier (eds). 2003. Árboles de Centro America. Un Manual para Extensionistas. Oxford Forestry Institute, Oxford, Reino Unido y CATIE, Turrialba, Costa Rica. Disponible en: http://orton.catie.ac.cr/repdoc/a11445e/ a11445e.pdf

Barry, D. 2012. Programa Nacional de Restauración de Ecosistemas y Paisajes (PREP): Esfuerzo Principal de Adaptación al Cambio Climático en El Salvador [en línea].
Disponible en: http://www.marn.gob.sv/descarga/programa-nacional-de-restauracion-de-ecosistemas-y-paisajes-documento-conceptual/?wpdmdl=16146 [2016, 5 de mayo].

Berrizbeitia L., Castro de Doens L. 2014. Índice de vulnerabilidad y adaptación al cambio climático en la región de América Latina y el Caribe. Corporación Andina de Fomento, Caracas, Venezuela.

Bockel, L., Sutter, P., Touchemoulin, O. y Jönsson, M. 2012. Using Marginal Abatement Cost Curves to Realize the Economic Appraisal of Climate Smart Agriculture Policy Options. EASYPol Series 116. FAO, Roma, Italia. Disponible en: http://www.fao.org/3/a-bq866e.pdf

CAF. 2014. Índice de vulnerabilidad y adaptación al cambio climático en la región de América Latina y el Caribe. Caracas: CAF. Recuperado de http://scioteca.caf.com/ handle/123456789/517.

BCR. 2016. Producto Interno Bruto (PIB) por Rama de Actividad Económica. A precios constantes de 1990 millones de dólares [en línea]. Disponible en: http://www.bcr.gob. sv/bcrsite/?cdr=30 [2016, 25 de agosto].

Campanale, M. 2014. Chapter Two: Exploring characteristics of existing forestry investment vehicles. En: The Forest Investment Review. Forum for the Future, Londres, Reino Unido.

Campos, J., Serebrisky, T., Suárez. 2016. Tasa de descuento social y evaluación de proyectos: algunas reflexiones prácticas para América Latina y el Caribe [en línea]. Disponible en: https://publications.iadb.org/bitstream/ handle/11319/7416/Monografia\%20Tasa\%20de\%20 descuento\%20social\%20y\%20Evaluacion\%20de\%20 proyectos.pdf?sequence $=1$ \&isAllowed $=y$ 
Casen, S., Romero, E., Fernanda, L., Bugeau, T., Perez, D., Paredes, V., Fejiio, E. 2016. Manejo de los residuos agrícolas de la cosecha de caña de azúcar: disponibilidad potencial y alternativas de enfardado. Estación Experimental Agroindustrial Obispo Colombres, Tucumán, Argentina.

CDB (Convenio sobre la Diversidad Biológica). (2010) Metas de Aichi para la diversidad biológica.

Disponible en: https://www.cbd.int/sp/targets/. [2017, 16 de junio].

CDB (Convenio sobre la Diversidad Biológica). 2012. UNEP/ CBD/COP Decision XI/16. Ecosystem Restoration. Disponible en: http://www.cbd.int/doc/decisions/cop-11/ cop-11-dec-16-en.pdf. [2017, 16 de junio].

CEPAL y CAC/SICA (Consejo Agropecuario Centroamericano del Sistema de la Integración Centroamericano). 2014. Impactos potenciales del cambio climático sobre el café en Centroamérica, LC/MEX/L.1169. Sede Subregional de la CEPAL en México, México, D.F.

Chacón M. y Harvey, C.A. 2013. Reservas de Biomasa de Árboles Dispersos en Potreros y Mitigación al Cambio Climático. Agronomía Mesoamericana 24 (1), 17-26

Cifuentes, M. y Rivera, C. 2016. Carbono azul en El Salvador, Programa Regional del Cambio Climático del USAID. Presentación no publicada.

Clenaghan, S., Morenos, J.L. y Thomas, A. 2014. Chapter Three: Stimulating private capital investment to achieve REDD+. pp. 73-94. En: The Forest Investment Review. Forum for the Future, Londres, Reino Unido.

Conant, R.T. y Paustian, K. 2002. Potential soil carbon sequestration in overgrazed grassland ecosystems. Global Biogeochemical Cycles, 16 (4), 90-1-90-9. doi:10.1029/2001GB001661

Consejo Nacional de Salario Mínimo. 2016. "Tarifas de salarios mínimos vigentes a partir del 1 de enero 2015”. Diario Oficial $n^{\circ}$ 119, Tomo 400 del 1 de julio 2013 [en línea]. Ministerio de Trabajo y Previsión Social, San Salvador, El Salvador.

CONSAA, 2016, informe final de producción zafra 2015-2016, Consejo Salvadoreño de la Agroindustria azucarera. Disponible en : www.consaa.gob.sv/informe-final-deproduccion-zafra-2015-2016/, San Salvador El Salvador

CSC. 2014. Consejo Salvadoreño del café, producción y empleo, Departamento de estudios económicos y estadísticas cafetaleras, San Salvador, El Salvador. Disponible en: http://www.csc.gob.sv/descargas/
Cubbage, F., Davis, R., Frey, G. 2011. Guía para la evaluación económica y financiera de proyectos forestales comunitarios en México. Washington D.C.: Banco Mundial Región de Latinoamérica y el Caribe.

DEA (División de Estadísticas Agrícolas). 2015. Anuario de Estadísticas Agropecuarias 2014-2015 y precios de mercado, encuesta nacional agropecuario de propósitos múltiples, octubre 2015, DEA, Ministerio de Agricultura y Ganadería, San Salvador, El Salvador

de Figueiredo, E.B., Panosso, A.R., Romão, R. y La Scala Jr., N. 2010. Greenhouse gas emission associated with sugar production in southern Brazil. Carbon Balance and Management, 5 (3) https://doi.org/10.1186/1750-0680-5-3

Department for Communities and Local Government. 2009. Multi-criteria analysis: a manual. Communities and Local Government Publications, Wetherby, West Yorkshire, Reino Unido. Disponible en: https://www.gov.uk/government/uploads/system/uploads/attachment_data/ file/7612/1132618.pdf

DG REGIO (Dirección General de Política Regional y Urbana, Comisión Europea). Guide to Cost-Benefit Analysis of Investment Projects. Economic appraisal tool for Cohesion Policy 2014-2020. Oficina de Publicaciones de la Unión Europea, Luxemburgo. Disponible en: http:// ec.europa.eu/regional_policy/sources/docgener/studies/pdf/cba_guide.pdf

DIGESTYC (Dirección General de Estadística y Censos). 2008a. IV censo agropecuario 2007-2008, resumen de resultados. MINEC-DIGESTYC, San Salvador, El Salvador. Disponible en: http://www.fao.org/fileadmin/templates/ ess/ess_test_folder/World_Census_Agriculture/Country_info_2010/Reports/ESV_SPA_RES.REP_2008.pdf

DIGESTYC (Dirección General de Estadística y Censos). 2008b. VI censo de población y V de vivienda 2007. MINECDIGESTYC, San Salvador, El Salvador. Disponible en: http://www.digestyc.gob.sv/index.php/temas/des/poblacion-y-estadisticas-demograficas/censo-de-poblacion-y-vivienda/poblacion-censos.html

DIGESTYC (Dirección General de Estadística y Censos). (2015) Encuesta de Hogares de Propósitos Múltiples 2014. MINEC-DIGESTYC, San Salvador, El Salvador

de Groot, R., Brander, L., van der Ploeg, S., Costanza, R., Bernard, F., Braat, L., Christie, M., Crossman, N., Ghermandi, A., Hein, L., Hussain, S., Kumar, P., McVittie, A., Portela, R., Rodriguez, L.C., ten Brink, P., van Beukering, P. 2012. Global estimates of the value of ecosystems and their services in monetary units. Ecosystem Services 1, 50-61. doi:10.1016/j.ecoser.2012.07.005. 
Donato, D.C., Kauffman, J.B., Murdiyarso, D., Kurnianto, S., Stidham, M., Kanninen, M. 2011. Mangroves among the most carbon-rich forests in the tropics. Nature Geosci 4, 293-297. doi:10.1038/ngeo1123.

FAO. 2013. Planning, implementing and evaluating ClimateSmart Agriculture in Smallholder.

Farming Systems. The experience of the MICCA pilot projects in Kenya and the United Republic of Tanzania. FAO, Roma. Disponible en: http://www.fao.org/3/a-i5805e.pdf

FAO. 2014. Manual de directrices de uso y herramienta EX ACT [en línea]. Disponible en: http://www.fao.org/tc/exact/ ex-act-herramienta/es/

FAO \& Global Mechanism of the UNCCD. 2015. Sustainable financing for forest and landscape restoration: Opportunities, challenges and the way forward. Discussion paper. Roma.

FAOSTAT. 2016. FAOSTAT base de datos [en línea]. Disponible en: http://www.fao.org/faostat/en/ [2016, 15 de junio y 25 de agosto].

Flores, M., Bratescu, A., Martínez, J.O., Oviedo, J.A., Acosta, A. (Eds.). 2002. Centroamérica: el impacto de la caída de los precios del café, Serie estudios y perspectivas. México, D. F.: CEPAL.

Favretto, N., Stringer, L.C., Dougill, A.J., Dallimer, M., Perkins, J.S., Reed, M.S., Atlopheng, J.R. y Mulale, K. 2016. MultiCriteria Decision Analysis to identify dryland ecosystem service trade-offs under different rangeland land uses. Ecosystem Services, 17, 142-151

FIAES. 2011. Restauración de manglares: desafío para la adaptación al cambio climático - memoria-de-Foro-Restauración de Manglares. Disponible en: http://www.fiaes.org. sv/library/memoria-de-Foro-RestauraciondeManglares. pdf

Fonseca, F.; Nello, T.; Raes, L.; Sanchún, A.; Saborio, J. y Chacón, O. (2018a). Zafra verde en caña de azúcar. Serie de guías técnicas para la restauración en El Salvador, 1. UICN-ORMACC, San José, Costa Rica

Fonseca, F.; Nello, T.; Raes, L.; Sanchún, A.; Saborío, J. y Chacón, O. (2018b). Renovación de cafetales. Serie de guías técnicas para la restauración en El Salvador, 2. UICNORMACC, San José, Costa Rica

FUSADES. 2007. Estado Situacional del Medio Ambiente y Recursos Naturales de El Salvador. Estudio Técnico N¹: Gobernabilidad Ambiental para el Desarrollo Sostenible de El Salvador. FUSADES, San Salvador, El Salvador.

Galdos, M.V., Cerri, C.C., y Cerri, C.E.P. 2009. Soil carbon stocks under burned and unburned sugarcane in Brazil. Geoderma 153, 347-352. doi:10.1016/j. geoderma.2009.08.025

GCF. 2014. Investment framework, GCF/B.07/06, p. 13, [en línea]. Disponible en: https://www.greenclimate.fund/ documents/20182/24943/GCF_B.07_06_-_Investment_Framework.pdf/dfc2ffe0-abd2-43e0-ac3474f3b69764c0. [2016, 30 de julio].

Ghile Y. 2016. Invest 2.2.1 Nutrient retention model [en línea]. Woods Institute for the environment Stanford University, The Nature Conservancy, Natural Capital Project. Disponible en: http://data.naturalcapitalproject.org/training_feb2012_stanford/InVEST_Nutrient\%20model.pdf

GOES. 2012a. Política nacional del medio ambiente, aprobado por el consejo de ministro el 30 de marzo 2012. GOES, San Salvador, El Salvador.

GOES. 2012b. FOMILENIO II. Evaluación Ambiental Estratégica. Informe $n^{\circ} 2$, Expoloración de alternativas, pesca, agroforestería y turismo, sobre la base de restauración de y aprovechamiento inclusivo de los ecosistemas y recursos costero marinos. GOES, San Salvador, El Salvador.

Gollier, C. 2002. Discounting an uncertain future. Journal of Public Economics, 85 (2), 149-166.

Gutiérrez, F. 2014. El manejo orgánico del cultivo de maíz y frijol, costos de producción ganancias y costos indirectos de esta tecnología. CORDES, San Salvador, El Salvador.

Hamilton, K., Bayon, R., Turner, G., Higgins, D. 2016. State of the voluntary carbon markets 2016. Picking up steam. Forest Trends, Washington, D. C., EE. UU.

Hughes T., Acosta J., Lochhead J., Producción a gran escala de caña de azúcar en El Salvador, Movimiento de agricultura orgánica de El Salvador, San Salvador, El Salvador

Pancel, L. 2016. "Desafío de Bonn, Latinoamérica 2016" (Memoria de taller) [en línea]. REDD+ Landscape/CCAD, San Salvador, El Salvador. Disponible en: Memoria-Desafiode-Bonn-Latinoamerica-2016b.pdf

IICA. 2011. Caracterización de la cadena de lácteo -El SalvadorMAG/CENTA/. IICA, San Salvador, El Salvador.

IPBES (Intergovernmental Platform on Biodiversity and Ecosystem Services). 2013. Deliverable 3(b)(i): Thematic assessment on land degradation and restoration. Disponible en: http://ipbes.net/work-programme/objective-3/45-work-programme/459-deliverable-3bi.html

James, D. y Predo, C. 2015. Principles and Practice of CostBenefit Analysis. pp 11-46. En: James, D. y Francisco, H.A. (eds.). Cost-Benefit Studies of Natural Resource Management in Southeast Asia. Springer Singapore, Singapore. 
Kaonga, M.L. y Bayliss-Smith, T.P. 2009. Carbon pools in tree biomass and the soil in improved fallows in eastern Zambia. Agroforestry Systems, 76, 37-51. doi:10.1007/ s10457-008-9185-7

Kovacs, K., Polasky, S., Nelson, E., Keeler, B.L., Pennington, D., Plantinga, A.J. y Taff, S.J. 2013. Evaluating the Return in Ecosystem Services from Investment in Public Land Acquisitions. PLoS ONE 8(6): e62202. doi:10.1371/journal.pone.0062202

Knoke, T., Weber, M., Barkmann, J., Pohle, P., Calvas, B., Medina, C., Aguirre, N.,Günter, S., Stimm, B., Mosandl, R., von Walter, F., Maza, B., y Gerique, A. 2009.Effectiveness and distributional impacts of payments for reduced carbonemissions from. ERDKUNDE 63, 365-384, http:// dx.doi.org/10.3112/erdkunde.2009.04.06.

Knoke, T. y Wurm, J. 2006. Mixed forests and a flexible harvest strategy: a problem for conventional risk analysis? In: European Journal of Forest Research 125, 303-315. Doi:10.1007/s10342-006-0119-5

Lefèvre, C., Rekik, F., Viridiana, A., Liesl, W. 2017. Soil Organic Carbon: the hidden potential, LiesI W., Viridiana A., Rainer B., Ronald V. ed. FAO, Roma, Italia.

Lewis, R.R. III. 1999. Key concepts in successful ecological restoration of mangrove forests. Páginas 11-32 en "proceeding of the TCE workshop Noll, coastal environmental improvements in mangrove/wetland ecosystem, 18-23 August 1998, Danish SE-Asian Collaboration in tropical costal ecosystems Research and Training Bangkok, Thailand. Disponible en: http://www.mangroverestoration.com/pdfs/Lewis\%201999\%20TCE.pdf

Lin, J. 2004. Review of published export coefficient and event mean concentration (EMC) data, WRAP Technical Notes Collection (ERDC TN-WRAP-04-3). Vicksburg, MS.

MAG (Ministerio de Agricultura y Ganadería). 2003. Diagnostico de los recursos zoo genéticos en El Salvador, Oficina de políticas y estrategias del MAG, San Salvador, El Salvador.

MAG (Ministerio de Agricultura y Ganadería). 2011. Caracterización de la cadena productiva de El Salvador. MAG, San Salvador, El Salvador.

MAG (Ministerio de Agricultura y Ganadería). 2016a. Anuarios de estadísticas agropecuarias [en línea]. Disponible en: http://www.mag.gob.sv/direccion-general-de-economia-agropecuaria/estadisticas-agropecuarias/anuariosde-estadisticas-agropecuarias/ [2016, 14 de mayo].

MAG (Ministerio de Agricultura y Ganadería). 2016b. Informe anual sobre costos de producción de cultivos agrícolas [en línea]. Disponible en: http://www.mag.gob. sv/direccion-general-de-economia-agropecuaria/estadisticas-agropecuarias/informe-anual-sobre-costos-deproduccion-de-cultivos-agricolas/ [2016, 10 de junio].

Markandya, A., Perelet, R., Mason, P. y Taylor, T. 2001. Dictionary of Environmental Economics. Earthscan, Londres Reino Unido.

MARN (Ministerio de Medio Ambiente y Recursos Naturales). 2002. Informe Inicial Prediagnóstico: Plan Nacional de Ordenamiento y Desarrollo Territorial. MARN, San Salvador, El Salvador.

MARN (Ministerio de Medio Ambiente y Recursos Naturales). 2013. Segunda Comunicación Nacional sobre Cambio Climático. MARN, San Salvador, El Salvador.

MARN (Ministerio de Medio Ambiente y Recursos Naturales). 2014. Quinto Informe Nacional para el Convenio sobre la Diversidad Biológica. MARN, San Salvador, El Salvador.

MARN (Ministerio de Medio Ambiente y Recursos Naturales). 2016. Hacía la restauración y reforestación de ecosistemas y paisajes. MARN, San Salvador, El Salvador.

Martínez-Paz, J.M., Perni, A. y Martínez-Carrasco, F. 2013. Assessment of the Programme of Measures for Coastal Lagoon Environmental Restoration Using Cost-Benefit Analysis. European Planning Studies, 21 (2), 131-148

McCarthy, R., Najera, M. y Raes, L. (2017). Fortaleciendo la estrategia nacional de restauración. MARN El Salvador y UICN. Disponible en: https://www.iucn.org/sites/dev/ files/content/documents/2017/fortaleciendo_la_estrategia_nacional_de_restauracion.uv_.pdf

Mathier, D., Saleme, P., Bragachini, M., Sánchez, F., Mendez, J., 2013. La caña de azucar como cultivo energético. Ministerio de Agricultura, pesca y ganadería, Tucumán, Argentina.

MINEC (Ministerio de Economía). 2016. Encuesta Nacional de hogares de propósitos múltiples [en línea]. Disponible en: http://www.digestyc.gob.sv/index.php/temas/des/ ehpm/publicaciones-ehpm.html [2016, 20 de mayo].

Menchú M., Méndez, H. 2011. El Salvador. Análisis de situación alimentaria Guatemala, INCAP. Disponible en: http:// www.mdgfund.org/sites/default/files/ISAN_ESTUDIO_ El\%20Salvador_Analisis\%20Situacion\%20AlimentariaINCAP.pdf\#page =2

Morris, K.S., Mendez, E. y Olson, M.B. 2013. 'Los meses flacos': seasonal food insecurity in a Salvadoran organic coffee cooperative. The Journal of Peasant Studies, 40 (2), 423-446, http://dx.doi.org/10.1080/03066150.2013. 777708 
Nello, T.; Fonseca, F.; Raes, L.; Sanchún, A.; Saborío, J. y Chacón, O. (2018a). Restauración de manglar y bosque de galería. Serie de guías técnicas para la restauración en El Salvador, 6. UICN-ORMACC, San José, Costa Rica.

Nello, T.; Fonseca, F.; Raes, L.; Sanchún, A.; Saborío, J. y Chacón, O. (2018b). Sistemas agroforestales de granos básicos. Serie de guías técnicas para la restauración en El Salvador, 5. UICN-ORMACC, San José, Costa Rica.

Nello, T.; Fonseca, F.; Raes, L.; Sanchún, A.; Saborío, J. y Chacón, O. (2018c). Sistema silvopastoril y agrosilvopastoril. Serie de guías técnicas para la restauración en El Salvador, 3. UICN-ORMACC, San José, Costa Rica.

Nello, T.; Fonseca, F.; Raes, L.; Sanchún, A.; Saborío, J. y Chacón, O. (201bd). Sistemas agroforestales de cacao. Serie de guías técnicas para la restauración en El Salvador, 4. UICN-ORMACC, San José, Costa Rica.

Noleppa, S. 2013. Economic approaches for assessing climate change adaptation options under uncertainty. Excel tools for Cost-Benefit and Multi-Criteria Analysis. Deutsche Gesellschaft für Internationale Zusammenarbeit (GIZ) GmbH, Eschborn, Alemania. Disponible en: http:// www.adaptationcommunity.net/?wpfb_dl=144

OLADE (Organización Latinoamericana de Energía). 2013. Uso racional y sostenible de la leña en los países de SICA. OLADE, Quito, Ecuador. Disponible en: http://www.olade.org/wp-content/uploads/2015/08/ UsoLe\%C3\%B1a_OLADE-SICA-2013.pdf

PAHO (Organización Panamericana de Salud. (2012). El Salvador. Disponible en: http://www2.paho.org/hq/index. php?option=com_docman\&task=doc_view\&ltemid=270 \&gid=33591\&lang=es

Pérez Trejo, C.A. 2013. El Salvador: análisis de sostenibilidad fiscal. Fundación Nacional para el Desarrollo. consultado en línea el 31 de julio 2016: http://www.repo.funde. org/id/eprint/571.

Payton, M.E., Greenstone, M.H. y Schenker, N. 2003. Overlapping confidence intervals or standard error intervals: What do they mean in terms of statistical significance? Journal of Insect Science, 3 (34).

PNUD y FAO. 2016. Cuaderno sobre Desarrollo Humano N. 12. Seguridad alimentaria y nutricional: camino hacia el desarrollo humano. PNUD y FAO, San Salvador, El Salvador. Disponible en: http://www.sv.undp.org/content/ el_salvador/es/home/library/hiv_aids/seguridad-alimentaria-y-nutricional--camino-hacia-el-desarrollo-.html

Pendleton, L., Donato, D.C., Murray, B.C., Crooks, S., Jenkins, W.A., Sifleet, S., Craft, C., Fourqurean, J.W., Kauffman,
J.B., Marbà, N., Megonigal, P., Pidgeon, E., Herr, D., Gordon, D. y Baldera, A. 2012. Estimating Global "Blue Carbon" Emissions from Conversion and Degradation of Vegetated Coastal Ecosystems. PLoS ONE 7, e43542. doi:10.1371/journal.pone.0043542

PRISMA. 2015. Mitigación basada en Adaptación: Enfrentando el cambio climático en El Salvador y Centroamérica. PRISMA, San Salvador, El Salvador.

PROCAFÉ. 2010. Manual Técnica Drench 70 [en línea]. Disponible en: https://www.yumpu.com/es/document/ view/14833083/tecnica-drench-70-procafe-fundacionsalvadorena-para-la- [2016, 5 de julio].

Pirard, R. 2008. Estimating opportunity costs of Avoided Deforestation (REDD): application of a flexible stepwise approach to the Indonesian pulp sector. International Forestry Review, 10 (3), 512-522.

PROCAFÉ. 2014. Diagnóstico de la Caficultura de El Salvador 2014. PROCAFÉ, San Salvador, El Salvador.

República de El Salvador, Constitución Política de la República, Républica de El Salvador, decreto $n^{\circ}$ 852, Diario Oficial $n^{\circ} 110$, tomo n³5, ultima modificación el 20/04/2012.

Rivera, G. 2013. Manejo pesquero sostenible de Ucides occidentalis ("punche"), recurso hidrobiológico de la cuenca baja del Río Lempa, Bahía de Jiquilisco, departamento de Usulután. Universidad de El Salvador, San Salvador, El Salvador.

Rivera, C. y Córdoba, D. 2010. Ecología alimentaria de Ucides occidentalis del Sector Occidental de la Bahía Jiquilisco. En: Rivera, C. y Cuéllar, T. (eds). El ecosistema de manglar de la Bahíade Jiquilisco (Sector Occidental). FIAES, San Salvador, El Salvador.

Sermeño. 2009. Análisis de la cobertura forestal de El Salvador mediante imágenes Corine Land Cover.

Sanchún, A., Botero, R., Morera Beita, A., Obando, G., Russo, R.O., Scholz, C. y Spinola, M.2016. Restauración funcional del paisaje rural: manual de técnicas. UICN, San José, Costa Rica. Disponible en: https://portals.iucn. org/library/sites/library/files/documents/ST-GFE-no.03. pdf

Sappal, S.M., Ranjan, P. y Ramanathan, A. 2016. Blue Carbon Ecosystems and Their Role in Climate Change Mitigation-An Overview. Journal of Climate Change, 2 (2), 1-13.

Sharp, R., Tallis, H.T., Ricketts, T., Guerry, A.D., Wood, S.A., Chaplin-Kramer, R., Nelson, E., Ennaanay, D., Wolny, S., Olwero, N., Vigerstol, K., Pennington, D., Mendoza, G., Aukema, J., Foster, J., Forrest, J., Cameron, D., Arkema, K., Lonsdorf, E., Kennedy, C., Verutes, G., Kim, C.K., Guannel, 
G., Papenfus, M., Toft, J., Marsik, M., Bernhardt, J., Griffin, R., Glowinski, K., Chaumont, N., Perelman, A., Lacayo, M. Mandle, L., Hamel, P., Vogl, A.L., Rogers, L., Bierbower, W., Denu, D., and Douglass, J. 2016. InVEST +VERSION+ User's Guide. The Natural Capital Project, Stanford University, University of Minnesota, The Nature Conservancy, and World Wildlife Fund. Disponible en: http://data.naturalcapitalproject.org/nightly-build/invest-users-guide/html/

Smith, P., M. Bustamante, H. Ahammad, H. Clark, H. Dong, E.A. Elsiddig, H. Haberl, R. Harper, J. House, M. Jafari, O. Masera, C. Mbow, N.H. Ravindranath, C.W. Rice, C. Robledo Abad, A.

Romanovskaya, F. Sperling, and F. Tubiello. 2014. Climate Change 2014: Mitigation of Climate Change. Contribution of Working Group III to the Fifth Assessment Report of the Intergovernmental Panel on Climate Change C. Cambridge University Press, Cambridge, United Kingdom and New York, NY, USA., pp. 827-842.

Solís, D., Bravo-Ureta, B.E. y Quiroga, R. E. 2007. Soil conservation and technical efficiency among hillside farmers in Central America: a switching regression model. The Australian Journal of Agricultural and Resource Economics, 51 (4), 491-510 DOI: 10.1111/j.1467-8489.2007.00394.x

Somarriba, E., Cerda, R., Orozco, L., Cifuentes, M., Dávila, H., Espin, T., Mavisoy, H., Ávila, G., Alvarado, E., Poveda, V., Astorga, C., Say, E. y Deheuvels, O. 2013. Carbon stocks and cocoa yields in agroforestry systems of Central America. Agric. Ecosyst. Environ. 173, 46-57. doi:10.1016/j.agee.2013.04.013

Trejos, S.A. 2011. Cobertura y uso de la tierra en el ecosistema de mangle y zona ecotonal del corredor del mangle, desde la bahía de Jiquilisco, El Salvador, hasta el estero padre ramos, Jiquilillo, Nicaragua. Revista Geográfica de América Central, 2 (47E), 1-19

Tubiello, F.N., Cóndor-Golec, R.D., Salvatore, M., Piersante, A., Federici, S. 2015. Estimating greenhouse gas emissions in agriculture a manual to address data requirements for developing countries. FAO, Roma, Italy.

UICN. 2017. Informe de consultoría del análisis de mecanismos de financiamiento para la restauración de paisajes productivos en El Salvador. Informe de uso interno, no publicado.

UICN y WRI. 2014. Guía sobre la Metodología de evaluación de oportunidades de restauración (ROAM): Evaluación de las oportunidades de restauración del paisaje forestal a nivel nacional o subnacional. Documento de trabajo (edición de prueba). Gland, Suiza: UICN. 125 pp.
UICN y MARN. 2015. Clasificación de uso de suelo con base en imágenes Rapideyes de 2014 de El Salvador. Mapa en shapefile.

UNIQUE. 2016. Estimation of REDD+ cost elements. User Manual for the REDD+ cost elements assessment tool. Banco Mundial, Wahsington D. C., EE. UU.

Verdone, M. 2015. A cost-benefit framework for analyzing forest landscape restoration decisions. UICN, Gland, Suiza.

Vergara, W., Gallardo Lomeli, L., R. Rios, A., Isbel, P., Prager, S., De Camino, R. 2016. The Economic Case for Landscape Restoration in Latin America. Washington D. C, pp. 46-50.

Vigiak, O., Borselli, L., Newham, L.T.H., Mcinnes, J., Roberts, A.M. 2012. "Comparison of conceptual landscape metrics to define hillslope-scale sediment delivery ratio". Geomorphology 138, pp. 74-88.

Vogl, A.L., Dennedy-Frank, P. J., Wolny, S., Johnson, J.A., Hamel, P., Narain, U. y Vaidya, A. 2016. Managing forest ecosystem services for hydropower production. Environmental Science \& Policy, 61, 221-229

Watson, R., Noble, I. y Bolin, B. 2000. IPCC - Special report Land use, land use change and forestry [WWW Document]. URL https://www.ipcc.ch/pdf/special-reports/ spm/srl-en.pdf [2017, 22 de junio]

White, D., Peter, M., Meine, van N. 2011. Estimación de los costos de oportunidad de REDD+. Manual de capacitación. World Bank Institute, Washington D. C., EEUU.

WorldClim. 2016. WorldClim Version 1. [2016, 15 de noviembre] WorldClim. 2017. WorldClim Version 1. [2017, 20 de marzo].

Wunder, S., Engel, S. y Pagiola, S. 2008. Taking stock: A comparative analysis of payments for environmental services programs in developed and developing countries. Ecological Economics, 65 (4), 834-852.

Yin D. y Meyer S., 2016. Impact Investors Find Value in Smallholder Agriculture. Conservation Finance Network, Disponible en: http://www.conservationfinancenetwork.org/2016/01/18/ impact-investors-find-value-in-smallholder-agriculture

Zhou, Z., Sun, O.J., Huang, J., Li, L., Liu, P. y Han, X. 2007. Soil carbon and nitrogen stores and storage potential as affected by land-use in an agro-pastoral ecotone of northern China. Biogeochemistry 82, 12-138. doi:10.1007/ s10533-006-9058-y 


\section{Anexo}

\section{Anexo 1 Detalles costos de asistencia técnica}

Un supuesto de particular importancia, a la hora de la ampliación del programa de restauración a nivel nacional, es el área que posee cada productor (Cuadro A1) ya que los gastos se calculan conforme a este parámetro (véase costos de asistencia técnica). ${ }^{67}$

Cuadro A1 Área promedio por tipo de productor

\begin{tabular}{lc} 
Uso actual del suelo & Área promedio (ha) \\
Granos básicos & 1,4 \\
\hline Café, cacao & 3,0 \\
\hline Ganadería & 4,0 \\
\hline Caña & 27,0 \\
\hline
\end{tabular}

Fuentes: Elaboración propia a partir de DIGESTYC 2008, CSC 2014, CONSAA 2016.

\section{Gastos indirectos contemplados para la asistencia técnica}

Visita de las fincas para la selección del sitio: según el tamaño de la finca del productor se asume un promedio de dos a tres parcelas visitadas por día. ${ }^{68}$ Cada viático incluye US\$10 que se paga a los/las promotores encargados de las escuelas de campo comunitarias. ${ }^{69}$ Estas visitas pueden representar, por cada promotor(a), entre 10 y 50 jornales por año. Se incluirán

67 En otros términos, los gastos de transferencia de tecnología se incrementan en la medida en que los productores tengan fincas más pequeñas (Molenaar et al., 2010).

68 Comunicación personal de Amaya, G., director de la Alianza Cacao, septiembre 21 de 2016.

69 Comunicación personal de Morrales, I., de la Fundación para el Desarrollo Socioeconómico y Restauración Ambiental. giras para la selección del sitio y la planificación para las áreas que cubre cada escuela de campo.

Mantenimiento de la parcela demostrativa: se pagará a cada promotor(a) un salario de 500 dólares mensuales por administrar la escuela de campo, en promedio puede atender a 25 productores. ${ }^{70}$ Además de reportar las necesidades técnicas y sistematizar la información sobre el rendimiento, la aplicación e incidencia de plagas en la parcela demostrativa que él/ella administra, el productor/

la productora facilita espacios de investigación participativa a través de los días de campo.

Días de campo: dos veces al año cada escuela de campo da a conocer las técnicas de manejo, según las necesidades y las condiciones locales. Se asume que pueden participar hasta 25 productores por taller, quienes traerán los insumos para el establecimiento de las obras de manejo que caracterizan cada acción de restauración. Se privilegiará este método de aprendizaje participativo frente a los modelos de extensión verticales donde los técnicos sirven de vector de transmisión entre el mundo científico y los productores (Faure 2007).

\section{Bibliografía}

CONSAA, 2016, informe final de producción zafra 2015-2016, Consejo Salvadoreño de la Agroindustria azucarera, disponible en: www.consaa.gob.sv/informe-final-deproduccion-zafra-2015-2016/, San Salvador El Salvador

CSC, 2014, Consejo Salvadoreño del café, producción y empleo, Departamento de estudios económicos y

70 Comunicación personal con el equipo técnico de la mancomunidad de La Montañona durante la gira de campo, septiembre 20 de 2016. 
estadísticas cafetaleras, San Salvador, El Salvador, disponible en: http://www.csc.gob.sv/descargas/

DIGESTYC (Dirección General de Estadística y Censos). 2008. IV censo agropecuario 2007-2008, resumen de resultados. MINEC-DIGESTYC, San Salvador, El Salvador. disponible en: http://www.fao.org/fileadmin/templates/ ess/ess_test_folder/World_Census_Agriculture/Country_info_2010/Reports/ESV_SPA_RES.REP_2008.pdf
Faure G. 2007. L'exploitation agricole dans un environnement changeant: innovation, l'aide à la décision et processus d'accompagnement. Economies et finances. Université de Bourgogne, Francia.

Molenaar, J.M., Orth, M., Lord, S., Meekers, P., Taylor, C., Alsy Hanu, M.D., Elson, D. y Ginting, T. 2010. Analysis of the agronomic and institutional constraints to smallholder yield improvement in Indonesia. 2010, Aidenvironment, Amsterdam y Global Sustainability Associates, Singapore. 


\section{Anexo 2 Base cálculo Ex Act}

Cuadro A2.1 Supuestos utilizados para parametrizar Ex Act (1)

\begin{tabular}{|c|c|c|c|c|}
\hline Uso del suelo & $\begin{array}{c}\text { Práctica } \\
\text { de línea base }\end{array}$ & Escenario sin restauración & Escenario con restauración & Fuente \\
\hline Bosque de galería & $\begin{array}{l}\text { Uso del suelo agrícola, en su mayoría gra- } \\
\text { nos básicos y caña de azúcar. También se } \\
\text { reportan áreas de pasto y en regeneración } \\
\text { natural. }\end{array}$ & No se proyectan cambios & $\begin{array}{l}\text { Restauración de } 20000 \text { ha en los már- } \\
\text { genes de los principales ríos primarios y } \\
\text { segundarios del país. }\end{array}$ & $\begin{array}{l}\text { UICN 2015, Asamblea } \\
\text { Legislativa } 2012 .\end{array}$ \\
\hline Mangle & $\begin{array}{l}\text { Área de } 2000 \text { ha mangle con azolvamiento } \\
\text { que se extiende en una franja de } 20 \mathrm{~km}\end{array}$ & No hay cambio. & $\begin{array}{l}\text { Se procede al desazolvamiento de las } 2000 \\
\text { ha identificadas. }\end{array}$ & $\begin{array}{l}\text { MARN 2015, Quinto In- } \\
\text { forme sobre Biodiversidad. }\end{array}$ \\
\hline Pasto natural & $\begin{array}{l}\text { Pasto natural (jaragua, maralfalfa, mulato } \\
\text { II) en tierras de laderas donde cada } 5 \text { años } \\
\text { se usa la quema a finales del verano. Tierra } \\
\text { poco apta para la agricultura (clase V, VI y } \\
\text { VII) modernamente degradas y en proceso } \\
\text { de degradación. }\end{array}$ & $\begin{array}{l}\text { Continuación del proceso de degradación } \\
\text { de pasto. Para mantener un enfoque } \\
\text { conservador, se valora que } 5 \% \text { del área de } \\
\text { pasto podría adoptar el modelo silvopastoril } \\
\text { sin la restauración. }\end{array}$ & $\begin{array}{l}\text { Restauración del pasto bajo un modelo } \\
\text { silvopastoril. }\end{array}$ & MAG 2015, MARN 2010. \\
\hline
\end{tabular}

Cuadro A2.2. Supuestos utilizados para parametrizar Ex Act (2)

\begin{tabular}{|c|c|c|c|c|}
\hline Uso del suelo & Práctica de línea base & Escenario sin restauración & Escenario con restauración & Fuente \\
\hline Granos básicos & $\begin{array}{l}\text { Se practica la quema en } 50 \% \text { del área } \\
\text { de granos básicos a nivel nacional. Los } \\
\text { residuos se queman en los meses de marzo } \\
\text { y abril, previo a la siembra de primera } \\
\text { (maíz). }\end{array}$ & $\begin{array}{l}\text { Se practica la quema en } 60 \% \text { del área } \\
\text { de granos básicos a nivel nacional. Se } \\
\text { proyecta la reducción de la quema de } \\
\text { residuos de cosecha en granos básicos } \\
\text { como resultados de los esfuerzos actuales } \\
\text { para limitar esta práctica. Para mantener } \\
\text { un enfoque conservador, se valora que } 5 \% \\
\text { del área de pasto podría adoptar el modelo } \\
\text { silvopastoril sin restauración. }\end{array}$ & $\begin{array}{l}\text { Solo en cuatro provincias (Chalatenango, } \\
\text { Santa Ana, Cabañas y Morazán) se } \\
\text { identificaron } 158000 \text { ha aptas para } \\
\text { establecer SAF de granos básicos. Por } \\
\text { tanto, a nivel nacional, la meta es del } 80 \% \\
\text { del área de granos básicos. 100\% no } \\
\text { quema del área en restauración. }\end{array}$ & MARN 2013. \\
\hline Caña de azúcar & $\begin{array}{l}\text { Se practica la quema en } 87 \% \text { del área } \\
\text { cultivada de caña de azúcar. }\end{array}$ & No se proyectan cambios & $\begin{array}{l}\text { Adopción de la zafra verde en una franja } \\
\text { de } 250 \mathrm{~m} \text { de ancho, a partir de la zona de } \\
\text { bosque de galería, establecidos en la ribera } \\
\text { de los ríos primarios y segundarios del país. }\end{array}$ & FUNDAZÚCAR 2016. \\
\hline Café & $\begin{array}{l}\text { Café bajo sombra manteniéndose como } \\
\text { tal con niveles de productividad bajo y alta } \\
\text { vulnerabilidad al cambio climático, en el } \\
\text { caso de no ser renovado. }\end{array}$ & $\begin{array}{l}\text { Se lograría renovar hasta } 30000 \text { ha de } \\
\text { café al finalizar el plan quinquenal 2014- } \\
2019 \text { ( } 5500 \text { ha/año), lo cual se centra en } \\
\text { las fincas que hoy son las más productivas. }\end{array}$ & $\begin{array}{l}\text { Se cumple una renovación integral } \\
\text { del parque cafetalero bajo un sistema } \\
\text { agroforestal diversificado. El área total de } \\
\text { cafetales está valorado en unos } 136727 \\
\text { ha en } 2015 \text {. }\end{array}$ & CENTA 2016. \\
\hline
\end{tabular}

\section{Bibliografía}

Asamblea Legislativa de El Salvador. 2012. Ley Forestal - decreto No 852, Diario oficial No 110, Tomo n 355.

CENTA. 2016. Memoria de labores. Centro Nacional de Transferencia de Tecnología Agropecuaría y Forestal. San Andrés, El Salvador.

FUNDAZÚCAR. 2016. Evaluación de la práctica de no-quema en el país. Asociación Azucarera de El Salvador, San Salvador El Salvador.

MAG. 2015. Estrategia ambiental de adaptación y mitigación al cambio climático del sector agropecuario, forestal, pesquero y acuícola. Ministerio de Agricultura y Ganadería, El Salvador.
MARN. 2015. Localización de azolvamiento de estéreos en el mangles de El Salvador. Ministerio de Medio Ambiente y Recursos Naturales, San Salvador, El Salvador.

MARN. 2010. Inventario de gases de efecto invernadero. informe narrativo, Ministerio de Medio Ambiente y Recursos Naturales: San Salvador, El Salvador.

MARN. 2013. Propuesta de preparación para REDD+ (RPP). Fondo Cooperativo del Carbono de los Bosques, Programa de Naciones Unidas para REDD, p. 85.

UICN y MARN. 2015. Cobertura por municipio de El Salvador. Clasificación de uso de suelo con base en imágenes Rapid eyes de 2014 de El Salvador. Mapa en shapefile. 


\section{Anexo 3 Datos tablas biofísicas InVEST}

Cuadro A3 Tabla de valores biofísicos del uso actual del suelo utilizados para InVEST

\begin{tabular}{|c|c|c|c|c|c|c|c|}
\hline Uso del suelo & Factor C & Factor $P$ & $\begin{array}{l}\text { Eficiencia } \\
\text { retención } \\
\text { sedimentos }\end{array}$ & $\begin{array}{c}\text { Tasa de } \\
\text { aplicación N }\end{array}$ & $\begin{array}{l}\text { Eficiencia } \\
\text { retención N }\end{array}$ & $\begin{array}{c}\text { Tasa de } \\
\text { aplicación P }\end{array}$ & $\begin{array}{l}\text { Eficiencia } \\
\text { retención P }\end{array}$ \\
\hline Infraestructura & $0,1^{(1)}$ & $1^{(1)}$ & $0,03^{(1)}$ & $7,375^{(1)}$ & $0^{(1)}$ & $1,15^{(1)}$ & $0^{(1)}$ \\
\hline Cuerpos de agua & $0^{(1)}$ & $1^{(1)}$ & $0^{(1)}$ & $0^{(23)}$ & $0^{(1)}$ & $0^{(23)}$ & $0^{(1)}$ \\
\hline Árboles frutales & $0,3^{(2)}$ & $1^{(1)}$ & $0,4^{(3)}$ & $64^{(2,6)}$ & $0,25^{(2)}$ & $18^{(2,6)}$ & $0,25^{(2)}$ \\
\hline Bosque caducifolio & $0,003^{(4)}$ & $1^{(1)}$ & $0,68^{(2)}$ & $1,61^{(9)}$ & $0,55^{(2)}$ & $0,125^{(8)}$ & $0,46^{(2)}$ \\
\hline Bosque de galería & $0,007^{(4)}$ & $1^{(1)}$ & $0,6^{(2)}$ & $3,26^{(9)}$ & $0,41^{(2)}$ & $0,171^{(8)}$ & $0,41^{(2)}$ \\
\hline Manglares & $0,2^{(4)}$ & $1^{(1)}$ & $0,8^{(2)}$ & $0,7^{(8,23-25)}$ & $0,6^{(2)}$ & $0,2^{(2)}$ & $0,6^{(2)}$ \\
\hline Bosque siempre verde & $0,003^{(4)}$ & $1^{(1)}$ & $0,65^{(2)}$ & $5,45^{(9)}$ & $0,50^{(2)}$ & $0,9^{(9)}$ & $0,50^{(2)}$ \\
\hline Coníferas & $0,086^{(4)}$ & $1^{(1)}$ & $0,6^{(3)}$ & $1,8^{(8,23-25)}$ & $0,40^{(2)}$ & $0,011^{(8,23-25)}$ & $0,40^{(2)}$ \\
\hline Bosques mixto & $0,005^{(4)}$ & $1^{(1)}$ & $0,65^{(2)}$ & $2,3^{(8,22-25)}$ & $0,46^{(2)}$ & $0,150^{(8,23-25)}$ & $0,46^{(2)}$ \\
\hline Bosques mixtos semi-caducifolios & $0,003^{(4)}$ & $1^{(1)}$ & $0,67^{(2)}$ & $1,61^{(8,22-25)}$ & $0,59^{(2)}$ & $0,125^{(8)}$ & $0,41^{(2)}$ \\
\hline Caña de azúcar & $0,17^{(5)}$ & $0,75^{(20)}$ & $0,25^{(3)}$ & $164^{(10,11)}$ & $0,15^{(2)}$ & $61,19^{(10,11)}$ & $0,15^{(2)}$ \\
\hline Caféa ${ }^{\prime /}$ & $0,085^{(4)}$ & $0,95^{(21)}$ & $0,54^{(2)}$ & $35,25^{(12)}$ & $0,28^{(2,22)}$ & $16,62^{(12)}$ & $0,28^{(2,22)}$ \\
\hline Cultivo de piña & $0,3^{(7)}$ & $1^{(1)}$ & $0,25^{(3)}$ & $382^{(13,14)}$ & $0,2^{(1)}$ & $74^{(13,14)}$ & $0,3^{(1)}$ \\
\hline Cultivos anuales asociados & $0,4175^{(4)}$ & $1^{(1)}$ & $0,25^{(3)}$ & $64^{(2,6)}$ & $0,15^{(2)}$ & $4,94^{(2,6)}$ & $0,15^{(2)}$ \\
\hline Espacio con vegetación escasa & $0,12^{(2)}$ & $1^{(1)}$ & $0,55^{(3)}$ & $0.07^{(2)}$ & $0.05^{(2)}$ & $0,001^{(2)}$ & $0,05^{(2)}$ \\
\hline Estuarios & $0^{(2)}$ & $1^{(1)}$ & $0^{(1)}$ & $0^{(2)}$ & $0^{(2)}$ & $0^{(2)}$ & $0^{(2)}$ \\
\hline Granos básicos & $0,5^{(4)}$ & $1^{(1)}$ & $0,25^{(3)}$ & $71^{(6,11)}$ & $0,15^{(2)}$ & 20,7 & $0,15^{(2)}$ \\
\hline Hortalizas & $0,41^{(4)}$ & $1^{(1)}$ & $0,35^{(3)}$ & $64^{(2,6)}$ & $0,15^{(2)}$ & $4,94^{(2,6)}$ & $0,15^{(2)}$ \\
\hline Morrales en potrero & $0,016^{(4)}$ & $1^{(1)}$ & $0,55^{(3)}$ & $43,2^{(15,16,17)}$ & $0,10^{(2)}$ & $36^{(15,16,17)}$ & $0,10^{(2)}$ \\
\hline Mosaico de cultivos y pasto $0^{\mathrm{b} /}$ & $0,31^{(4)}$ & $1^{(1)}$ & $0,43^{(3)}$ & $47,62^{(6,11,15,16,17)}$ & $0,18^{(2)}$ & $12,42^{(6,11,15,16,17)}$ & $0,18^{(2)}$ \\
\hline $\begin{array}{l}\text { Mosaico de cultivos, pastos y } \\
\text { Vegetacióncl }\end{array}$ & $0,21^{(4)}$ & $1^{(1)}$ & $0,45^{(3)}$ & $29,06^{(6,11,15,16,17)}$ & $0,21^{(2)}$ & $7,47^{(6,11,15,16,17)}$ & $0,21^{(2)}$ \\
\hline Otros cultivos irrigados & $0,2^{(3)}$ & $1^{(1)}$ & $0,35^{(3)}$ & $64^{(2,6)}$ & $0,10^{(2)}$ & $4,94^{(2,6)}$ & $0,10^{(2)}$ \\
\hline Palmera oleiferas & $0,3^{(7)}$ & $1^{(1)}$ & $0,4^{(3)}$ & $150^{(19)}$ & $0,20^{(2)}$ & $150^{(19)}$ & $0,20^{(2)}$ \\
\hline Pastos cultivados & $0,0215^{(4)}$ & $1^{(1)}$ & $0,65^{(3)}$ & $75^{(15,16,17)}$ & $0,20^{(1,27)}$ & $9,37^{(15,16,17)}$ & $0,20^{(1,27)}$ \\
\hline Pastos naturales ${ }^{\mathrm{d} /}$ & $0,12^{(4)}$ & $1^{(1)}$ & $0,60^{(3)}$ & $52,8^{(15,16,17)}$ & $0,20^{(1,27)}$ & $44^{(15,16,17)}$ & $0,20^{(1,27)}$ \\
\hline Perímetro acuícola & $0^{(1)}$ & $1^{(1)}$ & $0^{(3)}$ & $0^{(23)}$ & $0^{(2)}$ & $0^{(23)}$ & $0^{(2)}$ \\
\hline Bosque monoespecífico & $0,007^{(4)}$ & $1^{(1)}$ & $0,5^{(2)}$ & $2,5^{(2)}$ & $0,25^{(2)}$ & $0,1^{(2)}$ & $0,25^{(2)}$ \\
\hline Platanales y bananales & $0,062^{(4)}$ & $1^{(1)}$ & $0,25^{(3)}$ & $303^{(18)}$ & $0,15^{(4,18)}$ & $34,2^{(18)}$ & $0,15^{(4,18)}$ \\
\hline Playas dunas y arenales & $0,001^{(2)}$ & $1^{(1)}$ & $0^{(1)}$ & $0^{(2)}$ & 0 & $0^{(2)}$ & 0 \\
\hline Praderas pantanosas & $0,016^{(4)}$ & $1^{(1)}$ & $0,75^{(3)}$ & $21,6^{(15,16,17)}$ & 0,30 & $18^{(15,16,17)}$ & 0,30 \\
\hline Roqueda lavas & $0,12^{(3)}$ & $1^{(1)}$ & $0,26^{(1)}$ & $0^{(1)}$ & $0^{(1)}$ & $0^{(1)}$ & $0^{(1)}$ \\
\hline Salinas & $0,077^{(3)}$ & $1^{(1)}$ & $0,25^{(3)}$ & $0^{(1)}$ & $0^{(1)}$ & $0^{(1)}$ & $0^{(1)}$ \\
\hline Sistemas agroforestales & $0,2^{(4)}$ & $1^{(1)}$ & $0,4^{(3)}$ & $64^{(2,6)}$ & 0,25 & $4,94^{(2,6)}$ & 0,25 \\
\hline $\begin{array}{l}\text { Vegetación acuática sobre cuerpos } \\
\text { de agua }\end{array}$ & $0^{(1)}$ & $1^{(1)}$ & $0,5^{(2,3,27,28)}$ & $0^{(1)}$ & $0,3^{(2)}$ & $0^{(1)}$ & $0,2^{(2)}$ \\
\hline Vegetación arbustiva baja & $0,012^{(4)}$ & $1^{(1)}$ & $0,63^{(3)}$ & $1,61^{(2)}$ & $0,30^{(2)}$ & $0,001^{(2)}$ & $0,30^{(2)}$ \\
\hline Vegetación arbustiva de playa & $0,012^{(4)}$ & $1^{(1)}$ & $0,55^{(3)}$ & $1,61^{(2)}$ & $0,30^{(2)}$ & $0,001^{(2)}$ & $0,30^{(2)}$ \\
\hline Vegetación esclerófila o espinoso & $0,003^{(4)}$ & $1^{(1)}$ & $0,55^{(3)}$ & $1,61^{(2)}$ & $0,30^{(2)}$ & $0,001^{(2)}$ & $0,30^{(2)}$ \\
\hline Vegetación herbácea natural & $0,08^{(4)}$ & $1^{(1)}$ & $0,65^{(3)}$ & $1,61^{(2)}$ & $0,20^{(2)}$ & $0,001^{(2)}$ & $0,20^{(2)}$ \\
\hline $\begin{array}{l}\text { Viveros de plantas ornamentales y } \\
\text { otras }\end{array}$ & $1^{(4)}$ & $1^{(1)}$ & $0,03^{(2,3,28)}$ & $5^{(2)}$ & $0,1^{(2)}$ & $0,88^{(2)}$ & $0,1^{(2)}$ \\
\hline Zonas de extracción minera & $1^{(4)}$ & $1^{(1)}$ & $0,03^{(2,3,28)}$ & $7,5^{(2)}$ & $0^{(2)}$ & $1,2^{(2)}$ & $0^{(2)}$ \\
\hline Zonas ecotonales & $0,014^{(3)}$ & $1^{(1)}$ & $0,25^{(3)}$ & $1,61^{(2)}$ & $0,6^{(2)}$ & $0,001^{(2)}$ & $0,6^{(2)}$ \\
\hline Zonas quemadas & $0,35^{(3)}$ & $1^{(1)}$ & $0,25^{(3)}$ & $0,035^{(2)}$ & $0,05^{(2)}$ & $0,001^{(2)}$ & $0,05^{(2)}$ \\
\hline
\end{tabular}

a/ Según comunicación personal de Sanz, N. del MARN (septiembre 22, 2016), el 40\% del área de cafetales en el mapa de uso del suelo 2015 está ocupado por bosque secundario. Por tanto, para calcular los parámetros biofísicos de este uso del suelo se distribuyó la ponderación entre los parámetros de ambos usos de suelo (café y bosque secundario).

b/ Promedio ponderado de los valores de pasto natural y granos básicos.

c/ Promedio ponderado de los valores de pasto natural, granos básicos y vegetación secundaria.

d/ Basado en promedio de UA calculado para el país. 


\section{Bibliografía del Cuadro A3}

1. Tallis, HT, Ricketts, T, Guerry, AD, Wood, SA, Sharp, R, Nelson, E, et al. InVEST 3.0.0 User's Guide Integrated Valuation of Environmental Services and Tradeoffs. Stanford, USA: The Natural Capital Project; 2013.

2. Bhagabati, N., Barano, T., Conte, M., Ennaanay, D., Hadian, O., McKenzie, E., Olwero, N., Rosenthal, A., Suparmoko, Shapiro, A., Tallis, H. and Wolny, S. (2012). A green vision for Sumatra. Using ecosystem services information to make recommendations for sustainable land use planning at the province and district level. A Report by The Natural Capital Project, WWF-US, and WWF-Indonesia. The Natural Capital Project, Stanford University, USA. Available at: https://woods.stanford. edu/sites/default/files/files/GreenVision.pdf

3. Leh, M.D.K., Matlock, M.D., Cummings, E.C., Nalley, L.L. 2013. Quantifying and mapping multiple ecosystem services change in West Africa. Agric. Ecosyst. Environ. 165, 6-18. doi:10.1016/j.agee.2012.12.001

4. Lianes, E., Marchamalo, M., Roldán, M. 2009. Evaluación del factor $\mathrm{C}$ de la RUSLE para el manejo de coberturas vegetales en el control de la erosión en la cuenca del río Birrís, Costa Rica. Agron. Costarric. 33. http:// www.mag.go.cr/rev_agr/v33n02_217.pdf

5. Le Roux, J. 2005. Soil erosion prediction under changing land use on Mauritius. Faculty of Natural \& Agricultural Sciences, University of Pretoria, Pretoria, Mauritus. p 174

6. FAOSTAT. 2017. Basado en tasa de aplicación nacional de nutrientes dividido entre el area de cultivo anual y permanente, a partir de FAOSTAT 2017: http://www.fao. org/faostat/en/\#data/RF - http://www.fao.org/faostat/ en/\#data/RL

7. González Espino, C.J., Pozo Molina, G.J. 2008. Evaluación de la erosión hídrica en el sistema productivo de cafe (Coffea arabiga L.) de la Finca El Jardín y el efecto del uso y manejo de la tierra en la Quebrada del Río El Cairo, Managua, Nicaragua (engineer). Universidad Nacional Agraria, UNA.

8. Johnes P.J. Evaluation and management of the impact of land use change on the nitrogen and phosphorus load delivered to surface waters: the export coefficient modelling approach. J Hydrol. 1996;183: 323-349. doi:10.1016/0022-1694(95)02951-6

9. Bruijnzeel, L.A., 1991. Nutrient Input-Output Budgets of Tropical Forest Ecosystems: A Review. J. Trop. Ecol. 7, $1-24$.
10. García, Alvaro García O. y Carlos A. Rojas C. 2006. Nota técnica: Posibilidades de Uso de la Vinaza en la Agricultura de acuerdo con su modo de acción en los suelos http://www.tecnicana.org/pdf/2006/tec_v10_ no17_2006_p3-13.pdf

11. MAG. 2013. Informe anual sobre costos de producción agrícola, usado para cultivos de caña de azucar, frijol, maiz, sorgo. Disponible en http://www.mag.gob.sv/ direccion-general-de-economia-agropecuaria/estadisticas-agropecuarias/informe-anual-sobre-costos-deproduccion-de-cultivos-agricolas/

12. Landaverde J.M., 2010 tecnica drench 70 "fertilización inovadora", Simposio internacional sobre manejo del suelo y del postacio, San Salvador El Salvador, PROCAFE, disponible en https://www.ipipotash.org/udocs/ Landaverde_tecnica_drench_70_fertilizacion_innovadora_coffee.pdf

13. Ingwersen, W.W. 2012. Life cycle assessment of fresh pineapple from Costa Rica. J. Clean. Prod. 35, 152-163. doi:10.1016/j.jclepro.2012.05.035

14. MAG. 1991. Aspectos técnicos sobre Cuarenta y Cinco Cultivos Agrícolas de Costa Rica. Dirección general de Investigación y Extensión Agrícola. Obtenido de http:// www.mag.go.cr/bibioteca_virtual_ciencia/tec-pina.pdf

15. Pastos: Gillberto Cabalceta. (1999). Fertilización y Nutrición de Forrajes de altura. XI Congreso Nacional Agronomico / III Congreso Nacional de Suelos. San José, Costa Rica 19 to 23 July. Available at: http://www.mag. go.cr/congreso_agronomico_xi/a50-6907-III_239.pdf

16. DEA. 2015. Anuario de Estadísticas Agropecuarias 2014-2015 y precios de mercado, encuesta nacional agropecuario de propósitos múltiples, octubre 2015. DEA, Ministerio de Agricultura y Ganadería: San Salvador, El Salvador.

17. MAG. 2003. Diagnóstico de los recursos zoogenéticos en El Salvador. Oficina de políticas y estrategias.

18. Guerrero, M. 2011. Guía técnica del cultivo del plátano. CENTA, La libertad, El Salvador

19. Sáenz Mejía, L.E. 2006. Cultivo de la Palma Africana Guía Técnica. IICA, Managua, Nicaragua. Available at: http:// www.galeon.com/subproductospalma/guiapalma.pdf

20. Roose É. 1977. Érosion et ruissellement en Afrique de l'Ouest. Vingt années de mesures en petites parcelles. Édit. ORSTOM, Paris, série Travaux et Documents, $n^{\circ} 78$, $108 \mathrm{p}$.

21. Wischmeier W.H. et Smith D.D. 1978. Predicting rainfall erosion losses. A guide to conservation planning. 
Édit. US Department of Agriculture, Washington, vol. $537,58 \mathrm{p}$.

22. Jaramillo Robledo A. La lluvia y el transporte de nutrimentos dentro de ecosistemas de bosque y cafetales. Cenicafé. 2003;54(2): 134-144.

23. Rast W, Lee GF. Nutrient Loading Estimates for Lakes. J Environ Eng. 1983;109: 502-517. doi:10.1061/ (ASCE)0733-9372(1983)109:2(502)

24. Jeje Y. Export coefficients for total phosphorus, total nitrogen and total suspended solids in the southern Alberta region [Internet]. Alberta, Canada: Alberta Environment and Sustainable Resource Development; 2006 p. 27. Available: http://environment.gov.ab.ca/info/ library/7797.pdf
25. Lin JP. Review of Published Export Coefficient and Event Mean Concentration (EMC) Data [Internet]. Vicksburg, USA: U.S. Army Engineer Research and Development Center; 2004 p. 15. Available: http://el.erdc.usace.army. mil/elpubs/pdf/tnwrap04-3.pdf

26. Hunter HM, Walton RS. Land-use effects on fluxes of suspended sediment, nitrogen and phosphorus from a river catchment of the Great Barrier Reef, Australia. J Hydrol. 2008;356: 131- 146. doi:10.1016/j.jhydrol.2008.04.003

27. Fu B., Wang YK, Xu P., Yan K. Modelling nutrient retention function of ecosystem - a case study in Baoxing County, China. Procedia Environ Sci. 2012;13: 111-121. doi:10.1016/j.proenv.2012.01.011

Cuadro A4 Tabla de valores biofísicos usados para la implementación de las acciones de restauración para InVEST

\begin{tabular}{|c|c|c|c|c|c|c|c|}
\hline LULC_desc & Factor C & Factor $\mathrm{P}$ & $\begin{array}{l}\text { Eficiencia en } \\
\text { retención de } \\
\text { sedimentos }\end{array}$ & $\begin{array}{c}\text { Tasa } \\
\text { de aplicación N }\end{array}$ & $\begin{array}{l}\text { Eficiencia } \\
\text { retención N }\end{array}$ & $\begin{array}{c}\text { Tasa } \\
\text { de aplicación P }\end{array}$ & $\begin{array}{l}\text { Eficiencia } \\
\text { retención P }\end{array}$ \\
\hline Zafra verde en caña de azúcar & $0,13^{(1)}$ & $0,75^{(1)}$ & $0,4^{(2)}$ & $137,92^{(3,4)}$ & $0,19^{(4,5)}$ & $57,01^{(3,4)}$ & $0,15^{(5)}$ \\
\hline Renovación de cafetales & $0,084^{(5,8)}$ & $0,8^{(7)}$ & $0,54^{(5)}$ & $33,30^{(3,8)}$ & $0,28^{(5,14)}$ & $15,62^{(3,8)}$ & $0,28^{(5,14)}$ \\
\hline $\begin{array}{l}\text { Sistema agroforestal de } \\
\text { granos básicos }\end{array}$ & $0,48^{(5,8)}$ & $0,5^{(9,10)}$ & $0,28^{(2,5)}$ & $106,68^{(3,8,11)}$ & $0,17^{(5,15)}$ & $69^{(3,8,11)}$ & $0,17^{(5,15)}$ \\
\hline $\begin{array}{l}\text { Sistema agroforestal de } \\
\text { cacao (1) }\end{array}$ & $0,05^{(8)}$ & $0,6^{(12)}$ & $0,87^{(2)}$ & $113,03^{(3,8)}$ & $0,27^{(5)}$ & $13,65^{(3,8)}$ & $0,27^{(5)}$ \\
\hline Sistema silvopastoril & $0,044^{(6,8,16)}$ & $0,5^{(9)}$ & $0,585^{(2,5)}$ & $143,90(3,13)$ & $0,21^{(5)}$ & $90^{(3,13)}$ & $0,21^{(5)}$ \\
\hline Sistema agrosilvopastoril & $0,25^{(5,6,8,16)}$ & $0,65^{(9,10)}$ & $0,43^{(2,5)}$ & $124,84^{(3,8,11,13)}$ & $0,19^{(5)}$ & $79,5^{(3,8,11,13)}$ & $0,19^{(5)}$ \\
\hline $\begin{array}{l}\text { Sistema agroforestal de } \\
\text { cacao (2) }\end{array}$ & $0,064^{(8)}$ & $0,8^{(12)}$ & $0,44^{(2,5)}$ & $69,3^{(3,8)}$ & $0,28^{(5)}$ & $8,28^{(3,8)}$ & $0,28^{(5)}$ \\
\hline
\end{tabular}

\section{Bibliografía del Cuadro A4}

1. Le Roux, J. 2005. Soil erosion prediction under changing land use on Mauritius. Faculty of Natural \& Agricultural Sciences, University of Pretoria, Pretoria, Mauritus. p 174

2. Leh, M.D.K., Matlock, M.D., Cummings, E.C., Nalley, L.L. 2013. Quantifying and mapping multiple ecosystem services change in West Africa. Agric. Ecosyst. Environ. 165, 6-18. doi:10.1016/j.agee.2012.12.001

3. Datos calculados con base a recomendación técnica de la restauración (ver ficha técnica para detalles sobre la evolución de la tasa de aplicación en el tiempo)

4. Saucedo, S.F. 2007. Uso de los microorganismos eficaces em y la vinaza como potencializadores de microrganismos biotransformado res de residuos de cosecha y fijadores de nitrógeno en el cultivo de la caña de azúcar. Universidad Nacional de Colombia, Bogota, Colombia.
5. Bhagabati, N., Barano, T., Conte, M., Ennaanay, D., Hadian, O., McKenzie, E., Olwero, N., Rosenthal, A., Suparmoko, Shapiro, A., Tallis, H. and Wolny, S. 2012. A green vision for Sumatra. Using ecosystem services information to make recommendations for sustainable land use planning at the province and district level. A Report by The Natural Capital Project, WWF-US, and WWF-Indonesia. The Natural Capital Project, Stanford University, USA. Available at: https:// woods.stanford.edu/sites/default/files/files/GreenVision.pdf

6. Lianes Revilla E. 2008. Estudio del factor vegetación "factor C" de la Ecuación Universal de Pérdidas de Suelo Revisada "RUSLE" en la cuenca del río Birrís (Costa Rica) [Internet]. Madrid, Spain: Universidad politécnica de Madrid, p. 191. Available: http://oa.upm.es/1267/

7. Wischmeier W.H. et Smith D.D. 1978. Predicting rainfall erosion losses. A guide to conservation planning. Édit. US Department of Agriculture, Washington, vol. 537, 58 p. 
8. Lianes, E., Marchamalo, M., Roldán, M. 2009. Evaluación del factor $\mathrm{C}$ de la RUSLE para el manejo de coberturas vegetales en el control de la erosión en la cuenca del río Birrís, Costa Rica. Agron. Costarric. 33. http:// www.mag.go.cr/rev_agr/v33n02_217.pdf

9. ROOSE É. (1977) - Érosion et ruissellement en Afrique de l'Ouest. Vingt années de mesures en petites parcelles. Édit. ORSTOM, Paris, série Travaux et Documents, $\mathrm{n}^{\circ}$ $78,108 \mathrm{p}$.

10. Pavón, J. del C., Madero, E., Amézquita, E., others. 2007. Susceptibilidad del suelo a la degradación en parcelas con manejo agroforestal Quesungual en Nicaragua. Acta Agronómica Vol 59 Núm 12010 46-54 2323-0118 0120-2812.

11. Juárez Vásquez, M.A., 2008. Efecto de tecnologías de conservación de suelos, agroforestería y diversificación de cultivos, implementadas por el PAES, en Tenancingo y Guazapa. Universidad de El Salvador: San Salvador, El Salvador.

12. Wischmeier W.H. et Smith D.D. 1978. Predicting rainfall erosion losses. A guide to conservation planning. Édit.
US Department of Agriculture, Washington, vol. 537, 58 p.

13. Pastos: Gillberto Cabalceta. (1999). Fertilización y Nutrición de Forrajes de altura. XI Congreso Nacional Agronomico / III Congreso Nacional de Suelos. San José, Costa Rica 19 to 23 July. Available at: http://www.mag.go.cr/ congreso_agronomico_xi/a50-6907-III_239.pdf

14. Jaramillo Robledo A. La lluvia y el transporte de nutrimentos dentro de ecosistemas de bosque y cafetales. Cenicafé. 2003;54(2): 134-144.

15. Tallis, HT, Ricketts, T, Guerry, AD, Wood, SA, Sharp, R, Nelson, E, et al. 2013. InVEST 3.0.0 User's Guide Integrated Valuation of Environmental Services and Tradeoffs. Stanford, USA: The Natural Capital Project.

16. Burke L, Sugg Z. Modelamiento Hidrológico de la Descarga de las Cuencas Hidrológicas en el Arrecife Mesoamericano [Internet]. Washington, USA: World Resources Institute; 2006 p. 44. Available: https://www. wri.org/sites/default/files/pdf/mar_hydrologic_model_results_spanish.pdf

Cuadro A5 Tabla biofísica de los usos del suelo restaurados bajo la modalidad de agroforestería y su respectiva ponderación para un área de plantación de bosque tropical

\begin{tabular}{|c|c|c|c|c|c|}
\hline & Ponderación & Factor C & $\begin{array}{l}\text { Eficiencia retención } \\
\text { sedimentos }\end{array}$ & Eficiencia retención $\mathrm{N}$ & Eficiencia retención $\mathrm{P}$ \\
\hline $\begin{array}{l}\text { Granos básicos en sistema agroforestal de } \\
\text { granos básicos }\end{array}$ & 0,85 & $0,5^{(1,2)}$ & $0,25^{(3)}$ & $0,15^{(2)}$ & $0,15^{(2)}$ \\
\hline $\begin{array}{l}\text { Plantaciones de bosque tropical en sistema } \\
\text { agroforestal de granos básicos }{ }^{\text {a }}\end{array}$ & 0,15 & $0,086^{(1,2)}$ & $0,5^{(1,2)}$ & $0,33^{(1,2)}$ & $0,33^{(1,2)}$ \\
\hline Pasto en sistema silvopastoril & 0,87 & $0,12^{(1,2)}$ & $0,60^{(3)}$ & $0,20^{(5,6)}$ & $0,20^{(5,6)}$ \\
\hline $\begin{array}{l}\text { Plantaciones de bosque tropical en sistema } \\
\text { silvopastori//a }\end{array}$ & 0,13 & $0,086^{(1,2)}$ & $0,5^{(1,2)}$ & $0,33^{(1,2)}$ & $0,33^{(1,2)}$ \\
\hline Pasto en sistema agrosilvopastoril & 0,86 & $0,12^{(1,2)}$ & $0,60^{(3)}$ & $0,20^{(5,6)}$ & $0.20^{(5,6)}$ \\
\hline $\begin{array}{l}\text { Plantaciones de bosque tropical en sistema } \\
\text { agrosilvopastoril/a }\end{array}$ & 0,14 & $0,086^{(1,2)}$ & $0,5^{(1,2)}$ & $0,33^{(1,2)}$ & $0,33^{(1,2)}$ \\
\hline Café en renovación de cafetales & 0,94 & $0,085^{(1,2)}$ & $0,54^{(4)}$ & $0,28^{(4,7)}$ & $0,28^{(4,7)}$ \\
\hline $\begin{array}{l}\text { Plantaciones de bosque tropical en } \\
\text { renovación de cafetales }\end{array}$ & 0,06 & $0,086^{(1,2)}$ & $0,5^{(1,2)}$ & $0,33^{(1,2)}$ & $0,33^{(1,2)}$ \\
\hline
\end{tabular}

la para calcular el área donde predominan las condiciones de bosque tropical, se distribuyó la ponderación (Cuadro 4) según el área donde se realizan las obras de restauración (cerca viva, siembra de árboles, regeneración natural de árboles).

\section{Bibliografía del Cuadro A5}

1. Lianes, E., Marchamalo, M., Roldán, M. 2009. Evaluación del factor $\mathrm{C}$ de la RUSLE para el manejo de coberturas vegetales en el control de la erosión en la cuenca del río Birrís, Costa Rica. Agron. Costarric. 33. http:// www.mag.go.cr/rev_agr/v33n02_217.pdf
2. Lianes Revilla E. Estudio del factor vegetación "factor C" de la Ecuación Universal de Pérdidas de Suelo Revisada "RUSLE" en la cuenca del río Birrís (Costa Rica) [Internet]. Madrid, Spain: Universidad politécnica de Madrid; 2008 p. 191. Available: http://oa.upm.es/1267/

3. Leh, M.D.K., Matlock, M.D., Cummings, E.C., Nalley, L.L. 2013. Quantifying and mapping multiple ecosystem 
services change in West Africa. Agric. Ecosyst. Environ. 165, 6-18. doi:10.1016/j.agee.2012.12.001

4. Bhagabati, N., Barano, T., Conte, M., Ennaanay, D., Hadian, O., McKenzie, E., Olwero, N., Rosenthal, A., Suparmoko, Shapiro, A., Tallis, H. and Wolny, S. 2012. A green vision for Sumatra. Using ecosystem services information to make recommendations for sustainable land use planning at the province and district level. A Report by The Natural Capital Project, WWF-US, and WWF-Indonesia. The Natural Capital Project, Stanford University, USA. Available at: https://woods.stanford.edu/sites/default/files/files/GreenVision.pdf
5. Tallis, HT, Ricketts, T, Guerry, AD, Wood, SA, Sharp, R, Nelson, E, et al. 2013. InVEST 3.0.0 User's Guide Integrated Valuation of Environmental Services and Tradeoffs. Stanford, USA: The Natural Capital Project.

6. Fu B., Wang YK, Xu P., Yan K. Modelling nutrient retention function of ecosystem - a case study in Baoxing County, China. Procedia Environ Sci. 2012;13: 111-121. doi:10.1016/j.proenv.2012.01.011

7. Jaramillo Robledo A. La lluvia y el transporte de nutrimentos dentro de ecosistemas de bosque y cafetales. Cenicafé. 2003;54(2): 134-144.

Cuadro A6 Supuestos para la ponderación del área bajo condiciones forestales en sistemas agroforestales según el área de copa

\begin{tabular}{lcccc} 
& Cercas vivas (por metro lineal) & Árboles maderables & Árboles frutales & $\begin{array}{c}\text { Árboles/arbustos bajo poda } \\
\text { anual }\end{array}$ \\
$\begin{array}{l}\text { Área por árbol u obra de } \\
\text { conservación }\left(\mathrm{m}^{2}\right)\end{array}$ & 1,3 & 8,66 & 20 & 1 \\
\hline
\end{tabular}




\section{Anexo 4 Costos de restauración desagregados y VAN de la restauración y uso actual del suelo}

Cuadro A7 Desglose de los costos de cada acción de restauración (r=10\%)

\begin{tabular}{|c|c|c|c|}
\hline $\begin{array}{l}\text { Acciones } \\
\text { de restauración }\end{array}$ & $\begin{array}{l}\text { Costos de implementación } \\
\text { dentro de la finca }\end{array}$ & $\begin{array}{l}\text { Costos } \\
\text { de implementación fuera de la finca }\end{array}$ & $\begin{array}{l}\text { Costos } \\
\text { de mantenimiento }\end{array}$ \\
\hline Restauración de manglar & 600 & 300 & 14520 \\
\hline Restauración bosque de galería en granos básicos & 3954 & 169 & 1043 \\
\hline Restauración bosque de galería en pasto natural & 3954 & 169 & 1043 \\
\hline Restauración bosque de galería en caña de azúcar & 3954 & 169 & 1043 \\
\hline Restauración bosque de galería en mosaico de cultivos y pasto & 3954 & 169 & 1043 \\
\hline $\begin{array}{l}\text { Restauración bosque de galería en mosaico de cultivos, pastos } \\
\text { y vegetación }\end{array}$ & 3954 & 169 & 1043 \\
\hline Sistema agroforestal de granos básicos & 3692 & 571 & 13369 \\
\hline Sistema silvopastoril & 5717 & 245 & 18581 \\
\hline Sistema agrosilvopastoril & 4697 & 297 & 14808 \\
\hline Zafra verde en caña & 3324 & 13 & 17302 \\
\hline Sistema agroforestal de cacao en café (cacao 1) & 7885 & 327 & 11937 \\
\hline $\begin{array}{l}\text { Sistema agroforestal de cacao en mosaico de cultivo, pasto y } \\
\text { vegetación (cacao 2) }\end{array}$ & 8343 & 367 & 13662 \\
\hline Renovación de los cafetales de bajío & 5840 & 132 & 12723 \\
\hline Renovación de los cafetales de mediana altura & 5840 & 132 & 12723 \\
\hline Renovación de los cafetales de altura & 5840 & 132 & 12723 \\
\hline
\end{tabular}

Cuadro A8 Beneficios netos de la restauración y del uso actual ( $r=10 \%)$

\begin{tabular}{|c|c|c|}
\hline Acciones de restauración & $\begin{array}{l}\text { Beneficios netos } \\
\text { restauración (US\$/ha) }\end{array}$ & $\begin{array}{l}\text { Beneficios netos } \\
\text { uso actual (US\$/ha) }\end{array}$ \\
\hline Restauración de manglar & 4061 & 0 \\
\hline Restauración bosque de galería en granos básicos & -5166 & 4130 \\
\hline Restauración bosque de galería en pasto natural & -5166 & 7553 \\
\hline Restauración bosque de galería en caña de azúcar & -5166 & 3222 \\
\hline Restauración bosque de galería en mosaico de cultivos y pasto & -5166 & 4638 \\
\hline $\begin{array}{l}\text { Restauración bosque de galería en mosaico de cultivos, pastos } \\
\text { y vegetación }\end{array}$ & -5166 & 3100 \\
\hline Sistema agroforestal de granos básicos & 4438 & 4130 \\
\hline Sistema silvopastoril & 18269 & 7553 \\
\hline Sistema agrosilvopastoril & 12124 & 4638 \\
\hline Zafra verde en caña & 4067 & 3222 \\
\hline Sistema agroforestal de cacao en café (cacao 1) & 14767 & 1206 \\
\hline $\begin{array}{l}\text { Sistema agroforestal de cacao en mosaico de cultivos, pastos y } \\
\text { vegetación (cacao 2) }\end{array}$ & 15473 & 3100 \\
\hline Renovación de los cafetales de bajío & 2894 & 1096 \\
\hline Renovación de los cafetales de mediana altura & 6003 & 1372 \\
\hline Renovación de los cafetales de altura & 13076 & 2275 \\
\hline
\end{tabular}

Fuente: Elaboración propia. 


\section{Anexo 5 Costo, beneficios del uso actual y de la restauración con $r=15 \%$}

Cuadro A9 Costos de la restauración, del uso actual y costos incrementales de la restauración (r=15\%)

\begin{tabular}{|c|c|c|c|}
\hline Acciones de restauración & $\begin{array}{l}\text { Costos restauración } \\
\text { (US\$/ha) }\end{array}$ & Costos uso actual (US\$/ha) & Costos incrementales (US\$/ha) \\
\hline Restauración de manglar & 11123 & & 11123 \\
\hline Restauración bosque de galería en granos básicos & 4924 & 6479 & -1555 \\
\hline Restauración bosque de galería en pasto natural & 4924 & 12956 & -8032 \\
\hline Restauración bosque de galería en caña de azúcar & 4924 & 13612 & -8688 \\
\hline Restauración bosque de galería en mosaico de cultivos y pasto & 4924 & 12136 & -7212 \\
\hline $\begin{array}{l}\text { Restauración bosque de galería en mosaico de cultivos, pastos } \\
\text { y vegetación }\end{array}$ & 4924 & 8785 & -3861 \\
\hline Sistema agroforestal de granos básicos & 14370 & 6479 & 7891 \\
\hline Sistema silvopastoril & 19566 & 12956 & 6610 \\
\hline Sistema agrosilvopastoril & 15378 & 12136 & 3242 \\
\hline Zafra verde en caña & 16028 & 13612 & 2416 \\
\hline Sistema agroforestal de cacao en café (cacao 1) & 17200 & 2932 & 14268 \\
\hline $\begin{array}{l}\text { Sistema agroforestal de cacao en mosaico de cultivo, pasto y } \\
\text { vegetación (cacao 2) }\end{array}$ & 19033 & 8785 & 10248 \\
\hline Renovación de los cafetales de bajío & 14579 & 2664 & 11915 \\
\hline Renovación de los cafetales de mediana altura & 14579 & 3333 & 11246 \\
\hline Renovación de los cafetales de altura & 14579 & 5529 & 9050 \\
\hline
\end{tabular}

Cuadro A10 Beneficios brutos de la restauración, del uso actual e incrementales de la restauración (r=15\%)

\begin{tabular}{|c|c|c|c|}
\hline Acciones de restauración & $\begin{array}{l}\text { Beneficios brutos restauración } \\
\text { (US\$/ha) }\end{array}$ & $\begin{array}{l}\text { Beneficios brutos } \\
\text { uso actual (US\$/ha) }\end{array}$ & $\begin{array}{l}\text { Beneficios brutos incrementales } \\
\text { (US\$/ha) }\end{array}$ \\
\hline Restauración de manglar & 13594 & & 13594 \\
\hline Restauración bosque de galería en granos básicos & 0 & 9422 & -9422 \\
\hline Restauración bosque de galería en pasto natural & 0 & 18761 & -18761 \\
\hline Restauración bosque de galería en caña de azúcar & 0 & 16030 & -16030 \\
\hline Restauración bosque de galería en mosaico de cultivos y pasto & 0 & 15467 & -15467 \\
\hline $\begin{array}{l}\text { Restauración bosque de galería en mosaico de cultivos, pastos } \\
\text { y vegetación }\end{array}$ & 0 & 11160 & -11160 \\
\hline Sistema agroforestal de granos básicos & 15900 & 9422 & 6478 \\
\hline Sistema silvopastoril & 30123 & 18761 & 11362 \\
\hline Sistema agrosilvopastoril & 22709 & 15467 & 7242 \\
\hline Zafra verde en caña & 19033 & 16030 & 3003 \\
\hline Sistema agroforestal de cacao en café (cacao 1) & 25515 & 3910 & 21605 \\
\hline $\begin{array}{l}\text { Sistema agroforestal de cacao en mosaico de cultivo, pasto y } \\
\text { vegetación (cacao 2) }\end{array}$ & 28627 & 11160 & 17467 \\
\hline Renovación de los cafetales de bajío & 15260 & 3553 & 11707 \\
\hline Renovación de los cafetales de mediana altura & 17507 & 4445 & 13062 \\
\hline Renovación de los cafetales de altura & 22614 & 7373 & 15241 \\
\hline
\end{tabular}


Cuadro A11 Beneficios netos de la restauración, del uso actual, beneficios marginales de la restauración, razón beneficio-costo (RBC) y retorno de la inversión (ROI) (r=15\%)

\begin{tabular}{|c|c|c|c|c|c|}
\hline Acciones de restauración & $\begin{array}{l}\text { Beneficios netos } \\
\text { restauración (US\$/ha) }\end{array}$ & $\begin{array}{l}\text { Beneficios netos uso } \\
\text { actual (US\$/ha) }\end{array}$ & $\begin{array}{l}\text { Beneficios marginales } \\
\text { (US\$/ha) }\end{array}$ & $\mathrm{RBC}$ & $\mathrm{ROI}$ \\
\hline Restauración de manglar & 2471 & 0 & 2471 & 1,22 & 4,12 \\
\hline $\begin{array}{l}\text { Restauración bosque de galería en granos } \\
\text { básicos }\end{array}$ & -4924 & 2943 & -7867 & 0,00 & $-1,99$ \\
\hline $\begin{array}{l}\text { Restauración bosque de galería en pasto } \\
\text { natural }\end{array}$ & -4924 & 5805 & -10729 & 0,00 & $-2,71$ \\
\hline $\begin{array}{l}\text { Restauración bosque de galería en caña } \\
\text { de azúcar }\end{array}$ & -4924 & 2418 & -7342 & 0,00 & $-1,86$ \\
\hline $\begin{array}{l}\text { Restauración bosque de galería en mosaico } \\
\text { de cultivos y pasto }\end{array}$ & -4924 & 3331 & -8255 & 0,00 & $-2,09$ \\
\hline $\begin{array}{l}\text { Restauración bosque de galería en mosaico } \\
\text { de cultivos, pastos y vegetación }\end{array}$ & -4924 & 2375 & -7299 & 0,00 & $-1,85$ \\
\hline Sistema agroforestal de granos básicos & 1530 & 2943 & -1413 & 0,92 & $-0,38$ \\
\hline Sistema silvopastoril & 10557 & 805 & 4752 & 1,19 & 0,83 \\
\hline Sistema agrosilvopastoril & 7331 & 3331 & 4000 & 1,21 & 0,85 \\
\hline Zafra verde en caña & 3005 & 2418 & 587 & 1,03 & 0,18 \\
\hline Sistema agroforestal de cacao en café (cacao 1) & 8315 & 978 & 7337 & 1,40 & 0,93 \\
\hline $\begin{array}{l}\text { Sistema agroforestal de cacao en mosaico } \\
\text { de cultivo, pasto y vegetación (cacao 2) }\end{array}$ & 9594 & 2375 & 7219 & 1,34 & 0,87 \\
\hline Renovación de los cafetales de bajío & 681 & 889 & -208 & 0,99 & $-0,04$ \\
\hline $\begin{array}{l}\text { Renovación de los cafetales de mediana } \\
\text { altura }\end{array}$ & 2928 & 1112 & 1816 & 1,12 & 0,31 \\
\hline Renovación de los cafetales de altura & 8035 & 1844 & 6191 & 1,38 & 1,06 \\
\hline
\end{tabular}




\section{Anexo 6 Costo, beneficios del uso actual y de la restauración con $r=5 \%$}

Cuadro A12 Costos de la restauración, del uso actual y costos incrementales de la restauración (r=5\%)

\begin{tabular}{|c|c|c|c|}
\hline Acciones de restauración & $\begin{array}{l}\text { Costos restauración } \\
\text { (US\$/ha) }\end{array}$ & $\begin{array}{l}\text { Costos uso actual } \\
\text { (US\$/ha) }\end{array}$ & $\begin{array}{l}\text { Costos incrementales } \\
\text { (US\$/ha) }\end{array}$ \\
\hline Restauración de manglar & 22856 & & 22856 \\
\hline Restauración bosque de galería en granos básicos & 5541 & 11778 & -6237 \\
\hline Restauración bosque de galería en pasto natural & 5541 & 23553 & -18012 \\
\hline Restauración bosque de galería en caña de azúcar & 5541 & 24384 & -18843 \\
\hline Restauración bosque de galería en mosaico de cultivos y pasto & 5541 & 26178 & -20637 \\
\hline $\begin{array}{l}\text { Restauración bosque de galería en mosaico de cultivos, pastos } \\
\text { y vegetación }\end{array}$ & 5541 & 15934 & -10393 \\
\hline Sistema agroforestal de granos básicos & 23150 & 11778 & 11372 \\
\hline Sistema silvopastoril & 33174 & 23553 & 9621 \\
\hline Sistema agrosilvopastoril & 28380 & 26178 & 2202 \\
\hline Zafra verde en caña & 28487 & 24384 & 4103 \\
\hline Sistema agroforestal de cacao en café (cacao 1) & 25219 & 4734 & 20484 \\
\hline $\begin{array}{l}\text { Sistema agroforestal de cacao en mosaico de cultivo, pasto y } \\
\text { vegetación (cacao 2) }\end{array}$ & 28094 & 15934 & 12160 \\
\hline Renovación de los cafetales de bajío & 25786 & 4302 & 21484 \\
\hline Renovación de los cafetales de mediana altura & 25786 & 5383 & 20403 \\
\hline Renovación de los cafetales de altura & 25786 & 8929 & 16857 \\
\hline
\end{tabular}

Cuadro A13 Beneficios brutos de la restauración, del uso actual e incrementales de la restauración ( $r=5 \%)$

\begin{tabular}{|c|c|c|c|}
\hline Acciones de restauración & $\begin{array}{l}\text { Beneficios brutos restauración } \\
\text { (US\$/ha) }\end{array}$ & $\begin{array}{l}\text { Beneficios brutos uso actual } \\
\text { (US\$/ha) }\end{array}$ & $\begin{array}{l}\text { Beneficios brutos incrementales } \\
\text { (US\$/ha) }\end{array}$ \\
\hline Restauración de manglar & 29762 & & 29762 \\
\hline Restauración bosque de galería en granos básicos & 0 & 17129 & -17129 \\
\hline Restauración bosque de galería en pasto natural & 0 & 34105 & -34105 \\
\hline Restauración bosque de galería en caña de azúcar & 0 & 28992 & -28992 \\
\hline Restauración bosque de galería en mosaico de cultivos y pasto & 0 & 33364 & -33364 \\
\hline $\begin{array}{l}\text { Restauración bosque de galería en mosaico de cultivos, pastos } \\
\text { y vegetación }\end{array}$ & 0 & 20261 & -20261 \\
\hline Sistema agroforestal de granos básicos & 33150 & 17129 & 16021 \\
\hline Sistema silvopastoril & 66060 & 34105 & 31955 \\
\hline Sistema agrosilvopastoril & 48655 & 33364 & 15291 \\
\hline Zafra verde en caña & 34440 & 28992 & 5448 \\
\hline Sistema agroforestal de cacao en café (cacao 1) & 51924 & 6313 & 45611 \\
\hline $\begin{array}{l}\text { Sistema agroforestal de cacao en mosaico de cultivo, pasto y } \\
\text { vegetación (cacao 2) }\end{array}$ & 54078 & 20261 & 33817 \\
\hline Renovación de los cafetales de bajío & 32891 & 5737 & 27154 \\
\hline Renovación de los cafetales de mediana altura & 37432 & 7177 & 30255 \\
\hline Renovación de los cafetales de altura & 47864 & 11905 & 35959 \\
\hline
\end{tabular}


Cuadro A14 Beneficios netos de la restauración, del uso actual, beneficios marginales de la restauración, razón beneficio-costo (RBC) y retorno de la inversión $(\mathrm{ROI})(r=5 \%)$

\begin{tabular}{|c|c|c|c|c|c|}
\hline Acciones de restauración & $\begin{array}{l}\text { Beneficios netos } \\
\text { restauración (US\$/ha) }\end{array}$ & $\begin{array}{l}\text { Beneficios netos uso } \\
\text { actual (US\$/ha) }\end{array}$ & $\begin{array}{l}\text { Beneficios marginales } \\
\text { (US\$/ha) }\end{array}$ & $\mathrm{RBC}$ & $\mathrm{ROI}$ \\
\hline Restauración de manglar & 6906 & 0 & 6906 & 1,30 & 11,51 \\
\hline $\begin{array}{l}\text { Restauración bosque de galería en granos } \\
\text { básicos }\end{array}$ & -5541 & 5351 & -10892 & 0,00 & $-2,75$ \\
\hline $\begin{array}{l}\text { Restauración bosque de galería en pasto } \\
\text { natural }\end{array}$ & -5541 & 10552 & -16093 & 0,00 & $-4,07$ \\
\hline $\begin{array}{l}\text { Restauración bosque de galería en caña } \\
\text { de azúcar }\end{array}$ & -5541 & 4608 & -10149 & 0,00 & $-2,57$ \\
\hline $\begin{array}{l}\text { Restauración bosque de galería en mosaico } \\
\text { de cultivos y pasto }\end{array}$ & -5541 & 7186 & -12727 & 0,00 & $-3,22$ \\
\hline $\begin{array}{l}\text { Restauración bosque de galería en mosaico } \\
\text { de cultivos, pastos y vegetación }\end{array}$ & -5541 & 4327 & -9868 & 0,00 & $-2,50$ \\
\hline Sistema agroforestal de granos básicos & 10000 & 5351 & 4649 & 1,16 & 1,26 \\
\hline Sistema silvopastoril & 32886 & 10552 & 22334 & 1,51 & 3,91 \\
\hline Sistema agrosilvopastoril & 20275 & 7186 & 13089 & 1,37 & 2,79 \\
\hline Zafra verde en caña & 5953 & 4608 & 1345 & 1,04 & 0,40 \\
\hline $\begin{array}{l}\text { Sistema agroforestal de cacao en café } \\
\text { (cacao 1) }\end{array}$ & 26705 & 1579 & 25127 & 1,94 & 3,19 \\
\hline $\begin{array}{l}\text { Sistema agroforestal de cacao en mosaico } \\
\text { de cultivo, pasto y vegetación (cacao 2) }\end{array}$ & 25984 & 4327 & 21657 & 1,67 & 2,60 \\
\hline Renovación de los cafetales de bajío & 7105 & 1435 & 5670 & 1,21 & 0,97 \\
\hline $\begin{array}{l}\text { Renovación de los cafetales de mediana } \\
\text { altura }\end{array}$ & 11646 & 1794 & 9852 & 1,36 & 1,69 \\
\hline Renovación de los cafetales de altura & 22078 & 2976 & 19102 & 1,66 & 3,27 \\
\hline
\end{tabular}




\section{Anexo 7 Costo, beneficios del uso actual y de la restauración con límite inferior de precio y rendimiento}

Cuadro A15. Beneficios brutos de la restauración, del uso actual e incrementales de la restauración (límite inferior)

\begin{tabular}{|c|c|c|c|}
\hline Acciones de restauración & $\begin{array}{l}\text { Beneficios brutos restauración } \\
\text { (US\$/ha) }\end{array}$ & $\begin{array}{l}\text { Beneficios brutos uso actual } \\
\text { (US\$/ha) }\end{array}$ & $\begin{array}{l}\text { Beneficios brutos incrementales } \\
\text { (US\$/ha) }\end{array}$ \\
\hline Restauración de manglar & 16967 & & 16967 \\
\hline Restauración bosque de galería en granos básicos & 0 & 9457 & -9457 \\
\hline Restauración bosque de galería en pasto natural & 0 & 20172 & -20172 \\
\hline Restauración bosque de galería en caña de azúcar & 0 & 18485 & -18485 \\
\hline Restauración bosque de galería en mosaico de cultivos y pasto & 0 & 17041 & -17041 \\
\hline $\begin{array}{l}\text { Restauración bosque de galería en mosaico de cultivos, pastos } \\
\text { y vegetación }\end{array}$ & 0 & 11903 & -11903 \\
\hline Sistema agroforestal de granos básicos & 17287 & 9457 & 7830 \\
\hline Sistema silvopastoril & 36416 & 20172 & 16244 \\
\hline Sistema agrosilvopastoril & 26626 & 17041 & 9585 \\
\hline Zafra verde en caña & 21967 & 18485 & 3482 \\
\hline Sistema agroforestal de cacao en café (cacao 1) & 26506 & 2901 & 23605 \\
\hline $\begin{array}{l}\text { Sistema agroforestal de cacao en mosaico de cultivo, pasto y } \\
\text { vegetación (cacao 2) }\end{array}$ & 28381 & 11903 & 16478 \\
\hline Renovación de los cafetales de bajío & 14535 & 2599 & 11936 \\
\hline Renovación de los cafetales de mediana altura & 16721 & 3355 & 13366 \\
\hline Renovación de los cafetales de altura & 21254 & 5734 & 15520 \\
\hline
\end{tabular}

Cuadro A16 Beneficios netos de la restauración, del uso actual, beneficios marginales de la restauración, razón beneficio-costo $(\mathrm{RBC})$ y retorno de la inversión (ROI) (límite Inferior)

\begin{tabular}{|c|c|c|c|c|c|}
\hline Acciones de restauración & $\begin{array}{l}\text { Beneficios netos } \\
\text { restauración } \\
\text { (US\$/ha) }\end{array}$ & $\begin{array}{l}\text { Beneficios netos uso actual } \\
\text { (US\$/ha) }\end{array}$ & $\begin{array}{l}\text { Beneficios marginales } \\
\text { (US\$/ha) }\end{array}$ & $\mathrm{RBC}$ & ROI \\
\hline Restauración de manglar & 2435 & 0 & 2435 & 1,17 & 4,06 \\
\hline $\begin{array}{l}\text { Restauración bosque de galería en granos } \\
\text { básicos }\end{array}$ & -5166 & 1028 & -6194 & 0,00 & $-1,57$ \\
\hline Restauración bosque de galería en pasto natural & -5166 & 3316 & -8482 & 0,00 & $-2,15$ \\
\hline $\begin{array}{l}\text { Restauración bosque de galería en caña de } \\
\text { azúcar }\end{array}$ & -5166 & 1194 & -6360 & 0,00 & $-1,61$ \\
\hline $\begin{array}{l}\text { Restauración bosque de galería en mosaico de } \\
\text { cultivos y pasto }\end{array}$ & -5166 & 145 & -5311 & 0,00 & $-1,34$ \\
\hline $\begin{array}{l}\text { Restauración bosque de galería en mosaico de } \\
\text { cultivos, pastos y vegetación }\end{array}$ & -5166 & 486 & -5652 & 0,00 & $-1,43$ \\
\hline Sistema agroforestal de granos básicos & -5166 & 1028 & -6194 & 0,00 & $-1,57$ \\
\hline Sistema silvopastoril & 11873 & 3316 & 8557 & 1,31 & 1,50 \\
\hline Sistema agrosilvopastoril & 6824 & 145 & 6679 & 1,33 & 1,42 \\
\hline Zafra verde en caña & 1796 & 1194 & 602 & 1,03 & 0,18 \\
\hline Sistema agroforestal de cacao en café (cacao 1) & 6358 & 726 & 5632 & 1,27 & 0,71 \\
\hline $\begin{array}{l}\text { Sistema agroforestal de cacao en mosaico de } \\
\text { cultivo, pasto y vegetación (cacao 2) }\end{array}$ & 6009 & 486 & 5523 & 1,24 & 0,66 \\
\hline Renovación de los cafetales de bajío & -4160 & 650 & -4810 & 0,75 & $-0,82$ \\
\hline Renovación de los cafetales de mediana altura & -1974 & 839 & -2813 & 0,86 & $-0,48$ \\
\hline Renovación de los cafetales de altura & 2559 & 1434 & 1125 & 1,06 & 0,19 \\
\hline
\end{tabular}




\section{Anexo 8 Costo, beneficios del uso actual y de la restauración con límite superior de precio}

Cuadro A17 Beneficios brutos de la restauración, del uso actual e incrementales de la restauración (límite superior)

\begin{tabular}{|c|c|c|c|}
\hline Acciones de restauración & $\begin{array}{l}\text { Beneficios brutos restauración } \\
\text { (US\$/ha) }\end{array}$ & $\begin{array}{l}\text { Beneficios brutos uso actual } \\
\text { (US } \$ / \text { ha) }\end{array}$ & $\begin{array}{l}\text { Beneficios brutos incrementales } \\
\text { (US\$/ha) }\end{array}$ \\
\hline Restauración de manglar & 22069 & & 22069 \\
\hline Restauración bosque de galería en granos básicos & 0 & 15482 & -15482 \\
\hline Restauración bosque de galería en pasto natural & 0 & 28587 & -28587 \\
\hline Restauración bosque de galería en caña de azúcar & 0 & 23234 & -23234 \\
\hline Restauración bosque de galería en mosaico de cultivos y pasto & 0 & 25882 & -25882 \\
\hline $\begin{array}{l}\text { Restauración bosque de galería en mosaico de cultivos, pastos } \\
\text { y vegetación }\end{array}$ & 0 & 17331 & -17331 \\
\hline Sistema agroforestal de granos básicos & 27522 & 15482 & 12040 \\
\hline Sistema silvopastoril & 48936 & 28587 & 20349 \\
\hline Sistema agrosilvopastoril & 37585 & 25882 & 11703 \\
\hline Zafra verde en caña & 27583 & 23234 & 4349 \\
\hline Sistema agroforestal de cacao en café (cacao 1) & 43321 & 7223 & 36098 \\
\hline $\begin{array}{l}\text { Sistema agroforestal de cacao en mosaico de cultivo, pasto y } \\
\text { vegetación (cacao 2) }\end{array}$ & 47456 & 17331 & 30125 \\
\hline Renovación de los cafetales de bajío & 30284 & 6616 & 23668 \\
\hline Renovación de los cafetales de mediana altura & 34473 & 8133 & 26340 \\
\hline Renovación de los cafetales de altura & 44821 & 13146 & 31675 \\
\hline
\end{tabular}

Cuadro A18 Beneficios netos de la restauración, del uso actual, beneficios marginales de la restauración, razón beneficio-costo $(\mathrm{RBC})$ y retorno de la inversión (ROI) (límite superior)

\begin{tabular}{|c|c|c|c|c|c|}
\hline Acciones de restauración & $\begin{array}{l}\text { Beneficios netos } \\
\text { restauración } \\
\text { (US\$/ha) }\end{array}$ & $\begin{array}{c}\text { Beneficios netos uso } \\
\text { actual } \\
\text { (US\$/ha) }\end{array}$ & $\begin{array}{l}\text { Beneficios marginales } \\
\text { (US\$/ha) }\end{array}$ & $\mathrm{RBC}$ & ROI \\
\hline Restauración de manglar & 5787 & 0 & 5787 & 1,36 & 9,65 \\
\hline $\begin{array}{l}\text { Restauración bosque de galería en granos } \\
\text { básicos }\end{array}$ & -5166 & 7053 & -12219 & 0,00 & $-3,09$ \\
\hline Restauración bosque de galería en pasto natural & -5166 & 11731 & -16897 & 0,00 & $-4,27$ \\
\hline $\begin{array}{l}\text { Restauración bosque de galería en caña de } \\
\text { azúcar }\end{array}$ & -5166 & 5370 & -10536 & 0,00 & $-2,66$ \\
\hline $\begin{array}{l}\text { Restauración bosque de galería en mosaico de } \\
\text { cultivos y pasto }\end{array}$ & -5166 & 8986 & -14152 & 0,00 & $-3,58$ \\
\hline $\begin{array}{l}\text { Restauración bosque de galería en mosaico de } \\
\text { cultivos, pastos y vegetación }\end{array}$ & -5166 & 5914 & -11080 & 0,00 & $-2,80$ \\
\hline Sistema agroforestal de granos básicos & 9890 & 7053 & 2838 & 1,11 & 0,77 \\
\hline Sistema silvopastoril & 24393 & 11731 & 12662 & 1,35 & 2,21 \\
\hline Sistema agrosilvopastoril & 17783 & 8986 & 8797 & 1,31 & 1,87 \\
\hline Zafra verde en caña & 6479 & 5370 & 1109 & 1,04 & 0,33 \\
\hline Sistema agroforestal de cacao en café (cacao 1) & 23173 & 2600 & 20573 & 1,90 & 2,61 \\
\hline $\begin{array}{l}\text { Sistema agroforestal de cacao en mosaico de } \\
\text { cultivo, pasto y vegetación (cacao 2) }\end{array}$ & 25084 & 5914 & 19170 & 1,68 & 2,30 \\
\hline Renovación de los cafetales de bajío & 11589 & 1654 & 9935 & 1,49 & 1,70 \\
\hline Renovación de los cafetales de mediana altura & 15778 & 4018 & 11760 & 1,52 & 2,01 \\
\hline Renovación de los cafetales de altura & 26126 & 3287 & 22839 & 2,04 & 3,91 \\
\hline
\end{tabular}




\section{Anexo 9 Análisis multicriterio}

Cuadro A19 Matriz de rendimiento de los indicadores financieros

\begin{tabular}{|c|c|c|c|c|c|}
\hline Acciones de restauración & $\begin{array}{l}\text { Indicador financiero } \\
\qquad(r=10 \%)^{/ a}\end{array}$ & $\begin{array}{l}\text { Indicador financiero } \\
\qquad(\mathrm{r}=15 \%)\end{array}$ & $\begin{array}{l}\text { Indicador financiero } \\
\qquad(\mathrm{r}=5 \%)\end{array}$ & $\begin{array}{l}\text { Indicador financiero } \\
\text { (pesimista) }\end{array}$ & $\begin{array}{l}\text { Indicador financiero } \\
\text { (optimista) }\end{array}$ \\
\hline Restauración de manglar & 0,919 & 0,337 & 0,275 & 0,285 & 0,253 \\
\hline Restauración bosque de galería & $-0,468$ & $-1,109$ & $-0,462$ & $-0,738$ & $-0,554$ \\
\hline Sistema agroforestal de granos básicos & 0,291 & $-0,193$ & 0,185 & $-0,724$ & 0,124 \\
\hline Sistema silvopastoril & 0,835 & 0,648 & 0,889 & 1000 & 0,554 \\
\hline Sistema agrosilvopastoril & 0,704 & 0,545 & 0,521 & 0,781 & 0,358 \\
\hline Zafra verde en caña & 0,325 & 0,080 & 0,054 & 0,070 & 0,049 \\
\hline $\begin{array}{l}\text { Sistema agroforestal de cacao en café } \\
\text { (cacao 1) }\end{array}$ & 1000 & 1000 & 1000 & 0,658 & 0,901 \\
\hline $\begin{array}{l}\text { Sistema agroforestal de cacao en mosaico } \\
\text { de cultivo, pasto y vegetación (cacao 2) }\end{array}$ & 0,905 & 0,984 & 0,862 & 0,645 & 0,839 \\
\hline Renovación de los cafetales de bajío & 0,375 & $-0,028$ & 0,226 & $-0,562$ & 0,435 \\
\hline $\begin{array}{l}\text { Renovación de los cafetales de mediana } \\
\text { altura }\end{array}$ & 0,537 & 0,248 & 0,392 & $-0,329$ & 0,515 \\
\hline Renovación de los cafetales de altura & 0,886 & 0,844 & 0,760 & 0,131 & 1000 \\
\hline
\end{tabular}

/a Incluye VAN marginal, RBC y ROI.

Cuadro A20 Matriz de rendimiento de los indicadores ambientales no espaciales

\begin{tabular}{|c|c|c|c|}
\hline Acciones de restauración & Indicador carbono & Indicador conectividad & Indicador leña \\
\hline Restauración de manglar & 1000 & 1000 & 1000 \\
\hline Restauración bosque de galería & 0,948 & 1000 & 0,000 \\
\hline Sistema agroforestal de granos básicos & 0,629 & 0,935 & 0,381 \\
\hline Sistema silvopastoril & 0,078 & 0,815 & 0,381 \\
\hline Sistema agrosilvopastoril & 0,274 & 0,935 & 0,381 \\
\hline Zafra verde en caña & 0,519 & 0,000 & 0,000 \\
\hline Sistema agroforestal de cacao en café (cacao 1) & 0,491 & 0,828 & 0,686 \\
\hline $\begin{array}{l}\text { Sistema agroforestal de cacao en mosaico de cultivo, pasto y } \\
\text { vegetación (cacao 2) }\end{array}$ & 0,700 & 0,746 & 0,686 \\
\hline Renovación de los cafetales de bajío & 0,229 & 0,901 & 0,381 \\
\hline Renovación de los cafetales de mediana altura & 0,198 & 0,793 & 0,381 \\
\hline Renovación de los cafetales de altura & 0,198 & 0,901 & 0,381 \\
\hline
\end{tabular}


Cuadro A21 Matriz de rendimiento de los indicadores servicios ambientales espaciales (servicios ecosistémicos)

\begin{tabular}{|c|c|c|c|}
\hline Acciones de restauración & Indicador erosión & Indicador exportación sedimentos & Indicador exportación N y P \\
\hline Restauración de manglar & I & I & 1 \\
\hline Restauración bosque de galería & 0,131 & 0,337 & 1000 \\
\hline Sistema agroforestal de granos básicos & 0,765 & 0,415 & $-0,288$ \\
\hline Sistema silvopastoril & 0,409 & 0,242 & $-0,363$ \\
\hline Sistema agrosilvopastoril & 0,429 & 0,227 & $-0,438$ \\
\hline Zafra verde en caña & 0,080 & 0,048 & 0,132 \\
\hline Sistema agroforestal de cacao en café (cacao 1) & 0,279 & 1000 & $-0,023$ \\
\hline $\begin{array}{l}\text { Sistema agroforestal de cacao en mosaico de cultivo, pasto y } \\
\text { vegetación (cacao 2) }\end{array}$ & 1000 & 0,683 & $-0,161$ \\
\hline Renovación de los cafetales de bajío & 0,174 & 0,074 & 0,010 \\
\hline Renovación de los cafetales de mediana altura & 0,392 & 0,138 & 0,014 \\
\hline Renovación de los cafetales de altura & 0,432 & 0,136 & 0,009 \\
\hline
\end{tabular}

Cuadro A22 Matriz de rendimiento de los indicadores sociales

\begin{tabular}{lccc} 
Acciones de restauración & Indicador creación trabajo & Indicador medios de vida & Indicador seguridad alimentaria \\
\hline Restauración de manglar & 0,465 & 0,178 & 0,434 \\
\hline Restauración bosque de galería & $-0,863$ & $-0,347$ & $-0,299$ \\
\hline Sistema agroforestal de granos básicos & 0,278 & 0,223 & 1000 \\
\hline Sistema silvopastoril & 0,720 & 0,416 & 0,823 \\
\hline Sistema agrosilvopastoril & 0,499 & 0,312 & 0,806 \\
\hline Zafra verde en caña & 1000 & 0,038 & 0,159 \\
\hline Sistema agroforestal de cacao en café (cacao 1) & 0,399 & 0,904 & 0,737 \\
\hline $\begin{array}{l}\text { Sistema agroforestal de cacao en mosaico de cultivo, pasto y } \\
\text { vegetación (cacao 2) }\end{array}$ & 0,243 & 1000 & 0,629 \\
\hline Renovación de los cafetales de bajío & 0,400 & & 0,326 \\
\hline Renovación de los cafetales de mediana altura & 0,400 & 0,252 & 0,510 \\
\hline Renovación de los cafetales de altura & 0,400 & 0,406 & 0,560 \\
\hline
\end{tabular}






\section{UICN}

Unión Internacional

para la Conservación de la Naturaleza (UICN)

Oficina Regional para México, América Central y El Caribe Apdo. 607-2050

Montes de Oca, San José,

San José, Costa Rica

Tel: (506) 2283-8449

ormacc@iucn.org

www.iucn.org/ormacc 